\title{
Empfehlungen zur Diagnostik und Therapie nichttuberkulöser Mykobakteriosen des Deutschen Zentralkomitees zur Bekämpfung der Tuberkulose (DZK) und der Deutschen Gesellschaft für Pneumologie und Beatmungsmedizin (DGP)
}

\author{
Recommendations for Diagnosis and Treatment of Nontuberculous Mycobacterioses of the German Central \\ Committee against Tuberculosis and the German Respiratory Society
}

Autoren

Institute
N. Schönfeld ${ }^{1 *}$, W. Haas $^{2 * *}$, E. Richter ${ }^{3 * *}$, T. T. Bauer ${ }^{1,4}$, L. Bös ${ }^{4}$, S. Castell ${ }^{4,5}$, B. Hauer ${ }^{2}$, K. Magdorf ${ }^{\dagger 6}$ W. Matthiessen 7 , H. Mauch ${ }^{8}$, A. Reuß ${ }^{2}$, S. Rüsch-Gerdes ${ }^{3}$, P. Zabel ${ }^{9,10}$, K. Dalhoff $^{10 * *}$, T. Schaberg ${ }^{11 * *}$, R. Loddenkemper ${ }^{*}$

Die Institutsangaben sind am Ende des Beitrags gelistet.
Bibliografie

DOI http://dx.doi.org/

10.1055/s-0033-1344790

Pneumologie 2013; 67: 605-633

(c) Georg Thieme Verlag KG

Stuttgart · New York

ISSN 0934-8387

\section{Korrespondenzadresse}

\section{Prof. Dr. med. Torsten T. Bauer}

Deutsches Zentralkomitee zur Bekämpfung der Tuberkulose (DZK)

Walterhöferstr. 11

14165 Berlin

info@dzk-tuberkulose.de www.pneumologie.de/dzk/

\section{Zusammenfassung \\ $\nabla$}

Die nichttuberkulösen Mykobakteriosen umfassen eine Gruppe von Erkrankungen, die von Mykobakterien verursacht werden, die nicht dem Mycobacterium (M.) tuberculosis-Komplex und nicht $M$. leprae zugerechnet werden und durch eine breite Vielfalt in Hinsicht auf ihr Vorkommen und ihre Anpassungen an spezifische Umweltbedingungen charakterisiert sind. Einige Spezies können definierte Krankheitsbilder insbesondere bei Patienten mit systemischer Immunsuppression, vorbestehenden Lungenerkrankungen oder genetisch bedingter erhöhter Empfänglichkeit hervorrufen. Weltweit wird eine Zunahme der Prävalenz und der Bedeutung dieser Erregergruppe beobachtet. Die vorliegenden Empfehlungen fassen aktuelle Aspekte der Epidemiologie, der Pathogenese, Klinik, Diagnostik einschließlich mikrobiologischer Diagnostik und Resistenztestung, sowie der speziesabhängigen Therapie bei nichttuberkulösen Mykobakteriosen zusammen. AuBerdem werden die besonderen Aspekte der Diagnostik und Therapie im Kindesalter und bei HIV-infizierten Patienten dargestellt.

\section{Einleitung}

Weltweit, besonders in Ländern mit niedriger Tuberkuloseprävalenz, konnte in den letzten drei Dekaden eine Zunahme der Prävalenz und der Bedeutung der nichttuberkulösen Mykobakteriosen beobachtet werden [1 - 3]. Bekannt sind die nichttuberkulösen Mykobakterien (NTM) fast so lange wie $M$. tuberculosis selbst, allerdings wurde ihre klinische Bedeutung erst in den 1950er Jahren erfasst. Insbesondere die HIV-Infektion, die vor Einführung der antiretroviralen Therapie häufig durch Erkrankungen mit $M$. avium-Komplex

* federführend

** bei einzelnen Kapiteln federführend

\section{Abstract \\ $\nabla$}

Nontuberculous mycobacterioses comprise a group of diseases caused by mycobacteria which do not belong to the Mycobacterium (M.) tuberculosis complex and are not ascribed to M. leprae. These mycobacteria are characterized by a broad variety as to environmental distribution and adaptation. Some of the species may cause specific diseases, especially in patients with underlying immunosuppressive diseases, chronic pulmonary diseases or genetic predisposition, respectively. Worldwide a rising prevalence and significance of nontuberculous mycobacterioses can be recognized. The present recommendations summarise actual aspects of epidemiology, pathogenesis, clinical aspects, diagnostics - especially microbiological methods including susceptibility testing -, and specific treatment for the most relevant species. Diagnosis and treatment of nontuberculous mycobacterioses during childhood and in HIV-infected individuals are described in separate chapters.

(MAC) kompliziert wurde, hat die Aufmerksamkeit auf die NTM gelenkt [4]. Im Gegensatz zum Rückgang der Tuberkulose spielen NTM auch in Deutschland seit einigen Jahren eine zunehmende Rolle, hier vorwiegend bei nicht-HIV-infizierten Patienten [2,5-7].

Viele Aspekte von Epidemiologie, Pathogenese, Diagnostik und Therapie sind noch ungeklärt. Die vorliegenden Empfehlungen basieren im Wesentlichen auf dem sehr umfangreichen Statement der American Thoracic Society (ATS), das 2007 gemeinsam mit der Infectious Diseases Society of America (IDSA) erstellt wurde [1]. Die gemeinsamen Empfehlungen des Deutschen Zentralkomitees zur Bekämpfung der Tuberkulose (DZK) und der Deutschen Gesellschaft für Pneumologie und 


\begin{tabular}{|c|c|c|}
\hline \multicolumn{3}{|c|}{ Inhaltsverzeichnis } \\
\hline 1 & Einleitung & 605 \\
\hline 2 & Epidemiologie und Bedeutung & 607 \\
\hline 3 & Pathogenese & 607 \\
\hline 3.1 & Prädisponierende Faktoren & 608 \\
\hline 3.1.1 & Lokale Risikofaktoren & 608 \\
\hline 3.1 .2 & Systemische Risikofaktoren & 609 \\
\hline 4 & Diagnostik & 610 \\
\hline 4.1 & Klinik & 611 \\
\hline 4.2 & Radiologische Diagnostik & 611 \\
\hline 4.3 & Mikrobiologische Diagnostik und Resistenztestung & 612 \\
\hline 4.3.1 & Untersuchungsproben & 612 \\
\hline 4.3 .2 & Probenkontamination mit NTM & 612 \\
\hline 4.3 .3 & Mikroskopie & 613 \\
\hline 4.3.4 & \multicolumn{2}{|c|}{ Nukleinsäureamplifikationstests (NAT) zum Direktnachweis613 } \\
\hline 4.3 .5 & Kultureller Nachweis & 613 \\
\hline 4.3.6 & Identifizierung der Mykobakterien & 613 \\
\hline 4.3.7 & Plausibilitätskontrolle & 614 \\
\hline 4.3.8 & Empfindlichkeitsprüfung & 614 \\
\hline 5 & Therapie bei HIV-negativen Patienten & 615 \\
\hline 5.1 & Medikamentöse Therapie & 615 \\
\hline 5.2 & Chirurgische Therapie & 616 \\
\hline 5.3 & Therapie der Grundkrankheit & 616 \\
\hline 6 & Nichttuberkulöse Mykobakteriosen bei HIV-Infektion & 616 \\
\hline 6.1 & Klinik & 616 \\
\hline 6.2 & Diagnostik & 617 \\
\hline 6.3 & Therapie & 617 \\
\hline 6.4 & Prävention & 618 \\
\hline \multirow[t]{2}{*}{7} & \multicolumn{2}{|l|}{ Diagnostik und Therapie nichttuberkulöser Mykobakteriosen } \\
\hline & im Kindesalter & 618 \\
\hline 7.1 & Epidemiologie & 618 \\
\hline 7.2 & Erregerspektrum und klinisches Bild & 618 \\
\hline 7.3 & Diagnostik & 619 \\
\hline 7.4 & Therapie & 619 \\
\hline \multirow[t]{2}{*}{8} & Anhang 1 (mikrobiologische und therapeutische & \\
\hline & Besonderheiten bei ausgewählten NTM-Spezies) & 621 \\
\hline 8.1 & Langsam wachsende Mykobakterien & 621 \\
\hline 8.1.1. & M. avium-Komplex (MAC) & 621 \\
\hline 8.1 .2 & M. celatum & 622 \\
\hline 8.1 .3 & M. genavense & 622 \\
\hline 8.1 .4 & M. gordonae & 622 \\
\hline 8.1 .5 & M. haemophilum & 622 \\
\hline 8.1 .6 & M. kansasii & 623 \\
\hline 8.1 .7 & M. malmoense & 623 \\
\hline 8.1 .8 & M. marinum & 623 \\
\hline 8.1 .9 & M. simiae & 623 \\
\hline 8.1 .10 & M. szulgai & 623 \\
\hline 8.1 .11 & M. ulcerans & 624 \\
\hline 8.1 .12 & M. xenopi & 624 \\
\hline 8.2 & Schnell wachsende Mykobakterien & 624 \\
\hline 8.2 .1 & M. abscessus & 624 \\
\hline 8.2 .2 & M. chelonae & 624 \\
\hline 8.2 .3 & M. fortuitum & 625 \\
\hline \multirow[t]{2}{*}{9} & Anhang 2 (Eigenschaften der in der Therapie von & \\
\hline & NTM-Erkrankungen eingesetzten Medikamente) & 625 \\
\hline 10 & Glossar & 628 \\
\hline 11 & Literatur & 628 \\
\hline
\end{tabular}

Beatmungsmedizin (DGP) berücksichtigen zusätzlich die umfangreiche neuere Literatur, wobei einzelne Punkte des amerikanischen Statements differenziert dargestellt werden.

Der Begriff NTM bezeichnet eine umfangreiche Gruppe von Umweltmykobakterien, die durch eine breite Vielfalt in Hinsicht auf ihr Vorkommen und ihre Anpassungen an spezifische Umweltbedingungen charakterisiert sind. Dabei handelt es sich um Mykobakterien, die nicht dem M. tuberculosis-Komplex und nicht $M$. leprae zugerechnet werden. Der Bezug zu diesen beiden
Tab. 1 Häufig aus Patientenproben isolierte langsam und schnell wachsende nichttuberkulöse Mykobakterien (modifiziert nach [16]) (fett markiert s. Kapitel 8, Anhang 1: Mikrobiologische und therapeutische Besonderheiten bei ausgewählten NTM-Spezies, S. 621).

\begin{tabular}{ll}
\hline Langsam wachsende & Schnell wachsende \\
Mykobakterien & Mykobakterien \\
\hline M. arupense & M. abscessus ssp. abscessus \\
M. asiaticum & M. abscessus ssp. bolettii \\
M. avium & M. alvei \\
M. bohemicum & M. aurum \\
M. branderi & M. boenickei \\
M. celatum & M. brumae \\
M. chimaera & M. chelonae \\
M. europaeum & M. confluentis \\
M. florentinum & M. elephantis \\
M. genavense & M. fortuitum \\
M. gordonae & M. goodii \\
M. haemophilum & M. holsaticum \\
M. heckeshornense & M. immunogenum \\
M. interjectum & M. iranicum sp. nov. \\
M. intermedium & M. margeritense \\
M. intracellulare & M. mucogenicum \\
M. kansasii & M. peregrinum \\
M. kubicae & M. phocaicum \\
M. lentiflavum & M. septicum \\
M. malmoense & M. thermoresistible \\
M. marinum & \\
M. nebraskense & \\
M. palustre & \\
M. saskatchewanse & \\
M. scrofulaceum & \\
M. shimodei & \\
M. simiae & \\
M. szulgai & \\
M. ulcerans & \\
M. vulnerans & \\
M. xenopi & \\
& \\
\hline
\end{tabular}

obligat pathogenen Mykobakterienspezies spiegelt sich auch im Prozess der Namensgebung für die NTM wider: So wurden/werden neben Umweltmykobakterien als weitere Synonyme ubiquitäre, opportunistische Mykobakterien, „Mycobacteria other than tuberculosis" (MOTT) und atypische Mykobakterien verwendet. Die vorliegenden Empfehlungen verwenden vorwiegend die Bezeichnung NTM.

NTM sind weit verbreitet, sie besiedeln verschiedenste Umweltbereiche, wie z.B. Erde, Oberflächen- und Trinkwasser [8-10]. Über das Wasser erreichen sie auch Rohrleitungen in Haushalten, wo sie in Biofilmen in hohen Keimzahlen auftreten können $[8,11]$. Weiterhin können NTM u.a. auch in Lebensmitteln wie pasteurisierter Milch und Käse, jedoch nicht in homogenisierter Milch, nachgewiesen werden [12-15]. Die Konsequenz ist ein ständiger Kontakt von Menschen mit ubiquitären Mykobakterien [9].

Bislang wurden 147 verschiedene NTM-Spezies entdeckt ( $w w w$. bacterio.cict.fr/m/mycobacterium.html, Stand 06/2013). Die am häufigsten aus Patientenproben isolierten Spezies werden in - Tab. 1 aufgelistet.

Abzugrenzen von den nichttuberkulösen Mykobakteriosen sind die durch NTM (insbesondere M. avium-Komplex) ausgelösten exogen-allergischen Alveolitiden (,hot tub lung') [17-19]. M. immunogenum im Kühlschmierstoff ist Auslöser einer exogen-allergischen Alveolitis bei Metallarbeitern in der Autoindustrie [20]. 


\section{Epidemiologie und Bedeutung nichttuberkulöser Mykobakteriosen \\ $\nabla$}

Während der letzten drei Jahrzehnte hat die Prävalenz der Lungenerkrankungen durch NTM z.T. dramatisch zugenommen [3]. Mehrere Gründe werden hierfür angenommen wie eine alternde Bevölkerung mit vermehrten Komorbiditäten, HIV-Infektion, häufigere Anwendung von Immunsuppressiva, sensitivere Labordiagnostik und möglicherweise eine geringere kreuzreaktive Immunität gegenüber Mykobakterien als Folge der Abnahme an Tuberkuloseinfektionen [1-3].

Aus Kanada wurde eine Zunahme der NTM-Nachweise zwischen 1997 und 2003 von 9,1/100.00 auf 14,1/100.000 Einwohner berichtet [21], aus den USA eine Prävalenz von 5,5/100.000 Personenjahre (bei über 60-Jährigen 26,7/100.000) [22] sowie von 8,6/100.000 Personen [23]. Winthrop et al. fanden in ihrer Studie an einem großen Kollektiv, dass allein die mikrobiologischen Kriterien der ATS/IDSA [1] im Vergleich mit den vollen diagnostischen Kriterien in einem hohen Prozentsatz (86\%) eine echte Erkrankung mit NTM anzeigten [23]. In einer weiteren Studie bei über 65-Jährigen fand sich in den USA eine Zunahme der Prävalenz von 20 auf 47/100.000 Personen zwischen 1997 und 2007 [9]. In Australien wurde ein Anstieg der Prävalenz pulmonaler nichttuberkulöser Mykobakteriosen von 2,2 auf 3,3/100.000 Einwohner im Zeitraum 1999-2005 gesehen [24]. In einer Universitätsklinik in Taiwan wurde zwischen 2000 und 2008 ein Anstieg der Prävalenz pulmonaler nichttuberkulöser Mykobakteriosen von 1,3 auf 7,9 Fälle/100.000 Patienten beobachtet [25].

Aus Europa werden im Allgemeinen niedrigere Zahlen berichtet $[2,3]$. So nahmen in England, Wales und Nordirland die NTM-Isolate zwischen 1995 und 2006 von 0,9 auf 2,9/100.000 Personen zu [26]. In den Niederlanden ist die Inzidenz der echten pulmonalen NTM-Erkrankung ebenfalls angestiegen und wurde für 2008 konservativ auf 1,7/100.000 geschätzt [27,28], in Dänemark wurde die Inzidenz der echten NTM-Erkrankung auf 1,08/ 100.000 geschätzt [29]. Aus Kroatien wird ein Anstieg der NTMIsolate von 235 im Jahr 2006 auf 416 im Jahr 2010 berichtet [30], wobei aufgrund der angewandten mikrobiologischen Kriterien bei den meisten Fällen von einer echten Erkrankung ausgegangen werden kann $[23,31]$. Die klinisch relevantesten NTM-Spezies waren dabei M. xenopi und M. avium. Für die Beobachtung, dass in Kroatien die Inzidenz der wahrscheinlichen Lungenerkrankungen in küstennahen städtischen Gebieten doppelt so hoch wie auf dem Lande ist, wird als Erklärung eine unterschiedliche Wasserversorgung vermutet [30].

Für Deutschland gibt es bei Erwachsenen keine Prävalenzschätzungen (epidemiologische Daten für Kinder sind in Kapitel 7 „Diagnostik und Therapie nichttuberkulöser Mykobakteriosen im Kindesalter" (S. 618) aufgeführt). Für NTM besteht nach dem Infektionsschutzgesetz (IfSG) wegen der fehlenden Übertragbarkeit von Mensch zu Mensch keine Meldepflicht und keine systematische Surveillance (auch sind grundsätzlich Umgebungsuntersuchungen und besondere Infektionsschutzmaßnahmen bei nichttuberkulösen Mykobakteriosen nicht notwendig). Deshalb und angesichts der vielfältigen möglichen klinischen Erscheinungsformen (s. Kapitel 4 „Diagnostik“, S. 610) ist es kaum möglich, sich ein klares Bild zur Epidemiologie von Erkrankungen durch NTM zu machen [2].

Auch die Auswertung von Labordaten (z.B. durch das Nationale Referenzzentrum für Mykobakterien des Forschungszentrums Borstel) ermöglicht keine klinisch relevanten Aussagen, da der alleinige Nachweis von NTM nicht gleichbedeutend mit einer Er- krankung ist. So sind die besonders häufig isolierten Spezies (wie M. gordonae und M. avium-Komplex) auch in der Umwelt weit verbreitete Spezies. Darüber hinaus werden Labordaten von vielen anderen Faktoren beeinflusst, wie z.B. der Verfügbarkeit von einfachen Labormethoden zur Identifizierung der jeweiligen Spezies, aber auch durch Neubeschreibungen und Umbenennungen (siehe Kapitel 4.3 „Mikrobiologische Diagnostik und Resistenztestung“, S. 612).

Die Beurteilung des epidemiologischen Trends wird zudem erschwert durch Veränderungen, welche die Struktur der betrachteten Bevölkerung über die Zeit wesentlich beeinflussen; dazu zählen demografische Faktoren (steigende Lebenserwartung, Geschlechterverteilung), sich wandelnde Expositionsbedingungen (z.B. die Beliebtheit von Whirlpools), die unterschiedliche Prävalenz erkrankungsbegünstigender Faktoren (insbesondere schwere Immunsuppression, z.B. HIV-Infektion oder immunsuppressive Therapien, chronische Lungenkrankheiten im Alter), aber auch die zunehmende Verfügbarkeit und höhere Qualität diagnostischer Methoden und nicht zuletzt die wachsende Aufmerksamkeit gegenüber Erkrankungen durch NTM [32-36]. Auch sind regionale Unterschiede zu berücksichtigen, denn sowohl die Prävalenz als auch die jeweils vorherrschenden NTM-Spezies können von Region zu Region variieren [1,3,10,37]. So fanden z. B. Hoefsloot et al., dass die Isolierung von $M$. xenopi aus respiratorischen Materialien vorwiegend auf bestimmte geografische Regionen (Belgien, Frankreich, Kroatien, Ungarn) beschränkt ist [38].

Ein direkter Vergleich klinischer Studien scheitert häufig an der Anwendung uneinheitlicher diagnostischer Kriterien, ungenauer Erregercharakterisierung, fehlenden klinischen Bezugsdaten, unterschiedlichen Einschlusskriterien, nicht vergleichbaren Studienpopulationen (ambulant, stationär, Zugehörigkeit zu Risikogruppen) und (zumindest in älteren Studien) der unbekannten Rate HIV-positiver Patienten [9,39-41]. Ungeachtet der schwierigen Einschätzung der korrekten epidemiologischen Situation und der geschilderten Trends stellen nichttuberkulöse Mykobakteriosen aber ein relevantes Problem dar, denn ihre Diagnose ist oftmals komplex und die Therapie ist langwierig, kosten- und betreuungsintensiv und oft mit unerwünschten Arzneimittelwirkungen verbunden [42].

\section{Pathogenese}

Die Übertragung von NTM erfolgt vermutlich vorwiegend durch Aerosole oder durch Staubpartikel, die mit NTM belastet sind [1]. Sie können aber auch durch kontaminiertes Wasser oder kontaminierten Boden direkt aufgenommen werden (wie bei einer zervikalen Lymphadenitis bei kleinen Kindern oder einer Wundinfektion anzunehmen). Eine Übertragung von $M$. xenopi und $M$. avium mit kontaminiertem Staub aus einem Klärbecken und über Düngung mit Klärschlamm ist belegt [43]. Eine Übertragung der NTM von Mensch zu Mensch konnte dagegen bislang nicht nachgewiesen werden. Jedoch zeigten Ergebnisse von ,whole genome sequencing'-Analysen von M. abscessus-Isolaten bei Patienten mit zystischer Fibrose (CF) die Möglichkeit einer Transmission bestimmter Stämme [44]. Da die meisten NTM weit verbreitet in der Umwelt vorkommen, kann der Nachweis von NTM aus nicht sterilem humanem Untersuchungsgut (z. B. Sputum) auch durch eine zufällige Präsenz des Erregers bedingt sein und bedeutet nicht zwangsläufig eine Erkrankung $[1,45,46]$ (Definition von Kontamination, Kolonisation bzw. Infektion siehe Tab.2). 
Tab. 2 Definitionen verschiedener Konstellationen im Falle des Nachweises von nichttuberkulösen Mykobakterien in respiratorischen Materialien [1, 45, 46].

\begin{tabular}{|ll}
\hline Kontamination & $\begin{array}{l}\text { Verunreinigung des Untersuchungsguts durch } \\
\text { NTM von außen }\end{array}$ \\
\hline Kolonisation & Besiedlung der Atemwege ohne Krankheitswert \\
\hline $\begin{array}{l}\text { Infektion ohne } \\
\text { Erkrankungszeichen }\end{array}$ & $\begin{array}{l}\text { Ausbildung eines spezifischen Granulations- } \\
\text { gewebes, aber ohne Symptome }\end{array}$ \\
\hline $\begin{array}{l}\text { Infektion mit } \\
\text { Erkrankungszeichen }\end{array}$ & $\begin{array}{l}\text { Ausbildung eines spezifischen Granulations- } \\
\text { gewebes mit Symptomen }\end{array}$ \\
\hline
\end{tabular}

Tab.3 Erkrankungen durch nichttuberkulöse Mykobakterien und häufig nachgewiesene Erreger bei nicht-HIV-infizierten Erwachsenen (nach [1]).

\begin{tabular}{|ll|}
\hline Krankheitsbild & Haupterreger \\
\hline Pulmonale Infektionen & $\begin{array}{l}\text { M. avium-Komplex, M. kansasii, } \\
\text { M. xenopi, M. malmoense }\end{array}$ \\
\hline Haut- und Weichteilinfektionen & $\begin{array}{l}\text { M. marinum, M. ulcerans, } \\
\text { M. chelonae, M. abscessus }\end{array}$ \\
\hline Augeninfektionen & $\begin{array}{l}\text { M. chelonae, M. abscessus, } \\
\text { M. fortuitum }\end{array}$ \\
\hline Skelettinfektionen (Osteomyelitis) & M. abscessus \\
\hline Otitis media, Mastoiditis & M. abscessus, M. kansasii, M. xenopi \\
\hline $\begin{array}{l}\text { Zervikale Lymphadenitis } \\
\text { (vorwiegend bei Kindern) }\end{array}$ & $\begin{array}{l}\text { M. avium-Komplex, M. malmoense, } \\
\text { M. scrofulaceum, M. haemophilum }\end{array}$ \\
\hline Katheter- oder geräteassoziierte & M. abscessus, M. chelonae \\
\hline Infektionen & M. abscessus, M. avium-Komplex, \\
\hline $\begin{array}{l}\text { Zystische Fibrose } \\
\text { (pulmonale Infektionen) }\end{array}$ & M. chelonae \\
\hline $\begin{array}{l}\text { Generalisierte Erkrankung } \\
\text { (bei Immunsuppression oder } \\
\text { genetischer Disposition) }\end{array}$ & M. avium-Komplex \\
\hline Nach Transplantation & M. avium-Komplex, M. kansasii \\
\hline
\end{tabular}

Innerhalb des Artenspektrums der Mykobakterien sind Unterschiede in der Pathogenität der verschiedenen Spezies bekannt $[1,16,45]$. Arten wie $M$. gordonae oder $M$. fortuitum, die häufig in der Umwelt vorkommen, haben eine sehr geringe Pathogenität, wohingegen Spezies wie M. ulcerans oder M. marinum in den meisten Fällen mit einer Erkrankung assoziiert sind. Einige der NTM-Spezies können Erreger definierter Krankheitsbilder (nichttuberkulöse Mykobakteriosen) sowohl bei nicht-HIV-infizierten Patienten ( Tab.3) als auch im Rahmen einer HIV-Infektion sein, die in einem gesonderten Kapitel abgehandelt wird (Kapitel 6 „Nichttuberkulöse Mykobakteriosen bei HIV-Infektion“, S. 616).

\subsection{Prädisponierende Faktoren}

Bestimmte lokale oder allgemeine Risikofaktoren bzw. Grunderkrankungen sind wichtige Voraussetzungen für die Entwicklung von Erkrankungen durch NTM. $\bullet$ Tab.4 listet die wichtigsten prädisponierenden Faktoren auf.

Es gibt aber auch Patienten, bei denen bislang weder lokale noch systemische Risikofaktoren aufgedeckt werden konnten $[49,50]$. Eine kürzlich veröffentliche Studie erbrachte jedoch Hinweise darauf, dass bei den rein pulmonalen Manifestationen generell eine Störung der mukoziliären Klärfunktion vorliegen könnte [51] (siehe unten).

Daneben scheint die unterschiedliche Virulenz der einzelnen Spezies bei der Krankheitsentstehung eine Rolle zu spielen. Zum Beispiel ist der Nachweis von M. kansasii oft mit den klinischen Kriterien einer Krankheit verbunden [45,52], bei M. avium hin-
Tab.4 Prädisponierende Faktoren für nichttuberkulöse Mykobakteriosen ((?) = vermutet, aber nicht vollständig geklärt) $[1,47,48]$.

\begin{tabular}{|c|c|}
\hline $\begin{array}{l}\text { Vorbestehende } \\
\text { Lungenerkrankungen }\end{array}$ & $\begin{array}{l}\text { COPD, Asthma, Bronchiektasen, Bronchial- } \\
\text { karzinom, Rauchen, rezidivierende Aspiratio- } \\
\text { nen bei gastroösophagealer Refluxkrankheit } \\
\text { (GERD), inhalative Kortikosteroide, Lungen- } \\
\text { fibrosen, zystische Fibrose, Thoraxdeformitä- } \\
\text { ten wie M. Bechterew, Skoliose, frühere } \\
\text { Tuberkulose, postinfektiöse Resthöhle, } \\
\text { vorbestehende Bulla oder Zyste, Pneumo- } \\
\text { koniosen (Silikose), Alveolarproteinose }\end{array}$ \\
\hline $\begin{array}{l}\text { Systemische } \\
\text { Abwehrschwäche }\end{array}$ & 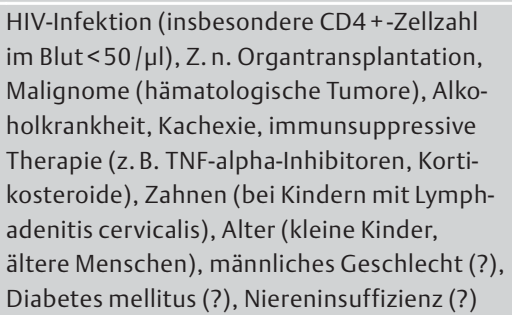 \\
\hline $\begin{array}{l}\text { Genetisch bedingt } \\
\text { erhöhte Empfänglichkeit } \\
\text { infolge von Mutationen } \\
\text { folgender Gene: }\end{array}$ & $\begin{array}{l}\text { Interferon-Gamma-Rezeptor Gen, Interleukin- } \\
12 \text { Rezeptor-Gen, Signal Transducer and Acti- } \\
\text { vator of Transcription } 1 \text { (STAT 1), Transmem- } \\
\text { brane Conductance Regulator-Gen (zystische } \\
\text { Fibrose), alpha-1-Antiprotease-Gen }\end{array}$ \\
\hline
\end{tabular}

gegen ist es ratsam, das Vorliegen einer behandlungsbedürftigen Erkrankung stets im Einzelfall zu prüfen ( $\bullet$ Abb. 1) [45].

\subsubsection{Lokale Risikofaktoren}

Im Gegensatz zur Tuberkulose kommen den lokalen bronchopulmonalen Veränderungen bei der Entstehung von Erkrankungen durch NTM bei der Mehrheit der HIV-negativen Patienten eine zentrale Bedeutung zu [48]. Häufigste lokale bronchopulmonale Risikofaktoren für nichttuberkulöse Mykobakteriosen ( Tab.4) sind COPD, Bronchiektasen, die zystische Fibrose (CF), eine vorausgegangene Tuberkulose mit Defektheilung, die Silikose und andere Pneumokoniosen sowie die Alveolarproteinose [53], auch bei schwierig behandelbarem Asthma bronchiale sollte an eine zusätzliche Infektion mit NTM gedacht werden [54]. Darüber hinaus scheinen habituelle Merkmale wie großer schlanker Körperwuchs oder Thoraxdeformitäten wie Skoliose, Pectus excavatum oder Morbus Bechterew zu nichttuberkulösen Mykobakteriosen zu prädisponieren, möglicherweise aufgrund einer Beeinträchtigung der bronchialen Klärfunktion $[45,51,55,56]$. Auch unter regelmäßiger Anwendung von inhalierten Kortikosteroiden werden vermehrt Erkrankungen durch NTM beobachtet, wobei eine Abhängigkeit von der Dosishöhe und dem Typ (bei Fluticason eher als bei Budenosid) gezeigt werden konnte [57].

Die Annahme, dass Frauen häufig bewusst das Aushusten von Auswurf vermeiden („Ladies don't spit“), hat Reich und Johnson dazu veranlasst, folgende Konstellation gemäß einer viktorianischen Figur aus einem Stück von Oscar Wilde als „Lady Windermere“-Syndrom zu bezeichnen: die Erkrankung von (eher) älteren Damen mit schlankem, hoch gewachsenen Habitus ohne pulmonale Vorerkrankungen durch M. avium-Komplex mit initialem Befall der Lingula oder des Mittellappens $[58,59]$.

Die gastro-ösophageale Refluxkrankheit (GERD) ist bei Patienten mit pulmonalen Infektionen durch NTM häufiger nachzuweisen und korreliert zudem mit dem Ausmaß der Bronchiektasen. Auch der Nachweis säurefester Stäbchen (NTM) im Sputum findet sich bei Patienten mit GERD häufiger [60]. 


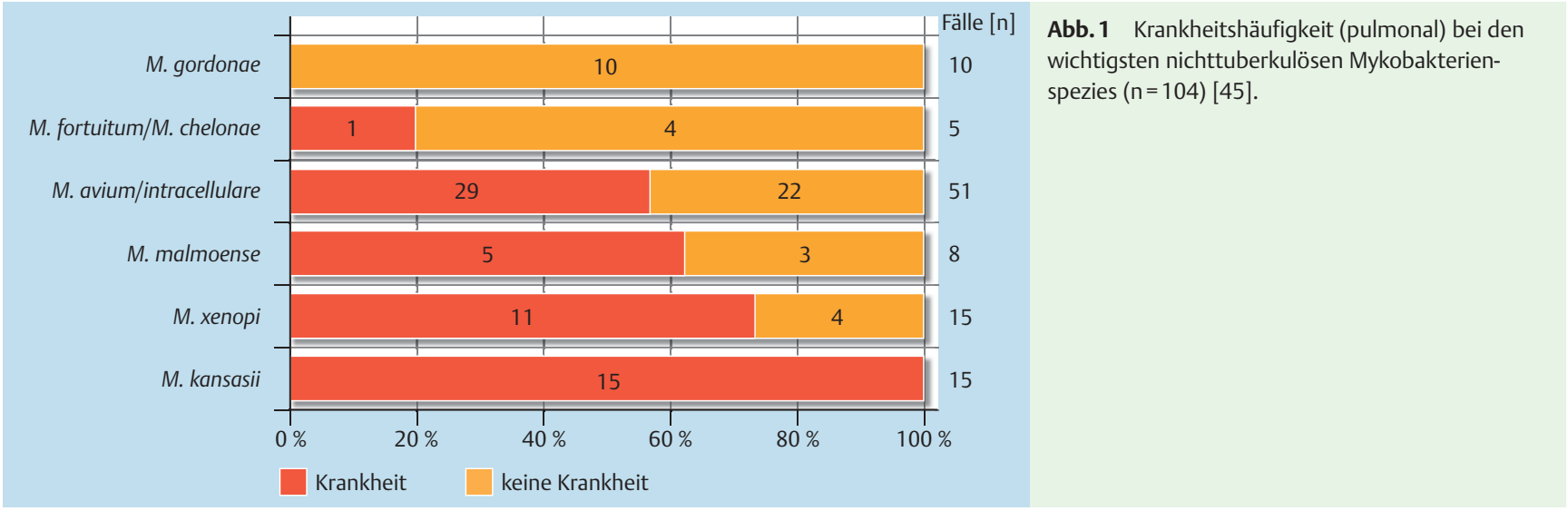

Bei Patienten mit pulmonalen prädisponierenden Faktoren („Terrainfaktor" nach Forschbach [61]) kommt einer Ventilationsstörung mit Verschlechterung der bronchialen Klärfunktion, die zu einer Sekretretention führt, offenbar eine entscheidende Bedeutung zu. Hier unterscheiden sich also die Risikofaktoren nicht von chronischen bronchopulmonalen Infektionen/Kolonisationen mit anderen Bakterien (Pseudomonas aeruginosa u.a.). Die meisten Patienten mit lokalen bronchopulmonalen Veränderungen, bei denen NTM nachgewiesen werden, müssen unter Berücksichtigung möglicher Laborkontaminationen nicht nur als kolonisiert, sondern wahrscheinlich auch als infiziert angesehen werden $[1,23]$.

Patienten mit zystischer Fibrose (CF) haben ein erhöhtes Risiko für eine lokale NTM-Infektion, vor allem durch M. abscessus oder M. avium-Komplex [62-64], ebenso Patienten mit Bronchiektasen ohne CF [65]. Bei Patienten mit CF ist beschrieben, dass trotz wiederholten Keimnachweises im Sputum autoptisch keine Granulome gefunden wurden [66]. Solche Befunde legen nahe, dass eine ausschließliche Kolonisation ohne Wirtsreaktion möglich ist.

Haben sich die NTM lokal vermehrt, kann es zur Ausprägung eines tuberkuloseähnlichen Krankheitsbildes mit pulmonalen Infiltrationen kommen, in welchen sich auch multiple Kavernen ausbilden können. Durch bronchogene Streuung ist auch eine Ausbreitung auf weitere Lungenabschnitte möglich. Klinisch und radiologisch ist das Krankheitsbild meist geringer ausgeprägt als bei der Tuberkulose (siehe Kapitel 4.2 „Radiologische Diagnostik“, Seite 611). Die Assoziation von Bronchiektasen und Infektionen mit M. avium ist pathogenetisch nicht sicher geklärt: So ist einerseits denkbar, dass sich die Keime bevorzugt in präexistenten Bronchiektasen ansiedeln, und andererseits, dass die Bronchiektasen erst durch die spezifische Entzündung der Bronchialwände, ähnlich wie bei der Tuberkulose, entstehen [65].

Darüber hinaus gibt es Formen der Erkrankung, die primären und postprimären Verläufen der Tuberkulose ähneln, ohne dass lokale abwehrmindernde Faktoren gefunden werden können. Hierbei mögen die Intensität der Exposition gegenüber NTM, die Virulenz der Erreger sowie Alter und genetische Faktoren des Wirtes eine Rolle spielen.

Neben der häufigsten Lokalisation, dem pulmonalen Befall, treten auch weitere lokale Infektionen auf ( $\bullet$ Tab.3). So können z.B. Haut-, Weichteil-, Augen- und Skelettinfektionen durch NTM ausgelöst werden [1,67], oder auch die zervikale Lymphadenopathie, die bevorzugt bei Kindern unter fünf Jahren auftritt (s. Kapitel 7 „Diagnostik und Therapie nichttuberkulöser Mykobakteriosen im Kindesalter“, S. 618).
Weitere Infektionsmöglichkeiten sind durch verschiedene medizinische Eingriffe (kontaminierte Instrumente, Spritzen, Operationen etc.) $[1,68-70]$ oder bei anderen Gelegenheiten (wie bei Fußbädern bei der Pediküre oder beim Tätowieren $[71,72]$ ) gegeben.

Eine nichttuberkulöse Mykobakteriose mit einem klar umschriebenen Krankheitsbild ist das Schwimmbadgranulom, dessen infektiöses Agens M. marinum ist. Fische sind der Hauptwirt und somit auch die Vektoren für die Übertragung auf den Menschen. Die Quelle für $M$. marinum-Infektionen ist kontaminiertes Wasser, meist in Aquarien mit erkrankten Fischen. Oberflächliche Hautwunden sind vermutlich als Eintrittspforte ausreichend [73]. Die in einigen tropischen Regionen weite Verbreitung des Buruli-Ulkus auf dem Boden einer Infektion mit M. ulcerans legt Wasser als Infektionsquelle nahe; neuere Untersuchungen weisen auf einen möglichen Zusammenhang mit aquatischen Insekten hin [74].

\subsubsection{Systemische Risikofaktoren}

Störungen der systemischen Immunität können das Auftreten von Erkrankungen durch NTM begünstigen ( $\bullet$ Tab.4.). So sind Patienten mit einer HIV-Infektion, deren CD4+-Zellzahl $<50 / \mu \mathrm{l}$ ist, besonders durch eine disseminierte Infektion mit NTM gefährdet [1]. Seit der Einführung der antiretroviralen Therapie ist die Anzahl der HIV-Patienten mit Mykobakteriosen allerdings deutlich rückläufig [75,76]. Die HIV-assoziierten nichttuberkulösen Mykobakteriosen, die aber immer noch eine wesentliche Rolle spielen, werden gesondert im Kapitel 6 „Nichttuberkulöse Mykobakteriosen bei HIV-Infektion“ (S. 616) behandelt.

Epidemiologische Untersuchungen zeigen, dass sich beim Diabetes mellitus - anders als bei der Tuberkulose - offenbar kein stark erhöhtes Risiko für die Entwicklung einer nichttuberkulösen Mykobakteriose findet; jedoch sind lokale Infektionen mit NTM an Injektionsstellen bei Insulin-pflichtigen Diabetikern beschrieben [69]. Ein chronisches Nierenversagen ist zumindest nach retrospektiven Analysen als möglicher Risikofaktor anzusehen [77], dabei auftretende Erkankungen durch NTM können durch invasive Eingriffe wie Peritoneal- oder Hämodialyse bedingt sein [70, 78]. Auch bei transplantierten Patienten werden nicht selten nichttuberkulöse Mykobakteriosen beobachtet [79].

Nichttuberkulöse Mykobakteriosen treten auch bei chronisch entzündlichen Erkrankungen unter der Therapie mit TNF- $\alpha$-Inhibitoren und anderen Biologika $[80,81]$ auf, im Vergleich zur Tuberkulose jedoch etwa $10 \mathrm{mal}$ seltener $[82,83]$. Auch unter systemischen und inhalativen Glukokortikosteroiden werden gehäuft Erkrankungen durch NTM beobachtet $[57,84]$. 
Tab.5 Klinische, radiologische und mikrobiologische Kriterien zur Diagnose einer pulmonalen Erkrankung durch nichttuberkulöse Mykobakterien (modifiziert nach [1]).

a) Klinisch/röntgenologisch (beide Kriterien müssen erfüllt sein)
1. Bronchopulmonale Symptome, noduläre oder kavernöse Beherdun-
gen im Thoraxröntgenbild, oder multilokuläre Bronchiektasen mit
mehreren kleinen nodulären Herden im hochauflösenden Computer-
tomogramm (HRCT)
und
2. Ausschluss anderer Krankheitsursachen.
b) Mikrobiologisch
1. Positive Kulturen aus mindestens zwei separaten expektorierten
Sputumproben (wenn die Ergebnisse nicht zu einer Diagnose führen,
sind wiederholte Sputumausstriche und -kulturen zu überlegen)
oder
2. Positive Kultur aus wenigstens einer bronchoskopisch entnommenen
Probe (Bronchialspülung oder Lavage)
oder
3. Transbronchiale oder andere Lungenbiopsie mit histopathologischen,
für Mykobakterien typischen Befunden (granulomatöse Entzündung
oder säurefeste Stäbchen) und positiver Kultur, oder Biopsie mit
Nachweis mykobakterieller histopathologischer Befunde (granulo-
matöse Entzündung oder säurefeste Stäbchen) und positiver Kultur
aus mindestens einem oder mehreren anderen Materialien (Sputum,
Bronchialspülung).
4. Eine Expertenmeinung sollte eingeholt werden, wenn eine seltene
Mykobakterien-Spezies nachgewiesen wird oder eine Spezies, die
üblicherweise auf eine Umweltkontamination hinweist.
5. Personen, bei denen eine nichttuberkulöse Mykobakteriose vermutet
wird, die aber nicht die genannten diagnostischen Kriterien erfüllen,
sollten bis zu einer definitiven Diagnosestellung oder bis zum Aus-
schluss einer Lungenerkrankung durch NTM beobachtet werden.
6. Die Diagnosestellung einer NTM bedeutet nicht per se eine Behand-
lungsindikation. Über diese muss unter Abwägung des potenziellen
Nutzens und der möglichen Risiken der Behandlung individuell für den
jeweiligen Patienten entschieden werden.

Der derzeitige Kenntnisstand über immunologische Defektsyndrome, z. B. beim IL12R-Defekt, aber auch über andere begünstigende systemische Faktoren und vermutete Ursachen für das Auftreten pulmonaler nichttuberkulöser Mykobakteriosen ist in aktuellen Übersichtsarbeiten zusammengefasst $[47,48,85]$.

Trotz dieser klinischen Beobachtungen sind die pathophysiologischen Mechanismen nur in Ansätzen verstanden. Die prädisponierenden Grundkrankheiten sind teilweise weit verbreitet (z. B. COPD, Bronchiektasen), dennoch erkranken nur wenige Patienten aus solchen großen Erkrankungsgruppen, sodass zusätzliche genetische Wirts- und Erregerkomponenten zu vermuten sind. Auch ein familiäres Auftreten von Lungenerkrankungen durch NTM ist nachgewiesen [86,87]. Zu erwarten ist, dass in Zukunft der Zusammenhang mit weiteren prädisponierenden Faktoren aufgedeckt wird $[50,88]$.

So konnten in der von Fowler et al. publizierten Studie bei Patienten mit einer nichttuberkulösen Mykobakteriose, bei denen eine CF oder eine primäre ziliäre Dyskinesie ausgeschlossen wurde, Hinweise darauf gefunden werden, dass die mukoziliäre Klärfunktion im Vergleich mit einer Kontrollgruppe von Gesunden gestört ist [51]. Dies könnte eine Erklärung dafür sein, dass Patienten mit einer pulmonalen Manifestation ohne zugrundeliegenden Immundefekt nicht bzw. selten gleichzeitig an extrapulmonalen Manifestationen der nichttuberkulösen Mykobakteriose erkranken, und auf eine zusätzliche erbliche Disposition hindeuten. Die verminderte NO-Produktion könnte nach Ansicht der Autoren einen therapeutischen Ansatz durch eine Erhöhung des „NO-cyclic guanosine monophosphate (cGMP) pathway“ bieten.

Zunehmend wird eine genetische Variabilität innerhalb vieler Spezies erkannt, wobei die Bedeutung dieser Variabilität für die Pathogenität bislang weitgehend unbekannt ist [89]. So sind für M. kansasii mehrere genetische Varianten beschrieben, von denen die Subspezies I weltweit verbreitet ist. Subspezies II scheint vermehrt bei HIV-Patienten nachzuweisen zu sein, wohingegen die anderen, weniger häufigen Subspezies vermutlich seltener mit Erkrankung einhergehen [90].

Neben den NTM, die auch in Umweltproben nachgewiesen werden konnten, gibt es Spezies, wie z.B. M. ulcerans, M. genavense oder M. haemophilum, die vermutlich sehr viel wirtsspezifischer sind als viele der anderen Arten. Für M. genavense sind Infektionen von Vögeln beschrieben, es gibt aber keinen Hinweis auf eine Verbreitung außerhalb dieses Wirts. Auch das natürliche Habitat und der Übertragungsweg von M. haemophilum sind bislang unklar, jedoch werden Wasser-Reservoire als eine wahrscheinliche Infektionsquelle angesehen [91].

\section{Diagnostik}

Die Diagnosestellung einer Erkrankung durch NTM ist komplex. Die diagnostischen Kriterien für eine nichttuberkulöse Mykobakteriose sind in dem Statement der ATS und der IDSA aus dem Jahre 2007 zusammengefasst [1]. Gefordert wird ein passendes klinisches und röntgenologisches Bild, der Ausschluss anderer plausibler Erkrankungsursachen bzw. die Symptomzunahme trotz Therapie differenzialdiagnostisch in Frage kommender anderer Krankheiten, der Ausschluss einer Kontamination, der mehrfache Nachweis des gleichen Erregers aus nicht-sterilen Proben (einfacher Nachweis aus sterilen Proben bzw. aus der bronchoalveolären Lavage) sowie im Fall einer pulmonalen Erkrankung die Erfüllung bestimmter klinischer, radiologischer und mikrobiologischer Kriterien ( Tab.5).

In der Regel erfolgt der Nachweis von NTM bei Nicht-HIV-Infizierten aus dem Sputum, aber auch aus anderen Untersuchungsmaterialien (siehe „Untersuchungsproben“ im Kapitel 4.3 „Mikrobiologische Diagnostik und Resistenztestung“, S. 612). Gelegentlich wird eine Probengewinnung zur histologischen Diagnostik erforderlich sein, wenn die Differenzialdiagnose nach erfolgloser mikrobiologischer Untersuchung noch offen ist. Die Bronchoskopie mit Bronchialabsaugung mit oder ohne vorherige Anspülung, peripherer Katheter- oder Nadelbiopsie, bronchoalveolärer Lavage und/oder peripherer transbronchialer Zangenbiopsie ist hierfür Methode der Wahl, ggf. auch die computertomografisch gestützte Lungenpunktion, wenn die Lungenfunktionswerte dies zulassen (Gefahr des Pneumothorax mit Entwicklung einer akuten respiratorischen Insuffizienz). Histologisch zeigt sich das typische Bild einer epitheloidzelligen Granu-

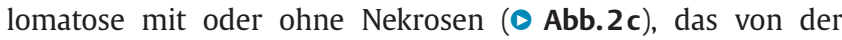
Tuberkulose nicht zu unterscheiden ist [92]. Wenn Gewebeproben entnommen und nicht in Formalin fixiert wurden, kann bei Verdacht auf eine nichttuberkulöse Mykobakteriose neben der kulturellen Diagnostik auch ein spezifischer DNA-Test zum Nachweis von NTM durchgeführt werden.

$\mathrm{Zu}$ beachten ist, dass der Tuberkulinhauttest mit zahlreichen Spezies (falsch-positiv) kreuzreagiert, wogegen der Interferongamma Release Assay (IGRA) fast immer (richtig-) negativ ausfällt. Nur bei Infektionen mit wenigen NTM-Spezies (M. flaves- 
cens, M. kansasii, M. marinum, M. szulgai) kann auch der IGRA falsch-positiv reagieren $[93,94]$.

Die Diagnose einer nichttuberkulösen Mykobakteriose verlangt eine genaue Identifizierung der NTM-Spezies [95]. Die Zunahme der valide beschriebenen NTM-Spezies ist Folge der verfeinerten molekularbiologischen Techniken [96]. Wie in der Einleitung erwähnt, sind bislang 147 unterschiedliche Spezies registriert (www.bacterio.cict.fr/m/mycobacterium.html, Stand 06/2013) mit einer Vielzahl potenziell pathogener Erreger $(\checkmark$ Tab. 1$)$. Die modernen Techniken ermöglichen eine exakte Artbestimmung auch mit heute routinemäßig durchführbaren Methoden (s. Kapitel 4.3 „Mikrobiologische Diagnostik und Resistenztestung“ S. 612).

Schwierig zu beurteilen ist der gleichzeitige Nachweis von $M$. tuberculosis und NTM $[97,98]$. Hier muss sorgfältig geprüft werden, ob neben der Tuberkulose auch eine Erkrankung durch NTM vorliegt, die ggf. einer zusätzlichen Therapie bedarf [1].

\subsection{Klinik}

Die klinischen Erscheinungsformen pulmonaler nichttuberkulöser Mykobakteriosen bei HIV-negativen Patienten mit lokalen Grundkrankheiten oder einer systemischen Immunsuppression sind unspezifisch. Husten, Auswurf (gelegentlich auch blutig), Dyspnoe, Fieber, Gewichtsverlust und Minderung des Allgemeinzustands lassen sich nicht selten nur der Grundkrankheit zuordnen und sollten erst dann auf eine Erkrankung durch NTM bezogen werden, wenn diese nach den genannten Kriterien ( $\bullet$ Tab.5) diagnostiziert ist und in ihrer Ausdehnung eingeschätzt werden kann. Die Symptome ähneln denjenigen einer Tuberkulose, sind jedoch häufig geringer ausgeprägt, eher subakut und lassen sich nicht ohne kulturelle bzw. molekularbiologische Identifizierung einer Spezies zuordnen. Der schnellstmöglichen Erregerdiagnostik kommt daher für das Behandlungskonzept eine entscheidende Bedeutung zu.

Die Symptome bei extrapulmonalen Infektionen durch NTM (s. Tab.3) richten sich nach den jeweilig betroffenen Organen $[1,95]$.

\subsection{Radiologische Diagnostik}

Die radiologische Diagnostik und Verlaufskontrolle hilft zu klären, ob eine behandlungsbedürftige Erkrankung vorliegt. Röntgenologisch lassen sich zwei typische pulmonale Formen unterscheiden: Eine vorwiegend fibrokavernöse Form ähnlich wie bei Tuberkulose und eine nodulär/bronchiektatische Form; beide können sich aber auch überlappen [1]. Zur Diagnostik wird man sich neben der Basisuntersuchung einer Röntgenthoraxaufnahme vor allem der hochauflösenden Computertomografie (HRCT) bedienen, um Bronchiektasen oder andere strukturelle Veränderungen der Lunge wie Infiltrate oder Kavernen besser zu erkennen. Typische Befunde von nichttuberkulösen Mykobakteriosen sind flächige Infiltrate, Kavernen mit verdickten Wänden, Bronchiektasen mit umgebenden Infiltraten, disseminierte kleinfleckige Infiltrate, weiterhin auch Lymphknotenvergrößerungen ( Abb.2 und $\bullet$ Abb.3). Die radiologische Differenzierung von einer Tuberkulose ist schwierig, letztlich entscheidet der Erregernachweis $[99,100]$.

Hiervon zu unterscheiden sind die röntgenologischen Befunde einer exogen-allergischen Alveolitis durch Inhalation von mit MAC kontaminiertem Wasser („hot tub lung“) [19] oder von mit M. immunogenum verunreinigtem Kühlschmierstoff [20] .
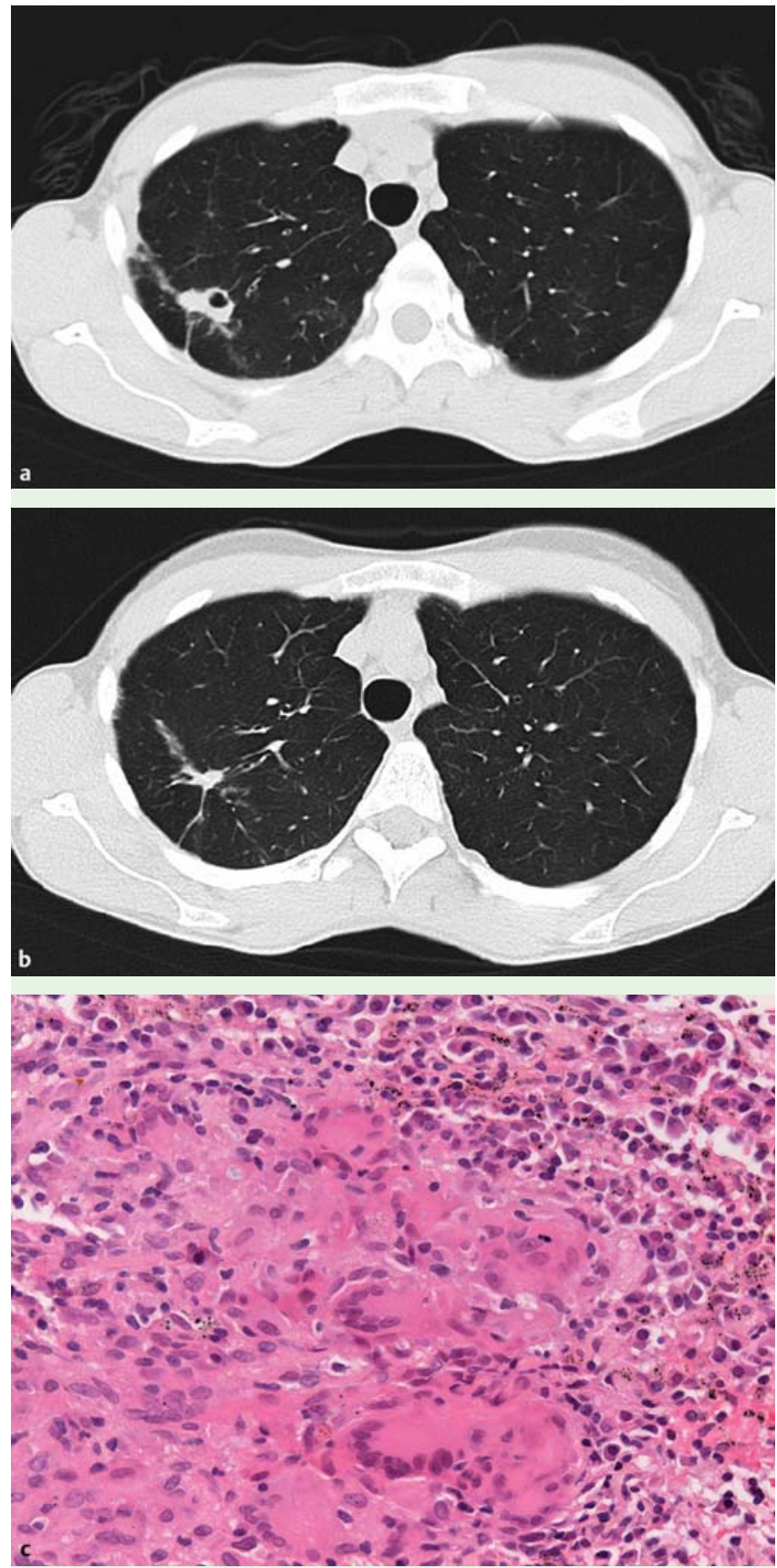

Abb.2a-c Nichttuberkulöse Mykobakteriose durch M. avium im rechten Lungenoberlappen, vom Erscheinungsbild her ähnlich einer postprimären Lungentuberkulose, weiblich, 29 Jahre (CT). (Mit freundlicher Genehmigung von Dr. Roland C. Bittner, Institut für Diagnostische und Interventionelle Radiologie [für Abb. 2a, b] sowie von PD Dr. Thomas Mairinger und Sergej Griff, Institut für Gewebediagnostik [für Abb. 2c], HELIOS Klinikum Emil von Behring.) Die Patientin war zunächst ohne Keimnachweis mehrere Monate auf Verdacht antituberkulös behandelt worden, ohne dass sich eine Rückbildung zeigte (a). Die CT-gesteuerte transthorakale Nadelbiopsie ergab den massenhaften Nachweis säurefester Stäbchen (molekularbiologisch M. avium) und histologisch epitheloidzellige Granulome ohne Nekrose (c). Die Mykobakteriose durch M. avium wurde später kulturell bestätigt. Unter einer spezifischen 18-monatigen Therapie zeigte sich ein guter Regress mit einem narbigen Residuum (b). 

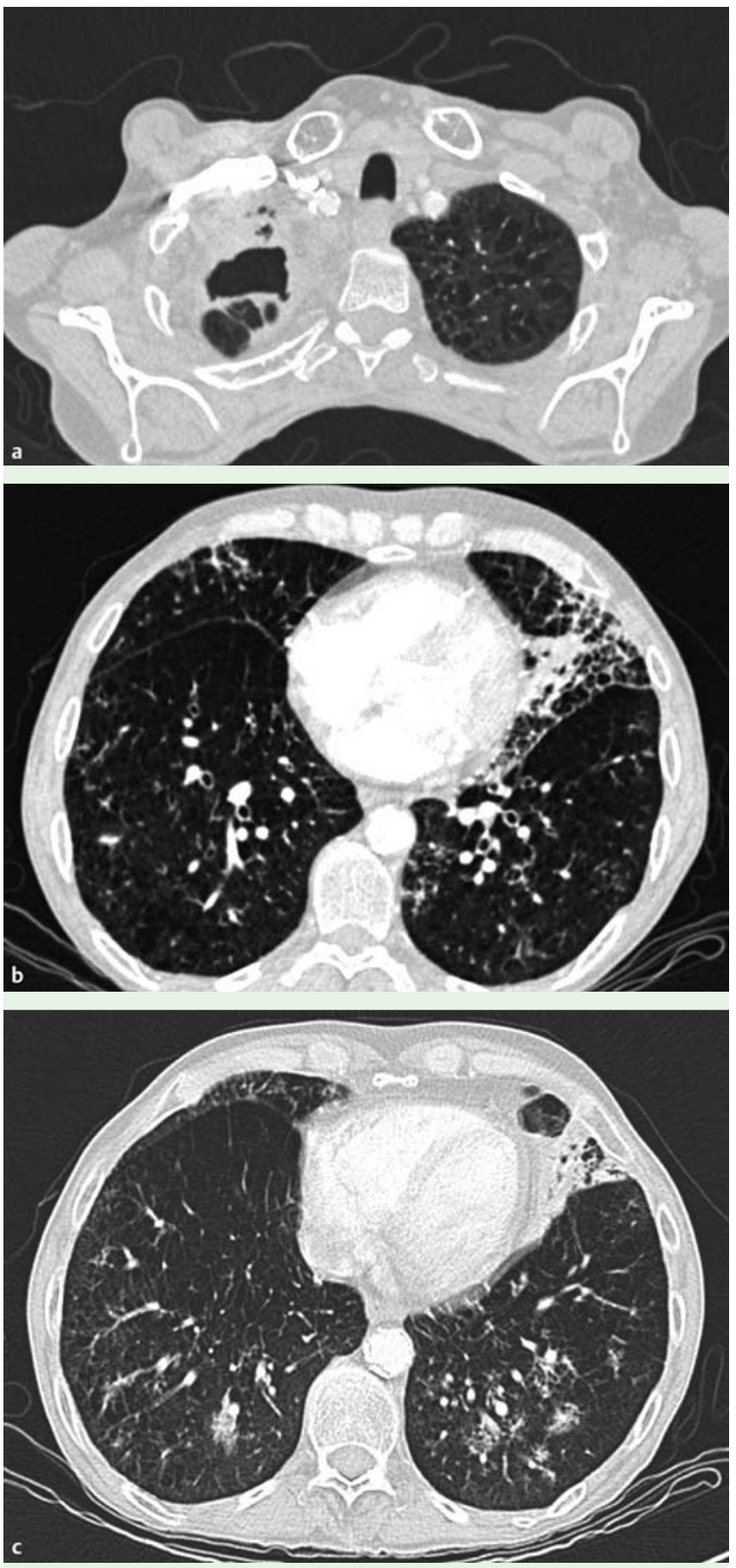

Abb.3a-c Nichttuberkulöse Mykobakteriose bei einem 59-jährigen Patienten mit schwerer Lungenvorerkrankung und mit massenhaftem Nachweis von M. malmoense. Höhlen im rechten Oberlappen innerhalb posttuberkulöser Residuen (a), Bronchiektasen in der Lingula mit Umgebungsinfiltrat (b), Streuherde mit Schwerpunkt in beiden Unterlappen (c). (Mit freundlicher Genehmigung von Dr. Roland C. Bittner, Institut für Diagnostische und Interventionelle Radiologie, HELIOS Klinikum Emil von Behring.)

\subsection{Mikrobiologische Diagnostik und Resistenztestung}

Den wichtigsten Beitrag zur Diagnosestellung leistet der mikrobiologische Erregernachweis aus dem Sputum oder anderen (bioptisch) gewonnenen Proben [1,95,101]. Diese Erregeridentifizierung trägt wesentlich zur Entscheidung über die Behandlungsbedürftigkeit bei (siehe Kapitel 5-8, S. 615-625).
Der kulturelle Nachweis von Mykobakterien ist nach wie vor der Referenzstandard in der mikrobiologischen Diagnostik der Infektionen durch NTM. Bei besonderen Fragestellungen (Dringlichkeit, nicht eindeutige kulturelle Ergebnisse) kann mit Hilfe von Nukleinsäureamplifikationstests (NAT) ein spezifischer Nachweis von NTM im Untersuchungsgut erfolgen (siehe auch unter 4.3.6 „Identifizierung der Mykobakterien“, S. 613).

Im Anhang finden sich zu ausgewählten Mykobakterienspezies mikrobiologische (und therapeutische) Besonderheiten (Kapitel 8, Anhang 1, S. 621).

\subsubsection{Untersuchungsproben}

Aufgrund der unterschiedlichen Lokalisationen von Erkrankungen durch NTM kommen für den kulturellen Nachweis von Mykobakterien eine Vielzahl von Materialien in Betracht $[1,102]$. Bronchopulmonale Materialien wie Sputum, Bronchialsekret, bronchoalveoläre Lavageflüssigkeit - bei Kindern auch Magennüchternsekret oder Magenspülflüssigkeit (siehe Kapitel 7 „Diagnostik und Therapie nichttuberkulöser Mykobakteriosen im Kindesalter“, S. 618) - können bei Verdacht auf eine pulmonale Infektion oder Erkrankung untersucht werden, ebenso das Biopsiematerial bei entsprechender Lokalisation (z. B. Lymphknoten, Haut). Wichtig ist hierbei, dass Gewebeproben mit physiologischer Kochsalzlösung versetzt werden und nicht mit Formalin. Abstrichtupfer sind zur Diagnostik weniger geeignet. Sofern keine andere Probenentnahme als Abstriche möglich sind, sollten die Tupfer nicht in für die allgemeine Mikrobiologie verwendete Transportgefäße (ungeeignetes Medium) gegeben, sondern in einem Röhrchen mit physiologischer Kochsalzlösung transportiert werden.

Punktate (z. B. Liquor, Pleurapunktate, Perikardpunktat) werden nativ, d.h. ohne Zusätze, zur Untersuchung geschickt. Da in diesen Proben die Mykobakterien zumeist in sehr geringer Zahl vorhanden sind, ist es wichtig, ein möglichst großes Probenvolumen zu entnehmen. Auch Blut- und Knochenmarksproben können untersucht werden, sind jedoch nur bei Patienten mit zellulärem Immundefekt sinnvoll.

Insbesondere zur Diagnosestellung einer pulmonalen nichttuberkulösen Mykobakteriose ist es wichtig, mehrfach Proben eines Patienten zu untersuchen [1]. Erst durch den Mehrfachnachweis des gleichen Keims in nicht-sterilen Untersuchungsproben wird die Diagnose wahrscheinlich (siehe $\bullet$ Tab.5). Aus primär sterilen Proben wie z. B. Lymphknotenpunktaten ist dagegen ein Mehrfachnachweis nicht erforderlich. Für die Diagnose eines Schwimmbadgranuloms ist bei passender Histologie der einmalige Nachweis von M. marinum aus einer Hautbiopsie ausreichend.

\subsubsection{Probenkontamination mit NTM}

Eine Kontamination von Untersuchungsgut durch NTM kann eine Fehldiagnose nach sich ziehen und sollte deshalb vermieden werden. Von NTM ist bekannt, dass sie in wässrigem Milieu verbreitet sind und sich in Biofilmen einlagern können [8,11,103]. Kartuschen von Wasseraufbereitungsanlagen und ähnliche mit Wasser durchspülte Einheiten können deshalb dicht besiedelt mit NTM sein. Aus diesem Grunde können NTM z. B. durch Bronchoskope, die mit z. B. deionisiertem Wasser gespült werden, in die zu untersuchende Patientenprobe eingebracht werden $[68,104]$. Patienten sollten vor der Sputumabgabe nicht die Zähne putzen oder den Mund mit Wasser spülen, um das Sputum nicht durch Mykobakterien aus dem Wasser zu kontaminieren. Dies ist vor allem unter dem Aspekt des Mehrfachnachweises wichtig. Da 
Patienten in der Regel an nachfolgenden Tagen denselben Wasserhahn benutzen, kann auf diese Weise mehrfach der gleiche Keim, der sich jedoch im Biofilm der Wasserzufuhr befindet, beim Patienten nachgewiesen werden, so dass das Kriterium des Mehrfachnachweises fälschlich erfüllt erscheint.

Aber auch Puffer und Lösungen, die zur Vorbehandlung der Untersuchungsproben eingesetzt werden und nicht autoklaviert worden sind, können durch NTM kontaminiert sein, die so ebenfalls im Verlauf der Verarbeitung im Labor in die Patientenprobe geraten können. Diese Gefahr kann jedoch durch qualitätsgesichertes Arbeiten im Labor verhindert werden.

\subsubsection{Mikroskopie}

Der mikroskopische Nachweis der Mykobakterien beruht auf der durch ihre typische Zellwand hervorgerufenen Säurefestigkeit [105]. Mikroskopisch können NTM nicht sicher von Tuberkulosebakterien unterschieden werden. Einige Spezies sind jedoch durch eine mehr kokkoide Morphologie oder auffällige Bänderung charakterisiert, sodass die Mikroskopie in einigen Fällen einen ersten Hinweis auf das Vorliegen von NTM geben kann.

Für den mikroskopischen Nachweis können zwei unterschiedliche Techniken eingesetzt werden. Die gängige Methode ist die lichtmikroskopische Untersuchung oder Hellfeldmikroskopie. Mit dieser Technik werden die mit Karbolfuchsin behandelten Präparate untersucht, die entweder mit der klassischen ZiehlNeelsen-Methode oder mit der Kinyoun-Methode ohne Erhitzung gefärbt wurden. Alternativ kann eine Fluoreszenzmikroskopie eingesetzt werden, die den Vorteil hat, dass mit einer kleineren Vergrößerung und damit auch ohne Öl mikroskopiert werden kann. So können bei zunehmender Tiefenschärfe mit einem vergrößerten Gesichtsfeld Präparate in kürzerer Zeit geprüft werden.

\subsubsection{Nukleinsäureamplifikationstests (NAT) zum Direktnachweis}

Kommerziell erhältliche Techniken zum Nukleinsäurenachweis von Mykobakterien direkt im Untersuchungsgut sind vorwiegend auf den Nachweis von Tuberkulosebakterien beschränkt [106]. Ein negatives Ergebnis eines solchen NAT bei einer mikroskopisch positiven Probe dient daher als schneller diagnostischer Hinweis auf NTM. Für den Direktnachweis von NTM im Untersuchungsgut gibt es dagegen bislang fast ausschließlich ,homemade'-Techniken. Besondere Bedeutung kommt dem molekularbiologischen Nachweis von NTM vor allem zur Absicherung einer Infektion mit nicht oder schlecht wachsenden Mykobakterien wie z.B. M. ulcerans oder M. genavense zu [107]. NAT zum Nachweis von NTM sollten jedoch nicht zum Screening eingesetzt werden. Die klinische Bedeutung eines Nukleinsäurenachweises von NTM ohne kulturelle Anzucht (mit Ausnahme der nicht oder schlecht wachsenden Spezies) ist derzeit unklar.

\subsubsection{Kultureller Nachweis}

Nach wie vor ist der kulturelle Nachweis von Mykobakterien der Gold-Standard in der Mykobakteriendiagnostik [106,108]. Das gilt nicht nur für Tuberkulosebakterien, sondern auch für NTM. Auch hier muss jedes nicht-sterile Untersuchungsmaterial vorbehandelt werden, um eine schnell wachsende Begleitflora abzutöten. Der kulturelle Nachweis erfolgt durch die Anzucht der Mykobakterien in Flüssigmedien und auf Festmedien [108]. Erstere sind gut geeignet für den Nachweis von NTM [109]. Einige Spezies, wie z.B. M. avium, können in Flüssigkulturen häufig bereits innerhalb weniger Tage nachgewiesen werden [110]. Spe- zielle Flüssigmedien erleichtern die Anzucht von Mykobakterien aus Blut.

Die Kulturmedien von Proben für die Mykobakteriendiagnostik werden routinemäßig bei $36 \pm 1{ }^{\circ} \mathrm{C}$ bebrütet. Werden Hautproben, Lymphknoten oder andere Gewebeproben aus der Körperperipherie untersucht, muss zusätzlich ein zweiter Kulturansatz bei $30 \pm 1^{\circ} \mathrm{C}$ bebrütet werden. Diese Proben können Mykobakterien enthalten, die bei $37^{\circ} \mathrm{C}$ nicht oder schlechter, aber bevorzugt bei niedrigeren Temperaturen wachsen (z. B. M. abscessus, M. chelonae, M. marinum, M. ulcerans). Auch bronchopulmonale Proben von Patienten mit zystischer Fibrose (Mukoviszidose) müssen parallel bei niedrigeren Temperaturen bebrütet werden, da diese Patienten häufig an Infektionen mit $M$. abscessus erkranken. Deshalb ist es wichtig, diese klinische Information an das untersuchende Laboratorium weiterzugeben.

Die Kultivierungszeit beträgt für Flüssigmedien in der Regel 6 Wochen, für Festmedien 8 Wochen. Längere Inkubationszeiten können in besonderen Fällen erforderlich sein, z.B. bei Verdacht auf $M$. genavense oder bei mikroskopisch positiven, aber nach 6 bzw. 8 Wochen noch kulturell negativen Proben.

Es wird zwischen langsam und schnell wachsenden NTM unterschieden (siehe Tab. 1 sowie Kapitel 8, Anhang „Mikrobiologische und therapeutische Besonderheiten bei ausgewählten NTMSpezies“, S. 621). Die Unterscheidung nach der Wachstumsgeschwindigkeit basiert jedoch auf Standardkulturbedingungen und bezieht sich nicht auf die Nachweiszeit aus den Untersuchungsproben.

Wachsen bei einer Untersuchung sowohl Tuberkulosebakterien als auch NTM in den Kulturen, ist in der Regel von einer zufälligen Begleitflora bei den NTM auszugehen [97,98]. Auch hier muss ein Mehrfachnachweis der NTM erbracht werden, um ggf. eine - sehr seltene - Koinfektion zu belegen. Werden Mischkulturen nicht erkannt, können sie zu falsch-resistenten Ergebnissen bei der Resistenzbestimmung der Tuberkulosebakterien führen.

\subsubsection{Identifizierung der Mykobakterien}

Bei Wachstum von säurefesten Stäbchen auf Fest- oder in Flüssigkulturmedien ist die rasche Unterscheidung zwischen Tuberkulosebakterien und NTM vor der Befunderstellung notwendig. Die Identifizierung bzw. der Ausschluss von Tuberkulosebakterien kann sehr schnell durch Einsatz von kommerziell erhältlichen molekularbiologischen Testverfahren durchgeführt werden [101] (siehe auch unter 4.3.4 „Nukleinsäureamplifikationstests (NAT)“). Ist der Nachweis von Tuberkulosebakterien negativ, sollte die Identifizierung der NTM-Spezies erfolgen. Da inzwischen mehr als 140 nichttuberkulöse Mykobakterienspezies beschrieben sind [http://www.bacterio.cict.fr/], ermöglichen konventionelle Methoden keine ausreichende Differenzierung. Nachweisverfahren, die z.B. auf der Analyse von Zellwandstrukturen beruhen (z.B. Hochleistungsflüssigkeitschromatografie [HPLC: high performance liquid chromatography] oder FlugzeitMassenspektrometrie [MALDI-TOF: Matrix Assisted Laser Desorption Ionization - Time Of Flight Mass Spectrometry]), sind entweder nicht ausreichend auflösend oder noch nicht hinreichend evaluiert. Mit molekularbiologischen Methoden können NTM derzeit mit einer hinreichenden Genauigkeit bestimmt werden. Als Methoden stehen Gensonden (für nur wenige Mykobakterienarten), Streifenhybridisierungstests (14 bzw. 30 Arten) oder die Sequenzierung spezifischer Gene oder Genabschnitte (z.B. 16S rDNA) zur Verfügung. 


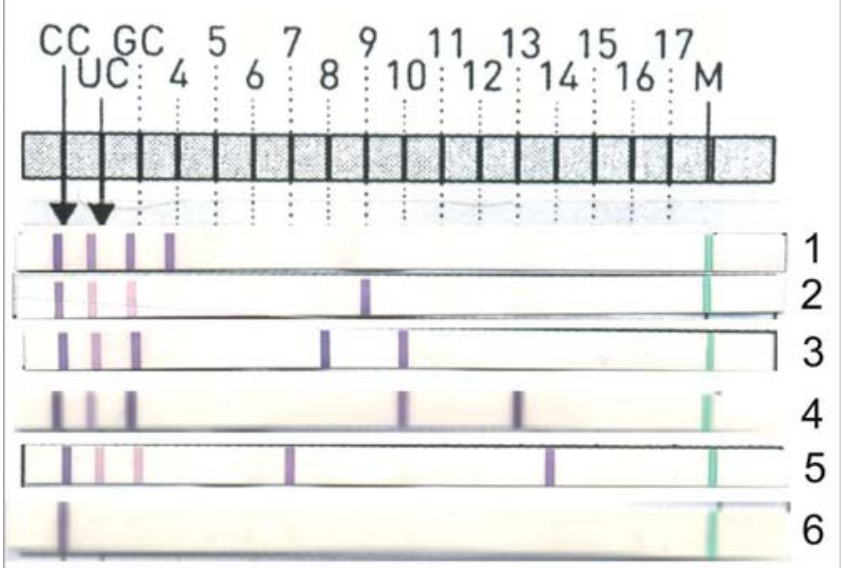

Abb.4 Spezies-spezifische Bandenmuster eines Streifenhybridisierungstests zur Identifizierung von Mykobakterien (GenoType ${ }^{\circledR}$ CM/AS). CC: Konjugatkontrolle; UC: Universalkontrolle; GC: Genus-spezifische Kontrolle für Mykobakterien; 4 bis 17: Spezies-spezifische Banden; M: Markierung der Streifenoberseite. Spur 1: M. avium, Spur 2: M. intracellulare; Spur 3: M. gordonae; Spur 4: M. malmoense; Spur 5: M. fortuitum; Spur 6: Negativkontrolle. (Mit freundlicher Genehmigung von PD Dr. Elvira Richter, Forschungszentrum Borstel, Nationales Referenzzentrum für Mykobakterien.)

Der erste kommerziell erhältliche Test zur Identifizierung von NTM war die Hybridisierung mit Gensonden (AccuProbe ${ }^{\circledR}$ von Gen-Probe) zum Nachweis von Spezies-spezifischer ribosomaler RNA. Jedoch ist dieser Test auf wenige Spezies beschränkt (M. avium-Komplex sowie M. avium und M. intracellulare, M. kansasii, M. gordonae).

Mit Hilfe von Streifenhybridisierungstests (GenoType CM/AS ${ }^{\circledR}$, HAIN Lifescience [111-113]; INNO-LiPA MYCOBACTERIA v2 ${ }^{\circledR}$, Innogenetics $[114,115])$ können heute in einer einzigen Analyse eine Vielzahl der wichtigsten Mykobakterienspezies identifiziert werden. Die Tests beruhen auf der Amplifikation und Detektion von Genbereichen, die sowohl konservierte als auch variable Sequenzabschnitte zeigen (23S rRNA-Gen bzw. „internal transcribed spacer"). Bei diesen Hybridisierungstests sind Nitrozellulosestreifen mit Spezies-spezifischen Oligonukleotiden versehen. Anhand der charakteristischen Bandenmuster werden die Spezies identifiziert ( $\mathbf{A b b}$.4). Innerhalb weniger Stunden können mit diesen Tests eine Vielzahl der wichtigsten Mykobakterienspezies, einschließlich der Tuberkulosebakterien, von positiven Flüssig- und Festkulturen identifiziert werden (am Direktpräparat bislang noch nicht sensitiv genug).

Eine Identifizierung der Spezies durch Sequenzierung bestimmter Gene ist die aufwändigste Methode, aber nur damit können alle und auch unbekannte Spezies differenziert werden. Die für die Mykobakterien am weitesten etablierte Methode ist die Sequenzierung des 5'-Bereichs des Gens der ribosomalen 16S rRNA [116-119]. Der Vorteil an der Analyse des 16S-Gens liegt vor allem darin, dass diese Sequenzen von allen Mykobakterienspezies bekannt sind und auch von allen neuen Arten diese Sequenz in Datenbanken abgelegt wird. Die Identifizierung der Spezies anhand der erhaltenen DNA-Sequenz erfolgt über Sequenzvergleich mit Datenbanken, wie z.B. dem National Center for Biotechnology (NCBI; http://www.ncbi.nlm.nih.gov/blast) oder der Ribosomal Differentiation of Medical Microorganisms (RIDOM; http://www.ridom-rdna.de/). Die endgültige Bewertung der Ergebnisse erfordert jedoch ausreichende Erfahrung, da sich einige Mykobakterienspezies nur durch wenige Basen in den betreffen- den Genabschnitten unterscheiden. Darüber hinaus enthalten Datenbanken, in die Sequenzdaten frei eingegeben werden können, oft fehlerhafte und nicht qualitätskontrollierte Sequenzen. Die Zuordnung zu einer bestimmten Spezies sollte nur bei vollständiger Übereinstimmung (Identität) erfolgen.

\subsubsection{Plausibilitätskontrolle}

Alle mit molekularbiologischen Techniken gewonnenen Ergebnisse sollten auch nach der Befunderstellung auf Plausibilität überprüft werden. Dies kann durch eine Überprüfung bestimmter physiologischer Eigenschaften der Mykobakterien erfolgen (z.B. Wuchsform, Wachstumsgeschwindigkeit, Temperaturpräferenz, Pigmentbildung, Photochromogenität) [101]. Mit diesen Merkmalen kann die Identifizierung bestimmter NTM-Spezies bestätigt werden. So können schnell und langsam wachsende Mykobakterien durch die Wachstumsgeschwindigkeit unterschieden werden. M. marinum und M. kansasii sind photochromogene Spezies, die erst nach Lichteinfall ein gelbes Pigment produzieren, wohingegen M. gordonae oder M. szulgai bereits bei Wachstum im Dunklen pigmentiert sind. M. marinum und M. malmoense wachsen bevorzugt bei ca. $30^{\circ} \mathrm{C}$ und schlechter bei $37^{\circ} \mathrm{C}$, vor allem auf Festmedien.

\subsubsection{Empfindlichkeitsprüfung}

Zur Empfindlichkeitsprüfung von NTM gibt es zurzeit kein Standardverfahren. Zu beachten ist, dass die Ergebnisse der In-vitroTestungen häufig nicht mit der In-vivo-Wirksamkeit übereinstimmen [1]. Die in den Richtlinien des CSLI (Clinical and Laboratory Standards Institute) [120] beschriebenen Methoden zur Empfindlichkeitsprüfung von M. avium, M. kansasii und M. marinum sowie schnell wachsenden Mykobakterien werden nicht mehr eingesetzt (das mit radioaktiv markierten Medien arbeitende BACTEC 460-System) oder sind nicht evaluiert (im Mikrotiterplattenformat durchzuführende Flüssigmedium-basierte Verfahren), sodass beide Methoden in Deutschland nicht routinemäßig durchgeführt werden. Einzelne spezialisierte Laboratorien führen für bestimmte Indikationen Testungen auf festen oder in flüssigen Agarnährböden durch, die in Analogie zu den vom CLSI vorgeschlagenen Methoden angesetzt werden.

Ein neueres Flüssigkultursystem, das BACTEC MGIT 960 (BectonDickinson), in dem die Empfindlichkeitsprüfung für M. tuberculosis weltweit etabliert ist $[121,122]$, kann für die Testung zumindest von langsam wachsenden Mykobakterien als Ersatz für das BACTEC 460-System verwendet werden [123,124], wenn auch hier noch keine klinische Evaluation stattgefunden hat. In der Routine wird bei der Empfindlichkeitsprüfung von Tuberkulosebakterien keine Bestimmung einer minimalen Hemmkonzentration (MHK) vorgenommen, sondern es werden die Empfindlichkeitsprüfungen bei nur jeweils einer bestimmten Konzentration (der kritischen Konzentration) durchgeführt [125]. Bei Empfindlichkeitsprüfungen mit diesen für Tuberkulosebakterien etablierten kritischen Konzentrationen sind NTM, häufig mit einem Spezies-charakteristischen Muster, resistent gegen verschiedene Antibiotika. So sind viele NTM, z. B. M. kansasii, M. malmoense, M. szulgai oder M. marinum, resistent gegenüber INH. Dass INH trotzdem zur Therapie von z.B. M. kansasii empfohlen wird [1], wird begründet mit einer ,low level'-Resistenz, die durch die Serumkonzentration des INHs kompensiert wird. Auch bei anderen Antibiotika liegen die MHKs von NTM oberhalb der klassischen, d.h. für M. tuberculosis angesetzten kritischen Konzentrationen, z.B. RMP bei M. avium. Bislang gibt es jedoch wenig Erfahrung sowohl zu MHK-Bestimmungen bei Mykobakte- 
rien als auch zur Bewertung dieser Ergebnisse im Hinblick auf die Therapie. Betont sei nochmals, dass nicht selten bei NTM eine Diskrepanz zwischen den Ergebnissen der In-vitro-Testungen und dem Behandlungserfolg beobachtet wird [1].

Für die Empfindlichkeitsprüfung von schnell wachsenden Arten kann das BACTEC MGIT 960-Verfahren zurzeit nicht eingesetzt werden. Flüssigmedium-basierte Verfahren mit manueller Auswertung werden z.T. für bestimmte Fragestellungen verwandt. Die Beobachtung, dass M. abscessus-Stämme in Gegenwart von Clarithromycin bei längerer Inkubationszeit Wachstum zeigen, wie auch der genetische Nachweis eines involvierten Gens, führten zu der Einschätzung, dass bestimmte M. abscessus-Stämme eine induzierbare Clarithromycin-Resistenz besitzen [126,127]. Die klinische Relevanz dieser Beobachtung ist noch nicht abzusehen. Insgesamt werden Resistenzentwicklungen unter Therapie bei NTM eher selten beobachtet [128].

Eine Etablierung von molekularen Methoden zur Resistenzbestimmung setzt eine zuverlässige phänotypische Bestimmung voraus, um Mutationen mit Resistenzmustern korrelieren zu können. Bislang umfassen molekulare Untersuchungen vor allem die Mutationsanalysen der 23S rRNA bei M. avium-Komplex und schnell wachsenden Mykobakterien und des erm-Gens bei M. abscessus zur Makrolid-Resistenz [126, 127,129].

In Zukunft könnte die Bestimmung der Serumkonzentrationen wegen möglicher Medikamenteninteraktionen, die zu niedrige Serumspiegel bedingen [130], größere Bedeutung bekommen $[131,132]$, wobei allerdings den nicht routinemäßig messbaren Konzentrationen im Gewebe größere Bedeutung beizumessen ist.

\section{Therapie der nichttuberkulösen Mykobakteriosen bei HIV-negativen Patienten \\ $\nabla$}

Neben der Speziesbestimmung entscheidet sich die Behandlungsbedürftigkeit nach semiquantitativen Kriterien, wie sie 2007 von ATS und IDSA publiziert wurden [1]. Je zahlreicher im Ausstrich und je öfter die Keime aus dem Sputum nachgewiesen werden, also je höher die Keimzahl ist, desto eher liegt Behandlungsbedürftigkeit vor ( Tab.5). Wenn das Sputum mikroskopisch negativ ist und die Mykobakterien ausschließlich kulturell nachgewiesen wurden, ist von einer relativ niedrigen Keimzahl auszugehen, d. h. die Behandlungsbedürftigkeit ist umso sorgfältiger zu prüfen. Gleiches gilt für den ausschließlichen Nachweis aus bronchoskopischen Materialien bei mikroskopisch und kulturell negativem oder nicht vorhandenem Sputum.

Eine Behandlungsbedürftigkeit kann auch bei niedriger Keimzahl gegeben sein, wenn ein röntgenologisch eindeutig pathologischer und fortschreitender Krankheitsprozess vorliegt, z.B. in Form einer dickwandigen, also frisch entzündlichen Kaverne oder bei disseminierten Infiltraten. Bei Vorliegen einer nichttuberkulösen Mykobakteriose ohne erkennbare lokale prädisponierende Lungenerkrankung („Terrainfaktor“ [61]) sollte bedacht werden, einen auch nur umschriebenen Krankheitsprozess (s. - Abb.2) zu behandeln, da eine solche Manifestation pathophysiologisch einer floriden Tuberkulose am ähnlichsten erscheint und selbst bei theoretisch möglicher Spontanheilung dauerhafte strukturelle Schäden durch die Mykobakteriose möglich sind. Bei nichttuberkulösen Mykobakteriosen mit vorhandenem Terrainfaktor muss hingegen umso gründlicher eine Besiedlung (Kolonisation) von einer behandlungsbedürftigen Erkrankung ( $\bullet$ Tab.2) abgegrenzt werden.
Die besondere Sorgfalt, die bei der Diagnosestellung einer Erkrankung durch NTM erforderlich ist, gilt wegen der damit verbundenen möglichen Risiken ebenso für die Entscheidung zu einer medikamentösen und/oder chirurgischen Therapie [16,133]. Die Behandlungskosten können erheblich sein und denen bei einer HIV-Infektion entsprechen [134].

\subsection{Medikamentöse Therapie}

Da eine antimykobakterielle Therapie nichttuberkulöser Mykobakteriosen mit erheblichen unerwünschten Arzneimittelwirkungen verbunden sein kann und die empfohlene Dauer meistens die Dauer einer antituberkulösen Therapie nach heutigem Empfehlungsstand überschreitet, werden hohe Anforderungen hinsichtlich der Akzeptanz an den Patienten gestellt. Zudem ist häufig eine chronische Grundkrankheit vorhanden, die oft bereits zu einer Einschränkung der Leistungsreserve des Patienten geführt hat, sodass zusätzliche Symptome durch die nichttuberkulöse Mykobakteriose womöglich als wenig besorgniserregend wahrgenommen werden. Aber auch ohne schwerwiegende funktionelle Einschränkungen durch eine Grundkrankheit sind aufgrund der geringeren Pathogenität der meisten NTM-Spezies die Symptome schwächer ausgeprägt als bei einer Tuberkulose (welche grundsätzlich immer behandlungsbedürftig ist!) vergleichbaren Ausmaßes, was Krankheitseinsicht und Leidensdruck des Patienten vermindern kann [45].

Solche Umstände machen verständlich, weshalb Patienten zögern, der Empfehlung zu einer längerfristigen antimykobakteriellen Therapie neben einer womöglich aufwändigen Therapie einer Grundkrankheit zu folgen. Die relative Symptomarmut sollte insbesondere dann von ärztlicher Seite bei der Aufstellung eines Therapiekonzepts berücksichtigt werden, wenn nur eine eingeschränkte Wirksamkeit der Behandlung wahrscheinlich ist. Das gilt insbesondere für Patienten mit fortgeschrittenen Lungengrundkrankheiten. Eine befürchtete weitergehende Zerstörung der Lungen durch die nichttuberkulöse Mykobakteriose kann aber eine Indikation für eine Behandlung darstellen. Jedoch muss das Bewusstsein dafür vorhanden sein, dass sich die Indikation zu einer - mutmaßlich palliativen - Behandlung in einer Grauzone von Erfahrung und individueller Beobachtung befinden kann. Über Langzeitverläufe von zehn Jahren und mehr nach Diagnosestellung einer NTM mit oder ohne Behandlung ist aus der Literatur wenig bekannt.

Die Grundsätze der konservativen medikamentösen Therapie sind denen bei der Tuberkulose ähnlich. Besonderheiten zur antibiotischen Therapie bei ausgewählten NTM-Spezies sind in Kapitel 8 (Anhang 1: Mikrobiologische und therapeutische Besonderheiten bei ausgewählten NTM-Spezies, S. 621) aufgeführt. Fast immer wird bei den Erkrankungen durch NTM eine Kombinationstherapie über einen längeren Zeitraum empfohlen, weil eine Monotherapie das Risiko einer raschen Resistenzentwicklung birgt [128].

In Kapitel 9 (Anhang 2: Eigenschaften der in der Therapie von NTM-Erkrankungen eingesetzten Medikamente, S. 625) sind die Eigenschaften (Wirkmechanismus, Pharmakogenetik, Dosierung, Kontraindikationen und Nebenwirkungen) der in der Therapie von NTM-Erkrankungen eingesetzten Medikamente in alphabetischer Reihenfolge kurz zusammengestellt. Weitere Einzelheiten finden sich in den Tuberkulose-Therapieempfehlungen des DZK und der DGP [135]. 


\subsection{Chirurgische Therapie}

Die chirurgische Therapie sollte grundsätzlich mit einer kurativen Absicht verbunden sein. Bei pulmonalen nichttuberkulösen Mykobakteriosen ist eine Resektion des erkrankten Lungenareals zu erwägen, wenn der Verlauf unter einer medikamentösen Therapie nicht erkennen lässt, dass das Krankheitsbild des Patienten hierdurch dauerhaft gebessert werden kann $[59,96,136]$. Weiterhin ist die Indikation zur Resektion einer Restkaverne oder eines infizierten zerstörten Lungenareals zu prüfen, wenn hierdurch andere Komplikationen wie Infektionen durch Bakterien (P. aeruginosa u.a.) oder Pilze (Aspergillus spp.) mit rezidivierenden Pneumonien, Hämoptysen oder eine fortschreitende chronischobstruktive Bronchitis (COPD) mit und ohne Bronchiektasen ausgelöst wurden.

Bei Patienten mit einer nur milden Ausprägung der Grundkrankheit oder fehlender Grundkrankheit empfiehlt sich nach Abschluss einer klinisch, radiologisch und mikrobiologisch bestätigten erfolgreichen Therapie zunächst eine längerfristige Beobachtung, auch wenn ein Residualbefund vorhanden ist, da - wie erwähnt - wenig Daten zu Langzeitverläufen vorliegen. Bei Patienten mit klinisch manifesten Einschränkungen durch die Grundkrankheit ist die Indikation zur Resektion unter dem Gesichtspunkt der Operabilität besonders sorgfältig zu prüfen, weil die Komplikationshäufigkeit höher ist als bei der Resektion posttuberkulöser Residuen [137]. Zudem kann die Abwägung schwierig sein, ob die Langzeitprognose des Patienten stärker durch die Grundkrankheit, die nichttuberkulöse Mykobakteriose oder die Operation eingeschränkt ist $[59,138]$.

Bei tiefergehenden Haut- und Weichteilinfektionen durch M. marinum kann ebenfalls ein chirurgisches Vorgehen (Debridement) indiziert sein, allerdings nur in Kombination mit einer medikamentösen Behandlung [1]. Gleiches kann auch für Haut- und Weichteilinfektionen durch M. xenopi, M. fortuitum oder andere NTM angenommen werden, beim Buruli-Ulkus ist die Thermotherapie zur Lokalbehandlung als eine zusätzliche Möglichkeit beschrieben [139].

Für die Operationsindikation bei kindlichen Lymphadenitiden wird auf das entsprechende Kapitel in diesen Empfehlungen verwiesen (Kapitel 7 „Diagnostik und Therapie nichttuberkulöser Mykobakteriosen im Kindesalter“, S. 618).

\subsection{Therapie der Grundkrankheit}

Stets sollte auch die Grundkrankheit behandelt werden, wie von Radenbach bereits seit den siebziger Jahren propagiert [40] und zuletzt auch ausdrücklich in die ATS/IDSA-Empfehlungen aufgenommen [1]. Was bei Patienten mit CF selbstverständlich ist, sollte es auch für Patienten mit COPD - mit und ohne Bronchiektasen - sein, da sich unabhängig von der Behandlung der Mykobakteriose die Prognose durch eine leitliniengerechte Therapie der Grunderkrankung verbessern lassen dürfte. Es ist ohne Weiteres plausibel, anzunehmen, dass eine Verbesserung der bronchialen Klärfunktion den bedingenden Terrainfaktor für die Ansiedlung und lokale Vermehrung der Mykobakterien mildert [140]. Leider wird bei der Interpretation von Chemotherapieergebnissen in Studien bisher nicht oder kaum berücksichtigt, ob eine adäquate Therapie der Grundkrankheit stattgefunden hat oder nicht, sodass der Einfluss solcher Maßnahmen nur aus klinischer Sicht abgeschätzt werden kann.

\section{Nichttuberkulöse Mykobakteriosen bei HIV-Infektion \\ $\nabla$}

\subsection{Klinik}

Epidemiologie und Klinik der nichttuberkulösen Mykobakteriosen weisen bei Patienten mit HIV-Infektion deutliche Besonderheiten auf. In Abhängigkeit vom zellulären Immunstatus lassen sich disseminierte und pulmonal lokalisierte Verlaufsformen unterscheiden. Disseminierte Formen als Spätmanifestation bei schwerer Immundefizienz (CD4-Zellzahl< $<50 / \mu \mathrm{l})$ gehören zu den ausgeprägtesten AIDS-definierenden Erkrankungen. Am häufigsten handelt es sich um die Mycobacterium avium-Komplex-Infektion, wobei in $95 \%$ M. avium der ätiologisch verantwortliche Mikroorganismus ist [1]. Die Übertragung des ubiquitär verbreiteten Erregers erfolgt inhalativ oder gastrointestinal, es sind keine risikoerhöhenden Expositionen bekannt [76]. Eine Transmission von Patient zu Patient ist nicht dokumentiert. Bei Patienten ohne effektive antiretrovirale Therapie und ohne Chemoprophylaxe liegt die Inzidenz dieser Infektion bei $20-40 \%$ über einen Zeitraum von zwei Jahren [141,142]. Die Klinik ist gekennzeichnet durch die Allgemeinsymptomatik mit Fieber, Nachtschweiß, Adynamie und Gewichtsverlust. Leitsymptome sind Lymphadenopathie und Hepatosplenomegalie, die Lunge kann mitbetroffen sein.

Im Zeitalter der effektiven antiretroviralen Therapie wird die disseminierte MAC-Infektion seltener beobachtet. Sie tritt bei unbehandelten AIDS-Patienten mit schwerem Immundefekt auf, wird in den westlichen Ländern aber zunehmend durch lokalisierte Manifestationen wie fokale Lymphadenitis ( $\bullet$ Abb.5), Lungen-
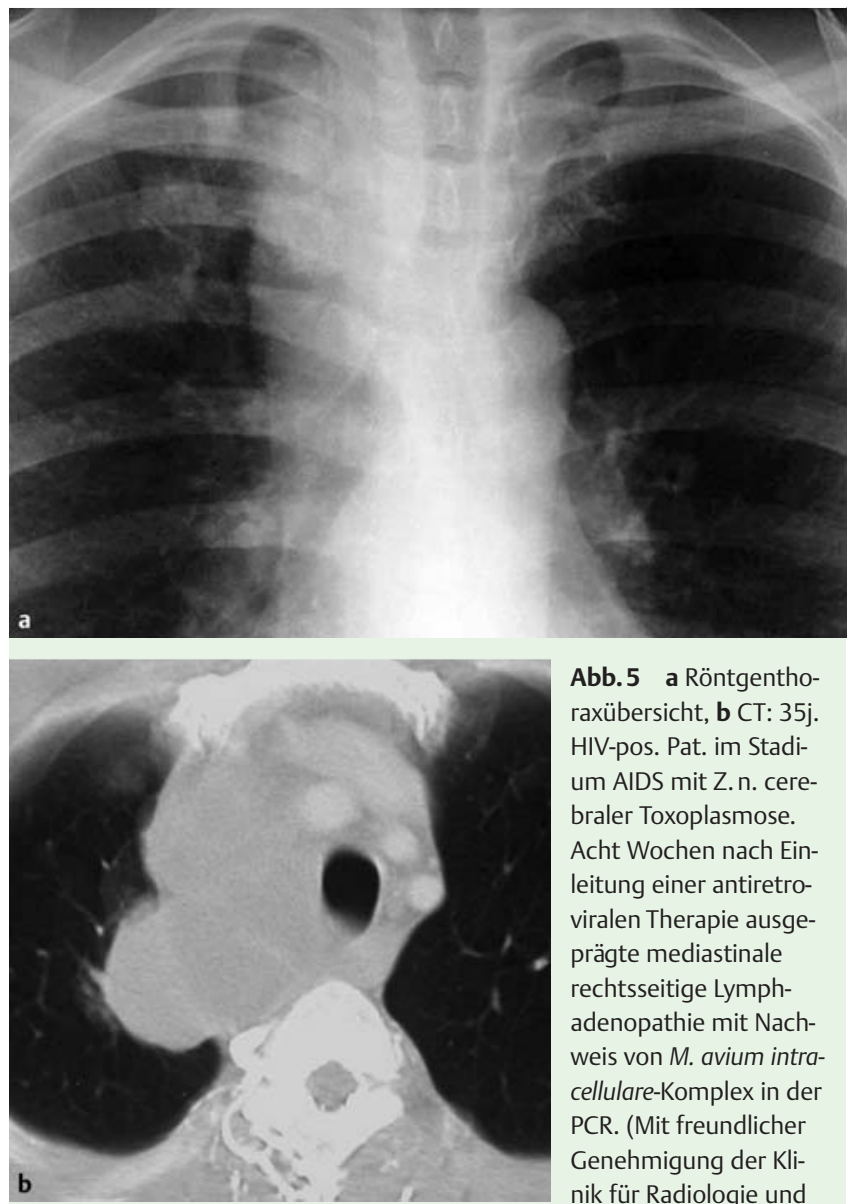

Abb.5 a Röntgenthoraxübersicht, b CT: 35 j. HIV-pos. Pat. im Stadium AIDS mit Z.n. cerebraler Toxoplasmose. Acht Wochen nach Einleitung einer antiretroviralen Therapie ausgeprägte mediastinale rechtsseitige Lymphadenopathie mit Nachweis von M. avium intracellulare-Komplex in der PCR. (Mit freundlicher Genehmigung der Klinik für Radiologie und

Nuklearmedizin, Universitätsklinikum Schleswig-Holstein Campus Lübeck.) 
infiltrate und (selten) Osteomyelitis abgelöst. Diese Verlaufsformen treten gehäuft nach Beginn der antiretroviralen Therapie im Rahmen eines Immunrekonstitutionssyndroms (IRIS, s.u.) auf [143].

Mit pulmonal begrenzten nichttuberkulösen Mykobakteriosen ( $\mathbf{\text { Abb.6) }}$ und Lymphadenitiden ist im Rahmen der HIV-Infektion ansonsten bereits bei mäßigem Immundefizit zu rechnen, sie werden schon bei CD4-Zellzahlen zwischen 200-500/ $\mathrm{ll}$ beobachtet [144]. Ein häufiger Erreger ist M. kansasii. Die Inzidenz war in einer Untersuchung der 1990er Jahre mit 115/100.000 HIV-positiven Patienten pro Jahr etwa 150-mal höher als in der untersuchten Normalbevölkerung [145]. In der Bildgebung finden sich überwiegend fokale, peripher betonte Infiltrate besonders in den Mittel- und Unterfeldern, seltener Kavernen, die eine ungünstigere Prognose haben [146].

Neben MAC und M. kansasii sind eine Vielzahl weiterer NTM als fakultativ pathogene Erreger bei HIV-Infektion beschrieben wie M. celatum, M. genavense, M. haemophilum, M. malmoense, $M$. simiae und M. xenopi. Da die Fallzahlen gering sind, existieren zu diesen Erregern keine bzw. wenig Studien.

Eine wichtige Therapiekomplikation stellt das Immunrekonstitutionssyndrom („Immune Reconstitution Inflammatory Syndrome“, IRIS) dar [147]. Es tritt bevorzugt nach Beginn einer antiretroviralen Therapie bei raschem Anstieg der CD4-Lymphozyten auf und wird bei MAC-Infektion in ähnlicher Häufigkeit wie bei der Tuberkulose beobachtet. Es besteht ein Missverhältnis zwischen ausgeprägten zellulären Infiltraten und paucibacillärem Befall [148], daher sind die Erreger meist schwer nachweisbar. Blutkulturen fallen regelmäßig negativ aus. Klinisch stehen Fieber und fokale Lungen- und Lymphknotenerkrankungen im Vordergrund [143]. Unter antimykobakterieller Therapie kann der Verlauf des IRIS sowohl selbstlimitierend als auch progredient sein; ein geringer Teil der Patienten bedarf zusätzlich einer entzündungshemmenden Therapie mit Glukokortikoiden, ähnlich wie bei Tuberkulose $[147,149]$.

\subsection{Diagnostik}

Die Diagnose der disseminierten MAC-Infektion wird in $>90 \%$ der Fälle durch Blutkulturen gesichert [1]. Häufig kann der Erreger auch aus respiratorischen Materialien isoliert werden. In unklaren Fällen sollte der Nachweis aus Lymphknotenbiopsien oder Knochenmarkaspiraten angestrebt werden. Im klinischen Labor ist neben einer meist normozytären Anämie eine Erhöhung der alkalischen Phosphatase charakteristisch [150].

Mikrobiologische Nachweisverfahren haben auch bei HIV-infizierten Patienten eine recht hohe Sensitivität und Spezifität zum Nachweis lokal begrenzter NTM-Infektionen. In einer populationsbasierten Studie waren $41 \%$ der M. kansasii-Erkrankungen im Ausstrich positiv. Bereits der einmalige kulturelle Erregernachweis hatte mit $85,7 \%$ bei HIV-positiven bzw. $71,4 \%$ bei HIVnegativen Patienten einen hohen prädiktiven Wert für eine klinisch relevante Infektion [145]. Eine Mykobakterien-PCR kann bei positivem Ausstrich die Differenzierung zwischen M. tuberculosis-Komplex und NTM beschleunigen.

\subsection{Therapie}

Für die Therapie der nichttuberkulösen Mykobakteriosen bei HIV-Infektion gelten im Wesentlichen auch die im Kapitel 8 (Anhang 1: „Mikrobiologische und therapeutische Besonderheiten bei ausgewählten Mykobakterienspezies“, S. 621) beschriebenen Empfehlungen. Hier seien nur einige Besonderheiten aufgeführt. Bei der disseminierten MAC-Infektion wird eine tägliche Kombi-
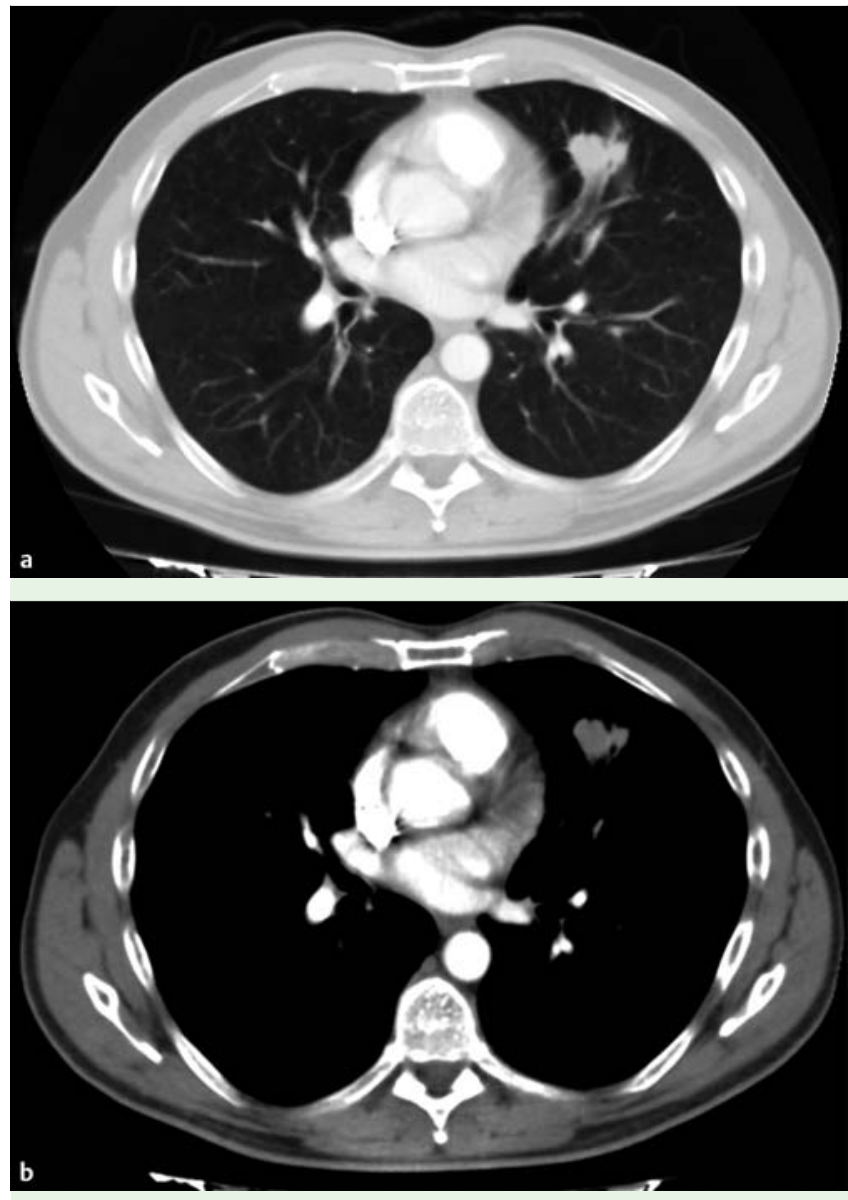

Abb. 6 HIV-positiver Patient mit Hämoptysen und inhomogenem Infiltrat in der Lingula: bioptisch epitheloidzellige Granulomatose, Nachweis von M. avium in der Kultur. (Mit freundlicher Genehmigung der Klinik für Radiologie und Nuklearmedizin, Universitätsklinikum Schleswig-Holstein Campus Lübeck.)

nationstherapie mit mindestens zwei Substanzen empfohlen [76]. Clarithromycin und Ethambutol sind die am besten untersuchten Substanzen [151]. Die Standarddosis von Clarithromycin (1000 mg/d) sollte nicht überschritten werden, da höhere Dosierungen mit einer erhöhten Mortalität assoziiert waren [152]. Alternativ kann Azithromycin eingesetzt werden, wobei für diese Substanz die Studienlage limitierter ist [153]. Der zusätzliche Nutzen einer Dreifachkombination mit Rifabutin war in zwei kontrollierten Studien bei HIV-infizierten Patienten hinsichtlich des Überlebens nicht konsistent und ist gegen eine höhere Nebenwirkungsrate abzuwägen; allerdings vermindert die Dreifachkombination die Entstehung von Makrolidresistenz unter Therapie [152]. Der Einsatz des dritten Kombinationspartners sollte insbesondere bei ausgedehnter Erkrankung, hoher Mykobakterienkonzentration in der Kultur und bei Nichtverfügbarkeit einer effektiven antiretroviralen Therapie erwogen werden [76]. Bei Patienten, die Proteaseinhibitoren zur Therapie der HIV-Infektion erhalten, ist eine Therapie mit Rifabutin nur unter Dosisanpassung und Spiegelkontrollen der antiretroviralen Medikamente empfehlenswert. Auch bei Therapie mit nichtnukleosidalen Hemmern der reversen Transkriptase (NNRTI) sind bei Komedikation mit Rifabutin Dosisanpassungen und Monitoring zu beachten, sodass diese Therapieoption nur in Betracht kommt, wenn Patient und behandelnde Ärzte engmaschige Kontrollen gewährleisten können [135]. Die Therapie sollte dann in Zusam- 
menarbeit mit einem in der Behandlung HIV-positiver Patienten erfahrenen Zentrum erfolgen. Als weitere Alternativen stehen die Aminoglykoside Streptomycin und Amikacin mit dem Nachteil der ausschließlich parenteralen Applikation zur Verfügung. Wie bei der Tuberkulose wird in internationalen Leitlinien empfohlen, eine antiretrovirale Therapie in der Regel erst zwei Wochen nach Start der antimykobakteriellen Therapie zu beginnen, um Manifestation und Komplikationen eines Immunrekonstitutionssyndroms (IRIS) zu reduzieren (siehe unter 6.1 „Klinik“, S. 616) [76].

Die Therapiedauer sollte nach den vorliegenden Studien mindestens 12 Monate betragen, bei verzögerter kultureller Konversion 12 Monate nach Negativierung der Kulturen. Der Therapieerfolg wird bei disseminierter MAC-Erkrankung klinisch sowie 2-4 Wochen nach Therapiebeginn durch die Blutkultur kontrolliert. Bei pulmonalen Infektionen erfolgt die mikrobiologische Kontrolle aus Sputum oder in Ausnahmefällen aus anderen respiratorischen Materialien mit initial positivem Befund. Bei Therapieversagen im Sinne einer ausbleibenden klinischen und röntgenologischen Besserung ist zunächst die Compliance kritisch zu überprüfen. Eine Therapieumstellung sollte mit mindestens zwei neuen Substanzen erfolgen, denn die Mykobakterien können sekundär unter Therapie gegen Clarithromycin resistent werden [150]. Kontrollierte Studien zur Effektivität dieses Ansatzes existieren allerdings nicht. In Betracht gezogen werden können u.a. neuere Fluorchinolone und Aminoglykoside [76]. Von zentraler Bedeutung bei der Therapie der MAC-Infektion ist der Immunstatus des Patienten, sodass immer geprüft werden sollte, ob eine Optimierung der antiretroviralen Therapie möglich ist.

Für die Therapie der M. kansasii-Infektion bei HIV-Infizierten gelten dieselben Empfehlungen wie bei HIV-negativen Patienten, Dreifachtherapie mit Isoniazid, Rifampicin und Ethambutol (siehe Kapitel 8, Anhang 1 „Mikrobiologische und therapeutische Besonderheiten bei ausgewählten NTM-Spezies“, S. 621). Allerdings sollte bei Personen, die gleichzeitig antiretroviral behandelt werden, der Ersatz von Rifampicin durch Rifabutin erwogen werden. Alternativ wird empfohlen, die Rifamycine durch ein Makrolid oder Moxifloxacin zu ersetzen [1].

Auf das Immunrekonstitutionssyndrom („Immune Reconstitution Inflammatory Syndrome“, IRIS) als mögliche Therapiekomplikation $[147,148,149]$ ist bereits oben eingegangen worden (siehe unter 6.1 „Klinik“, S. 616).

\subsection{Prävention}

Eine Primärprophylaxe bei HIV-positiven Patienten mit sehr

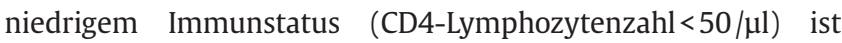
zwar effektiv, wird aber unter Abwägung von Inzidenz und medikamentöser Belastung nicht generell empfohlen, da unter effektiver antiretroviraler Therapie meist eine ausreichende Immunrekonstitution gelingt [76]. Eine Indikation ist am ehesten bei Patienten zu diskutieren, wenn der Immundefekt nicht therapeutisch beeinflusst werden kann. Zur Durchführung der Prophylaxe stehen die Makrolidantibiotika Azithromycin und Clarithromycin zur Verfügung, die das Risiko einer MAC-Infektion in kontrollierten Studien deutlich reduzierten $[154,155]$. Azithromycin hat bei dieser Indikation den Vorteil der einmal wöchentlichen Dosierung. Auf Nebenwirkungen der Substanzen in der Langzeitanwendung ist zu achten. Nach disseminierter MAC-Infektion ist eine Erhaltungstherapie wegen des hohen Rezidivrisikos erforderlich, bis die CD4-Zellzahl unter antiretroviraler Therapie die Schwelle von 100Zellen/ $\mu$ für einen Zeitraum von $\geq 3-6$ Monaten überschritten hat $[156,157]$. Standard ist die Zweifachkombi- nation aus Makrolid und Ethambutol. Eine Sekundärprophylaxe bei lokal begrenzten Infektionen ist nicht etabliert und nach klinischer Einschätzung meist verzichtbar.

\section{Diagnostik und Therapie nichttuberkulöser Mykobakteriosen im Kindesalter $\nabla$}

Erkrankungen durch nichttuberkulöse Mykobakterien im Kindesalter zeigen einige Besonderheiten, weshalb dies hier in einem eigenen Kapitel abgehandelt wird. Das Kapitel fußt auf einer Zusammenfassung aus dem Jahr 2005 [158], die um aktuelle Erkenntnisse ergänzt wurde.

\subsection{Epidemiologie}

Internationale Studien geben eine jährliche Inzidenz von Erkrankungen durch NTM zwischen 0,8 und 4,5 pro 100.000 Kinder an $[159,160,161,162]$.

In Deutschland wurde erstmals bundesweit von Oktober 2002 bis September 2005 die Epidemiologie der nichttuberkulösen Mykobakteriosen bei immunkompetenten Kindern untersucht [163]. Im Rahmen dieser prospektiven Studie des Robert KochInstituts (RKI) und der Erhebungseinheit seltener pädiatrischer Erkrankungen in Deutschland (ESPED) erhob ein Netzwerk von freiwillig teilnehmenden Kinderkliniken demografische und klinische Daten zu 102 Kindern mit einer laborbestätigten, erstmaligen Erkrankung durch NTM. Anhand der im gleichen Zeitraum erfassten Anzahl von NTM-Isolaten in einem bundesweiten Laborsentinel konnte eine jährliche Inzidenz von 1,3 pro 100.000 Kinder errechnet werden, wobei auch die geschätzte Zahl der in beiden Erhebungssystemen nicht erfassten Fälle berücksichtigt wurde. Die Mehrheit der Kinder wies eine lokalisierte Lymphadenitis auf (97\%) und war unter 5 Jahre alt (93\%). Daher liegt der Schwerpunkt dieses Kapitels auf der Diagnostik und Therapie der nichttuberkulösen mykobakteriellen Lymphadenitis.

\subsection{Erregerspektrum und klinisches Bild}

Ob eine Infektion mit NTM bei Kindern zu einer klinischen Erkrankung führt, ist abhängig von der Virulenz des Erregers und intrinsischen Wirtsfaktoren wie dem Immunstatus und dem Alter. Auch die Art der Infektionsquelle und der Exposition spielt eine Rolle. In Tab. 6 sind die typischen Krankheitsbilder den häufig nachgewiesenen Spezies bei Kindern gegenübergestellt. Im Gegensatz zur Lymphadenitis ist bei Befall von anderen Organen oder einer generalisierten Erkrankung eine spezifische Dispo-

Tab. 6 Erkrankungen durch nichttuberkulöse Mykobakterien und häufig nachgewiesene Erreger bei Kindern (nach [170]).

\begin{tabular}{|c|c|}
\hline Krankheitsbild & Haupterreger \\
\hline $\begin{array}{l}\text { Generalisierte Erkrankung } \\
\text { (bei Immunsuppression oder } \\
\text { genetischer Disposition) }\end{array}$ & M. avium-Komplex \\
\hline Haut- und Weichteilinfektionen & $\begin{array}{l}\text { M. marinum, M. ulcerans, M. chelonae, } \\
\text { M. abscessus }\end{array}$ \\
\hline Katheter-assoziierte Infektionen & M. abscessus, M. chelonae \\
\hline Lymphadenitis & $\begin{array}{l}\text { M. avium-Komplex, M. malmoense, } \\
\text { M. scrofulaceum, M. haemophilum }\end{array}$ \\
\hline Otitis media, Mastoiditis & M. abscessus, M. kansasii, M. xenopi \\
\hline Pulmonale Infektionen & $\begin{array}{l}\text { M. avium-Komplex, M. kansasii, } \\
\text { M. xenopi }\end{array}$ \\
\hline $\begin{array}{l}\text { Zystische Fibrose } \\
\text { (pulmonale Infektionen) }\end{array}$ & M. abscessus, M. avium, M. chelonae \\
\hline
\end{tabular}


Tab.7 Typisches klinisches Bild der nichttuberkulösen mykobakteriellen Lymphadenitis bei Kindern [171, 172].

einseitige Lymphknotenschwellung im Kieferwinkel, präaurikulär

(im Bereich der Parotis) oder submandibulär

bläulich-rote Färbung, ggf. Fistel-Ausführungsgang

Lymphknoten verschieblich

feste Konsistenz ohne Fluktuation

nicht druckdolent

sition, wie z. B. ein zellulärer Immundefekt (z. B. Human-Immundefizienz-Virus-(HIV)-Infektion), Interferon-gamma-(INF- $\gamma-$ ), Interleukin-12-(IL-12) Rezeptordefekte [164], STAT1-Defekt, septische Granulomatose CGD [165], eine zystische Fibrose [166,167] ( $\bullet$ Tab.4) oder der Zustand nach Operation [168] oder invasiver Untersuchung von Bedeutung.

Die häufigste Erkrankungsmanifestation bei immungesunden Kindern ist die zervikale Lymphadenitis ( $\bullet$ Abb.7). Prospektive Studien aus Deutschland, den Niederlanden und Australien zeigen übereinstimmend, dass der Haupterreger der M. aviumKomplex ist $[158,160,163]$. Weiterhin wurden im Rahmen der deutschen Studie vereinzelt M. kansasii, M. celatum, M. malmoense und $M$. chelonae nachgewiesen. Betroffen sind vor allem Kleinkinder unter dem fünften Lebensjahr. Die Häufigkeit einzelner NTM-Spezies ist von der geographischen Lage abhängig (siehe auch Kapitel 2 „Epidemiologie und Bedeutung“, S. 607). M. malmoense z.B. kommt in den USA nur selten vor, wird aber in Europa häufig isoliert [169].

Hinweise auf eine Lymphadenitis durch NTM liefern die Anamnese und die klinische Untersuchung. Tab. 7 gibt die Charakteristika des typischen klinischen Bilds wieder [171,172]. Zur Etablierung der Diagnose einer zervikalen Lymphadenitis tragen auch der meist gute Allgemeinzustand der Kinder ohne systemische Krankheitszeichen (kein hohes Fieber), ein fehlendes Ansprechen auf unspezifische Antibiotika und ein Krankheitsverlauf von mehr als 2 Wochen bei.

\subsection{Diagnostik}

Bei der differenzialdiagnostischen Abgrenzung von der Tuberkulose sind in der Anamnese das Expositionsrisiko und das Geburtsland bzw. die Staatsangehörigkeit der Kinder von Bedeutung: Für Tuberkulose spricht der enge Kontakt zu Menschen mit einer ansteckenden Tuberkulose bzw. die Herkunft aus Tuberkulose-Hochprävalenzregionen wie den Staaten der ehemaligen Sowjetunion, Südostasien oder dem südlichen Afrika.

Der Tuberkulin-Hauttest mit 2 Tuberkulineinheiten PPD RT 23 kann nach Kontakt mit NTM auch (falsch-)positiv ausfallen, da die im Test verwendeten Antigene in einigen NTM-Spezies ebenfalls vorkommen können (Kreuzreaktivität). So hatten $82 \%$ der Kinder in der deutschen Studie von RKI und ESPED eine Induration von mehr als $5 \mathrm{~mm}$ und $20 \%$ von mehr als $15 \mathrm{~mm}$ [163].

Ein positiver Tuberkulin-Hauttest kann generell als Hinweis auf eine mykobakterielle Genese (auch infolge BCG-Impfung) gewertet werden. Er erlaubt jedoch keine Differenzierung zwischen einer Infektion bzw. Erkrankung durch M. tuberculosis und durch NTM. In den meisten Fällen ist für die Differenzialdiagnostik ein Interferon- $\gamma$-Test (IGRA) auf Grund der höheren Spezifität für M. tuberculosis hilfreich $[173,174]$. Kreuzreaktionen mit falschpositiven Ergebnissen im IGRA sind nur bei M. flavescens, M. marinum, $M$. kansasii und $M$. szulgai möglich $[93,94]$. Eine vorbestehende BCG-Impfung führt im Gegensatz zum Hauttest nicht zu einem positiven Testausfall. Bei positivem Tuberkulin-Hauttest und negativem IGRA ist eine Tuberkulose daher eher unwahr-

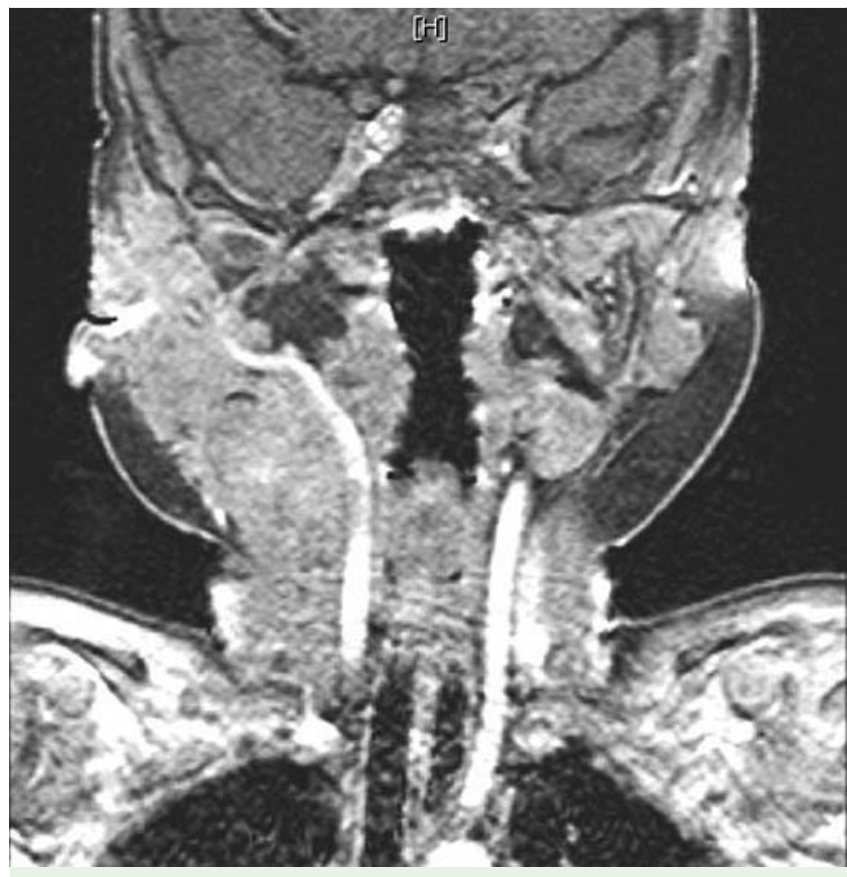

Abb.7 Nichttuberkulöse Mykobakteriose durch M. avium v.a. in den Lymphknoten der rechten Halsseite (MRT) bei einem 15 Monate alten Mädchen. (Mit freundlicher Genehmigung von Dr. Roland C. Bittner, Institut für Diagnostische und Interventionelle Radiologie, HELIOS Klinikum Emil von Behring, und PD Dr. Michael Barker, Klinik für Kinder- und Jugendmedizin, HELIOS Klinikum Emil von Behring.)

scheinlich und eine Erkrankung durch NTM umso wahrscheinlicher.

Zur weiteren Differenzialdiagnostik gehört eine Röntgenuntersuchung des Thorax. Bei immungesunden Patienten mit einer mykobakteriellen Lymphadenitis durch NTM ist das Thoraxbild fast immer unauffällig, wohingegen bei der Lymphknotentuberkulose eine gleichzeitige pulmonale Erkrankung bestehen kann [175]. Die sonografische Untersuchung liefert weitere diagnostische Hinweise und dient als Unterstützung bei der Planung der meist operativen Therapie. Kleine Verkalkungen im Lymphknoten können auf eine abgelaufene mykobakterielle Infektion hinweisen [176]. In unklaren Fällen kann der molekulargenetische oder kulturelle Nachweis von NTM aus dem mittels Feinnadelpunktion gewonnenen ansonsten sterilen Material zur Diagnosesicherung beitragen.

Bei der operativen Exstirpation der betroffenen Lymphknoten sollte auch immer unfixiertes Gewebe für die Erregerdiagnostik und ggf. für spezielle histopathologische Färbungen (bei Tumorverdacht) entnommen werden. Von einer Inzision und Drainage wird abgeraten, da dies üblicherweise zur Bildung eines Sinustrakts mit chronischem Ausfluss führt [177]. Schon der einmalige Nachweis von NTM aus sterilem Lymphknotengewebe ist beweisend für die Diagnose. Im Falle einer disseminierten Erkrankung sollte unbedingt eine immunologische Diagnostik im Hinblick auf eine Grundkrankheit erfolgen.

\subsection{Therapie}

Obwohl die Lymphadenitis durch NTM beim immungesunden Kind keine vitale Bedrohung darstellt, kann die Erkrankung aufgrund des lokal destruierenden Prozesses und chronischen Krankheitsverlaufs zu einer erheblichen Krankheitslast sowie zu langfristigen Folgeproblemen führen, ohne Therapie kommt es meist zur Einschmelzung und Fistelbildung [178]. 
Tab. 8 Medikamentöse Therapie bei immungesunden Kindern mit isolierter NTM Lymphadenitis durch M. avium-Komplex [170].

Clarithromycin $15-30 \mathrm{mg} / \mathrm{kg} \mathrm{KG} / \mathrm{Tag}$, in Einzeldosen p. o. (max. Tagesdosis s. Fachinformation) oder Azithromycin $10-12$ mg/kg KG/Tag (max. Tagesdosis s. Fachinformation)

Rifampicin $350 \mathrm{mg} / \mathrm{m}^{2} \mathrm{KOF}$, max. $600 \mathrm{mg} / \mathrm{Tag}$

(d. h.: 0 - 5 Jahre: $15 \mathrm{mg} / \mathrm{kg} \mathrm{KG/Tag,}$

6-9 Jahre: $12 \mathrm{mg} / \mathrm{kg} \mathrm{KG/Tag,} 10$ - 14 Jahre: $10 \mathrm{mg} / \mathrm{kg} \mathrm{KG} / \mathrm{Tag})$ oder

Rifabutin* $5 \mathrm{mg} / \mathrm{kg} \mathrm{KG/Tag,} \mathrm{max.} 300 \mathrm{mg} /$ Tag

Ethambutol $850 \mathrm{mg} / \mathrm{m}^{2} \mathrm{KOF}$, max. $1,75 \mathrm{~g} / \mathrm{Tag}$

(0 - 5 Jahre: $30 \mathrm{mg} / \mathrm{kg} \mathrm{KG/Tag,}$

$>5$ Jahre: $25 \mathrm{mg} / \mathrm{kg} \mathrm{KG/Tag)}$

* Rifabutin ist derzeit in Deutschland für das Kindesalter nicht zugelassen. Die Dosierungsangabe ist nicht evidenzbasiert. Bezüglich Toxizität und unerwünschten Wirkungen siehe Arzneimittelinformation der Hersteller.

Die Therapie der zervikalen Lymphadenitis durch NTM erfolgt primär chirurgisch. Die Evidenz hierfür basiert auf einer über 30 Jahre alte Studie aus Texas [179]. In dieser ersten großen Fallserie von 82 Fällen von Lymphadenitiden durch NTM und 298 Fällen aus der Literatur wurde eine Heilung in 92\% der Fälle allein durch eine chirurgische Entfernung der makroskopisch betroffenen Lymphknoten erreicht. Dieser Anteil unterschied sich nicht relevant von 95\% Heilung in der Vergleichsgruppe publizierter Fälle, die zusätzlich eine antimykobakterielle Kombinationstherapie erhalten hatte. Das alleinige Vorgehen mit Inzision und Drainage ohne Entfernung der pathologisch veränderten Lymphknoten führte dagegen lediglich zu einer Heilung in 16\% [179]. Die höheren Heilungserfolge durch eine chirurgische Therapie gegenüber einer antimykobakteriellen Kombinationstherapie wurden durch aktuelle randomisierte, kontrollierte Studien bestätigt [162,180]. In der prospektiven, randomisierten Studie von Lindeboom et al. wurde die chirurgische Therapie mit einer alleinigen Kombinationstherapie aus Clarithromycin und Rifabutin über eine Dauer von mindestens 12 Wochen verglichen [180]. Je Gruppe wurden 50 Kinder mit zervikofaszialer Lymphadenitis durch NTM eingeschlossen (Nachweis von M. avium in 71 Fällen und von M. haemophilum in 22 Fällen). Die Heilungserfolge nach chirurgischer Therapie lagen bei $96 \%$ nach drei und sechs Monaten. Nach medikamentöser Behandlung waren $44 \%$ nach drei Monaten geheilt und bei weiteren $32 \%$ wurde eine Rückbildung der Lymphknoten erzielt. Der Anteil der erfolgreich Behandelten nach sechs Monaten lag bei $66 \%$. Die Komplikationsraten der chirurgischen Therapie betrugen $28 \%$. Von $74 \%$ der medikamentös behandelten Kinder wurden unerwünschte Arzneimittelwirkungen berichtet, 2 Kinder wiesen schwerwiegende unerwünschte Arzneimittelwirkungen auf [180]. Die prospektive Studie von Blyth et al. 2009 zeigte vergleichbare Ergebnisse mit 94\% Heilung bei vollständiger chirurgischer Exstirpation und 70\% unter alleiniger medikamentöser Therapie (Makrolid-Monotherapie oder Kombinationstherapie mit Makrolid und Rifampicin) [162].

Auch das kosmetische Ergebnis nach einem Jahr wurde bei der Gruppe der chirurgisch therapierten Kinder hinsichtlich Vaskularisation, Hautdicke und Hautoberfläche in der betroffenen Region als besser eingeschätzt [181].

Die makroskopisch betroffenen Lymphknoten und evtl. bestehende Fistelgänge sollten möglichst komplett entfernt und eine Eröffnung von eingeschmolzenen Lymphknoten mit Entleerung von Eiter in die Wunde während der Entfernung vermieden werden [182]. Der Eingriff ist aufgrund der Nähe von wichtigen anatomischen Strukturen technisch anspruchsvoll. Komplikationen, insbesondere eine Kompression oder Schädigung von Ästen des
Nervus facialis sind bei Durchführung durch einen erfahrenen Chirurgen selten [181]. Auch wenn nicht immer alles betroffene Gewebe entfernt werden kann, sind bei diesem Vorgehen Rezidive eher selten. Häufig finden sich in der präoperativen Bildgebung auch auf der Gegenseite zum Hauptbefund vergrößerte und krankheitsverdächtige Lymphknoten. Dennoch kommt es nach einem einseitigen operativen Eingriff in der Regel auf der Gegenseite nicht zur Krankheitsprogression [181]. Postoperativ werden häufig sonografisch oder palpatorisch weitere verdächtige Lymphknoten bemerkt. Erfahrungsgemäß ist in diesen Fällen ein abwartendes Vorgehen mit regelmäßigen sonografischen Verlaufskontrollen ausreichend. Nur bei eindeutigen klinischen und/oder sonografischen Hinweisen auf Einschmelzung, Ausbildung von Fistelgängen etc. ist ein erneutes chirurgisches Vorgehen indiziert. Rezidive treten häufig bereits innerhalb der ersten 3 Monate, aber in Einzelfällen auch Jahre später nach dem Eingriff auf $[178,183]$.

Für ein Rezidiv gelten grundsätzlich die gleichen Therapieempfehlungen wie bei der Ersterkrankung. Bei einem Rezidiv mit Ausbildung einer drainierenden Fistel oder primär operativ schlecht zugänglichem Befund kann aber ein medikamentöses oder kombiniert medikamentös-chirurgisches Vorgehen erwogen werden $[1,170]$.

Die medikamentöse Therapie der Lymphadenitis durch M. aviumKomplex und andere langsam wachsende NTM erfolgt als Kombinationstherapie, da sich eine Monotherapie aufgrund der raschen Resistenzentwicklung verbietet. Aufgrund von Fallserien, empirischen Daten und Laboruntersuchungen wird eine Kombination aus Clarithromycin oder Azithromycin, Ethambutol und einem Rifamycinderivat (i.d. R. Rifampicin) empfohlen ( Tab. 8).

Bei dem Nachweis einer (seltenen) intermediären Makrolid-Resistenz des Erregers in vitro sollte Clarithromycin (oder Azithromycin) Bestandteil der Kombinationstherapie sein und der Therapieverlauf eng überwacht werden. [1]. Eine aufgrund pharmakokinetischer und in vitro gewonnener Daten vermutete Überlegenheit von Rifabutin gegenüber Rifampicin ist durch die klinische Anwendung nicht belegt. Rifabutin ist weiterhin in Deutschland für Kinder nicht zugelassen. Es liegen keine evidenzbasierten Daten zur Dosierung im Kindesalter vor. Daher und aufgrund der engen Toxizitätsgrenzen und häufigeren Komplikationen bei Rifabutingabe sollte in erster Linie Rifampicin in der Kombinationstherapie eingesetzt werden. Eine Ergänzung der Therapie mit Ethambutol ist unter regelmäßiger (vierwöchiger) Prüfung des Farbensehens zur Früherkennung einer Optikusneuritis sinnvoll und soll einer Resistenzentstehung entgegen wirken. $\mathrm{Zu}$ möglichen Nebenwirkungen von RMP und EMB siehe Kapitel 9 (Anhang 2, S. 625) und bei Schaberg et al. [135].

Bei Nachweis von anderen langsam wachsenden NTM (z.B. M. haemophilum, M. kansasii, M. malmoense, M. scrofulaceum) kann der gleiche Therapieansatz verfolgt werden, wobei die Empfindlichkeit in vitro gegenüber den eingesetzten Medikamenten je nach Spezies und Stamm des Erregers sehr variabel sein kann und klinische Daten über die Wirksamkeit und Therapiedauer weitgehend fehlen. Die Dauer der Therapie sollte mindestens 6 Monate betragen, wobei, je nach klinischem Verlauf, eine längere Therapie in einzelnen Fällen erforderlich werden kann [170]. Bei pulmonalen oder generalisierten Erkrankungen erfolgt primär eine medikamentöse Kombinationstherapie. Schnell wachsende Mykobakterien (z.B. M. chelonae, M. abscessus) sollten mit einer Kombinationstherapie entsprechend den Empfehlungen von ATS/IDSA behandelt werden [1] (siehe auch Kapitel 8, Anhang 1, S. 621). 


\section{Anhang 1: Mikrobiologische und therapeutische Besonderheiten bei ausgewählten Mykobakterien- spezies \\ $\nabla$}

Je nach Wachstumsgeschwindigkeit unter Standardkulturbedingungen wird zwischen langsam und schnell wachsenden NTM unterschieden ( $\bullet$ Tab.1). In diesem Anhang werden mikrobiologische und therapeutische Besonderheiten bei ausgewählten, klinisch besonders relevanten Mykobakterienspezies beider Gruppen beschrieben (siehe auch Kapitel 6 „Nichttuberkulöse Mykobakteriosen bei HIV-Infektion“ [S. 616] sowie Kapitel 7 „Diagnostik und Therapie nichttuberkulöser Mykobakteriosen im Kindesalter“ [S. 618]).

\subsection{Langsam wachsende Mykobakterien}

\subsubsection{M. avium-Komplex (MAC)}

Mikrobiologie

M. avium-Komplex umfasst die beiden Arten M. avium und M. intracellulare, die zu den wichtigsten und verbreitetsten pathogenen NTM zählen. Diese Spezies können biochemisch und morphologisch nur mit sehr aufwändigen Methoden voneinander unterschieden werden. Eine medizinische Notwendigkeit, diese Spezies genauer zu unterscheiden, schien lange nicht gegeben, da es für das Management dieser Patienten keinen Unterschied bedeutete. Inzwischen sind jedoch beachtliche genetische Unterschiede zwischen M. avium und M. intracellulare aufgezeigt worden. Welchen Einfluss die beobachteten genetischen Unterschiede auf Infektiosität oder Krankheitsverlauf haben, ist noch weitgehend ungeklärt. Jedoch wurde in einer großen koreanischen Studie festgestellt, dass Patienten mit $M$. intracellulare im Vergleich zu M. avium eine schwerere Erkrankung der Lunge mit einem schlechteren Ansprechen auf die Therapie zeigten [184]. Auch wurden bei $M$. intracellulare inzwischen die genetischen Variabilitäten teilweise bereits als eigene Spezies beschrieben (M. chimaera, M. colombiense, M. arosiense, M. vulneris [185188]. Mögliche Unterschiede in der klinischen Relevanz müssen noch geklärt werden.

Basierend auf physiologischen Merkmalen wurde M. avium bereits 1990 in drei Subspezies (M. avium avium, M. avium paratuberculosis und M. avium silvaticum) unterschieden [189]. Diese Differenzierung wurde durch genetische Analysen bestätigt und darüber hinaus eine neue vierte Subspezies (M. avium hominissuis) vorgeschlagen, die nahezu ausschließlich von Patienten, aber auch von Schweinen isolierte Stämme umfasst [190].

M. avium avium wird typischerweise bei Vögeln nachgewiesen [191], die nahe verwandte Subspezies M. avium silvaticum vorwiegend bei Ringeltauben [189], M. avium paratuberculosis ist das infektiöse Agens der "Johne's Disease“ bei Wiederkäuern [192]. Diese strikt wirtsassoziierte Subspezies kommt normalerweise nicht in der Umwelt vor. Infizierte Kühe können jedoch enorme Mengen an Organismen ausscheiden und so andere Tiere infizieren. Eine ursächliche Beteiligung von M. avium paratuberculosis bei Morbus Crohn beim Menschen wird kontrovers diskutiert und ist bislang noch nicht abschließend geklärt [193]. M. avium hominissuis ist ein Keim, der vor allem beim Menschen, aber auch bei Schweinen und in Umweltproben nachgewiesen wird. Diese Ergebnisse sprechen somit gegen die Hypothese, dass Infektionen mit M. avium beim Menschen nur von Vögeln übertragen werden. M. avium hominissuis ist genetisch hochvariabel. Der Einfluss dieser Variabilität auf Pathogenität oder Virulenz der verschiedenen Stämme ist Gegenstand aktueller Forschungen $[36,111,114,115,194]$.
MAC-Isolate kommen häufig in der Umwelt vor, z. B. in Leitungswasser. Der Nachweis von MAC vor allem aus bronchopulmonalen Proben muss deshalb auf seine klinische Bedeutung sehr kritisch hinterfragt werden [68, 195].

\section{Therapie}

Für klinisch schwere Erkrankungen empfehlen ATS/IDSA [1] die Therapie mit täglicher Gabe mit den folgenden Dosierungen (๑ Tab.9).

\begin{tabular}{l} 
Clarithromycin $1000 \mathrm{mg}$ oder Azithromycin $250 \mathrm{mg}$ \\
plus \\
Rifampicin $600 \mathrm{mg}$ oder Rifabutin $300 \mathrm{mg}$ \\
\hline plus \\
Ethambutol $15 \mathrm{mg} / \mathrm{kg}$ \\
\hline
\end{tabular}

Für klinisch moderat schwere Erkrankungen (noduläre und bronchiektatische radiologische Manifestation) empfehlen ATS/ IDSA [1] hingegen eine intermittierende Therapie an wöchentlich 3 Tagen mit folgenden Dosierungen ( $\bullet$ Tab. 10).

\begin{tabular}{l} 
Clarithromycin $1000 \mathrm{mg}$ oder Azithromycin $500 \mathrm{mg}$ \\
plus \\
Rifampicin $600 \mathrm{mg}$ oder Rifabutin $300 \mathrm{mg}$ \\
\hline plus \\
\hline Ethambutol $25 \mathrm{mg} / \mathrm{kg}$ \\
\hline
\end{tabular}

Die Wirksamkeit einer intermittierenden, dreimal wöchentlichen Therapie, die ATS/IDSA für die nodulär/bronchiekatische Form und für den Fall einer Unverträglichkeit bei täglicher Gabe oder für Patienten mit gering ausgedehnter Erkrankung empfehlen, ist jedoch nicht belegt [196]. Generell wird die intermittierende Therapie bei der Tuberkulose für Deutschland nicht empfohlen [135]. Daher wird auch hier empfohlen, derartige intermittierende Behandlungsvariationen allenfalls nach Auftreten von Nebenwirkungen und unter Berücksichtigung des individuellen Verlaufs unter einer täglichen Dreifachtherapie als Alternative in Betracht zu ziehen. Ebenfalls nicht geprüft ist die ATSEmpfehlung zur Behandlung mit EMB in einer hohen Dosis von $25 \mathrm{mg} / \mathrm{kg}$ Körpergewicht bei intermittierender Therapie, während bei der täglichen Therapie die übliche Dosis von $15 \mathrm{mg} / \mathrm{kg}$ Körpergewicht empfohlen wird. Die in vitro-MHK-Werte von EMB bei M. avium-Stämmen sind sehr variabel und korrelieren nicht mit dem Therapieausgang [197]. Die übliche Tagesdosis von EMB (15 mg/kg Körpergewicht) bei Erwachsenen wird für Deutschland als zuverlässig angesehen.

Die in den 90er Jahren empfohlene Behandlung mit Rifabutin anstelle von RMP konnte letztlich nicht überzeugen, da die Nebenwirkungsrate von Rifabutin in der Kombinationsbehandlung hoch ist (v.a. Uveitis und Leukopenie) und die klinische Überlegenheit trotz höherer Gewebekonzentrationen und zugleich niedriger Hemmkonzentrationen in vitro gegenüber RMP nicht belegt werden konnte [1]. Eine Ausnahme stellt die gleichzeitige antiretrovirale und antimykobakterielle Behandlung AIDS-Kranker dar, für die aufgrund pharmakologischer Interaktionen zwischen Virustatika und Rifamycinen dem Rifabutin der Vorzug zu geben ist [198] (siehe Kapitel 6 „Nichttuberkulöse Mykobakteriosen bei HIV-Infektion“, S. 616).

Die Hinzunahme von SM/Amikacin als viertes Medikament kann bei schweren und ausgedehnten kavernösen $M$. avium-Infektionen zur schnelleren Keimzahlreduktion in Betracht gezogen werden $[1,199]$. Weitere wirksame Substanzen, die bei Unverträg- 
lichkeit anderer Medikamente oder einer Makrolidresistenz in Frage kommen, sind Moxifloxacin, das allerdings im Tierversuch einen gewissen Antagonismus zu Clarithromycin zeigte [200], und Protionamid, zu dem es allerdings nur Erfahrungswerte gibt [40], ähnlich wie bei der eng verwandten Substanz Ethionamid. Auch Clofazimin wird als Alternative angesehen [140].

Die Behandlungsdauer richtet sich - bei gutem klinischen Erfolg u.a. nach den mikrobiologischen Befunden. Angestrebt werden sollte, die Therapie so lange fortzuführen, bis die Sputumkulturen über 12 Monate negativ geblieben sind. Hieraus resultieren in der Regel Therapiezeiten von 18 Monaten [1].

\subsubsection{M. celatum \\ Mikrobiologie}

M. celatum gehört zu den ,neueren' Spezies der NTM [201]. Der Keim wurde anfangs vorwiegend bei HIV-Patienten beschrieben $[202,203]$. Aber auch bei nicht immunsupprimierten Patienten wird der Keim als Erreger von pulmonalen Infektionen beobachtet [204].

Von dieser Spezies wurden drei verschiedene 16S-,,Sequenztypen“ beschrieben, wobei die Sequenzen von Typ 1 und Typ 3 sehr ähnlich sind. Die Sequenz von Typ 2 unterscheidet sich deutlich von den Sequenzen der Typen 1 und 3. M. celatum Typ 1/3 besitzt 2 RNA-Operons, die sich durch eine Baseninsertion unterscheiden, sodass die Sequenzanalyse problematisch auszuwerten ist. Die Stämme wachsen dysgon und farblos ( $\bullet$ Abb.8).

\section{Therapie}

Eine Resistenzprüfung spricht für eine wahrscheinliche Resistenz gegenüber INH und RMP, wohingegen die Empfindlichkeit gegenüber Rifabutin (RBT), EMB, den Aminoglykosiden und PTH stammabhängig variabel sein kann [201]. Chinolone scheinen stets empfindlich zu sein. Eine Resistenzprüfung wird hier empfohlen.

Da der Erreger selten zu pulmonalen Infektionen bei immunkompetenten Patienten führt, gibt es zur Therapie wenig Erfahrung. Beschrieben wird in einer Arbeit aus Korea, dass die Kombination von Clarithromycin, EMB und Ciprofloxacin gut wirksam war, allerdings gefolgt von einer Resektion einer persistierenden Kaverne [205].

\subsubsection{M. genavense}

Mikrobiologie

M. genavense ist durch extrem spärliches Wachstum charakterisiert, das in Flüssigkulturen z.T. so gering sein kann, dass es durch die Indikatorsysteme nicht angezeigt wird. Auch auf Agarnährböden ist nur minimales und auf Eiernährböden kein Wachstum zu erzielen. Bei Verdacht sollte auch ohne Anzeichen von Wachstum ein mikroskopisches Präparat aus der Flüssigkultur angefertigt werden, das bei M. genavense ein typisches Bild mit säurefesten, sehr kurzen Mykobakterien zeigt. Ebenso können molekularbiologische Nachweisverfahren bei Verdacht auf eine Erkrankung primär indiziert sein. $M$. genavense wird überwiegend bei HIV-Patienten nachgewiesen [206], es sind aber auch Einzelfälle bei Nicht-HIV-Patienten bekannt [207].

\section{Therapie}

Die optimale Therapie ist nicht bekannt, jedoch werden Clarithromycin mit RMP, einem FQ EMB und/oder SM/Amikacin kombiniert empfohlen $[1,208,209]$.

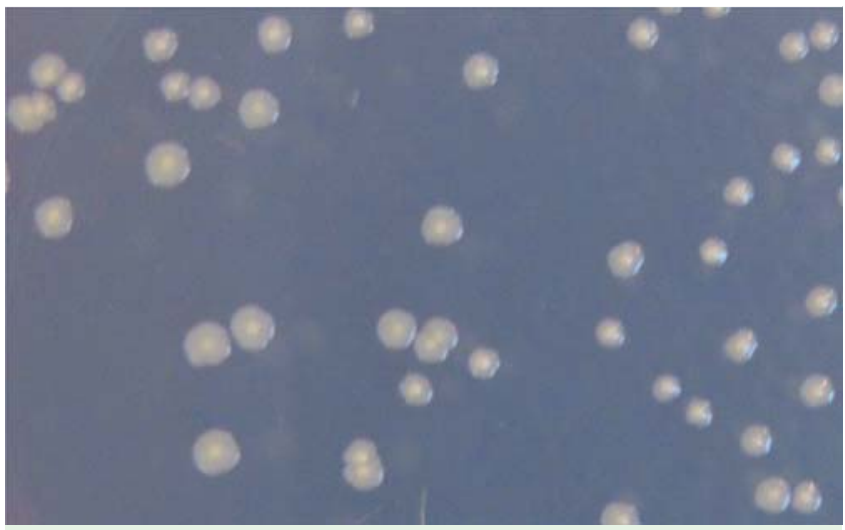

Abb.8 M. celatum auf 7H10 Middlebrook-Agar. (Mit freundlicher Genehmigung von PD Dr. Elvira Richter, Forschungszentrum Borstel, Nationales Referenzzentrum für Mykobakterien.)

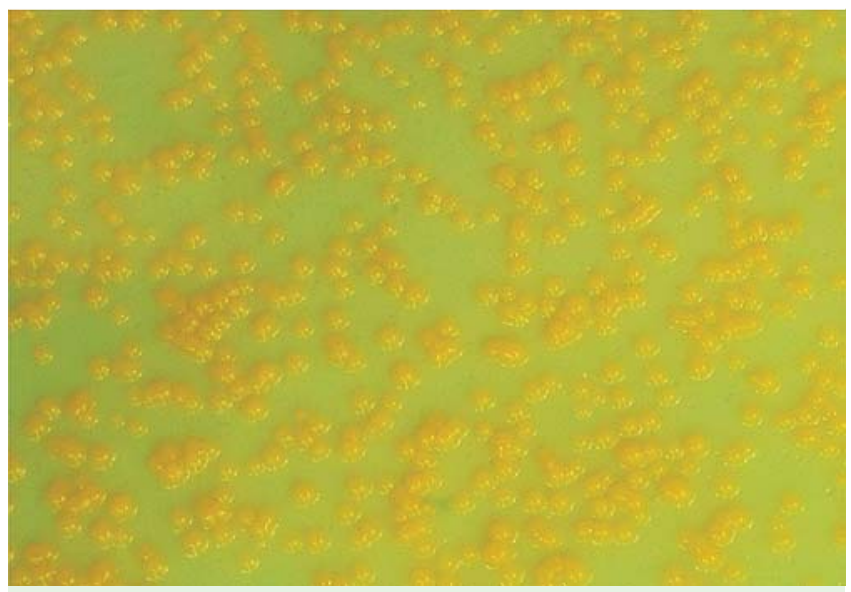

Abb.9 M. gordonae auf Löwenstein-Jensen-Medium. (Mit freundlicher Genehmigung von PD Dr. Elvira Richter, Forschungszentrum Borstel, Nationales Referenzzentrum für Mykobakterien.)

\subsubsection{M. gordonae}

Mikrobiologie

M. gordonae wird typischerweise im Leitungswasser nachgewiesen [8]. Deshalb ist der Nachweis von M. gordonae aus Sputum oder Magensaft oder bei Bronchoskopie [104] in der Regel ohne klinische Signifikanz, da eine Kontamination aus dem Leitungswasser mit hoher Wahrscheinlichkeit die Quelle für den Keim ist. M. gordonae wächst bevorzugt bei $31^{\circ} \mathrm{C}$ und auf Agarnährböden in feucht glänzenden gelb-orangefarbenen Kolonien (๑ Abb.9).

Therapie

Für M. gordonae existieren keine verbindlichen Empfehlungen zur Therapie, da der Keim fast immer als apathogen anzusehen ist. Nach ATS/IDSA besteht in vitro Empfindlichkeit gegen EMB, RBT, Clarithromycin, FQ und Linezolid [1].

\subsubsection{M. haemophilum}

Mikrobiologie

M. haemophilum kann aus oberflächlichen Hautläsionen, bronchopulmonalen Proben oder auch aus Blut bei immunsupprimierten Patienten isoliert werden [91]. Der Nachweis ist schwierig, da der Keim nur bei $31{ }^{\circ} \mathrm{C}$ und sehr langsam wächst und darüber hinaus einen Eisenzusatz im Medium benötigt. 


\section{Therapie}

Eine verlässliche Resistenzbestimmung ist aufgrund des limitierten Wachstums nicht möglich. Nach ATS/IDSA besteht in vitro Empfindlichkeit gegen RMP, Rifabutin, Clarithromycin, FQ und Amikacin [1]. Lindeboom et al. empfehlen eine Kombination von Clarithromycin, Ciprofloxacin und einem Antibiotikum aus der Gruppe der Rifamycine [91].

\subsubsection{M. kansasii}

Mikrobiologie

Pulmonale Infektionen mit M. kansasii ähneln in ihrer klinischen Präsentation Infektionen mit $M$. tuberculosis. In seltenen Fällen ist M. kansasii auch ätiologisches Agens der kindlichen Lymphadenitis.

Bei $M$. kansasii-Stämmen ist eine genetische Variabilität beschrieben. Es werden sechs Subspezies unterschieden, wobei die humanpathogenen Stämme vorwiegend zur Subspezies I gehören. M. kansasii gehört zu den photochromogenen Spezies. Der Keim wächst bei 31 und $37^{\circ} \mathrm{C}$ in trockenen, großen Kolonien und bildet erst unter Lichtexposition ein typisches gelbes Pigment.

$\mathrm{Zu}$ beachten ist, dass die IGRA-Teste hier wie bei $M$. marinum, M. flavescens und M. szulgai positiv ausfallen können, sich also nicht zum Ausschluss einer Tuberkulose eignen [93,94].

\section{Therapie}

Erkrankungen durch M. kansasii sind in der Regel mit einer Dreifachkombination aus INH, RMP und EMB gut behandelbar. Die MHK-Werte von Isoniazid in vitro liegen bei den meisten Stämmen bei $1,0 \mu \mathrm{g} / \mathrm{ml}$ und damit im Bereich gut erreichbarer Serumund Gewebespiegel bei normaler Dosierung (3 -5 mg/kg Körpergewicht) [210]. Alternativ kann eine Therapie mit Clarithromycin, EMB und RMP empfohlen werden, da hier alle Antibiotika niedrige MHK-Werte aufweisen. Ein Regime mit dieser Dreifachtherapie, obwohl intermittierend eingesetzt, war effizient [211]. Die Therapiedauer sollte ausreichend lang sein, d.h. bis zum Ablauf von 12 Monaten nach Sputumkonversion [1]. Für gegen RMP resistente Erreger kommen je nach Ergebnis der Empfindlichkeitsprüfung Clarithromycin/Azithromycin, Moxifloxacin, EMB, Trimethoprim/Sulfamethoxazol oder SM in Frage [1].

\subsubsection{M. malmoense}

Mikrobiologie

Dieser Keim wächst bevorzugt bei niedrigeren Temperaturen $\left(31^{\circ} \mathrm{C}\right)$, v.a. auf den Festmedien. Da M. malmoense auch pulmonale Infektionen verursachen kann, aber dieses Untersuchungsgut routinemäßig nicht auch bei $31^{\circ} \mathrm{C}$ bebrütet wird, kann der Nachweis einer pulmonalen M. malmoense-Infektion schwierig oder verzögert sein [212].

\section{Therapie}

In der Resistenzbestimmung ist $M$. malmoense resistent gegen INH und RMP, dagegen empfindlich gegen EMB, Rifabutin, Clarithromycin und Moxifloxacin [1] (und eigene Ergebnisse [ER]). Die optimale Therapie ist nicht bekannt. Als wirksam wird die Kombination von INH, RMP und EMB mit oder ohne Clarithromycin/Azithromycin und FQ berichtet [1]. Angepasst an die Ergebnisse der Empfindlichkeitsprüfung wird alternativ eine Therapie mit Clarithromycin, EMB und RMP/RBT empfohlen [16, $212-214]$.

\subsubsection{M. marinum}

Mikrobiologie

M. marinum ist das ätiologische Agens beim Schwimmbadgranulom und wird ausschließlich aus oberflächlichen Läsionen bzw. betroffenen Lymphknoten isoliert [215]. Typischerweise haben die Patienten Kontakt mit Aquarien. Infektionen mit diesem Keim werden auch als Folge von Therapien mit Biologika beschrieben $[80,81]$.

Auch $M$. marinum wächst bevorzugt bei $31^{\circ} \mathrm{C}$. Die Photochromogenität ist ein charakteristisches Merkmal. $\mathrm{Zu}$ beachten ist, dass die IGRA-Teste hier wie bei M. kansasii, M. flavescens und M. szulgai positiv ausfallen können, sich also nicht zum Ausschluss einer Tuberkulose eignen $[93,94]$.

Therapie

Die Resistenzprüfung zeigt für M. marinum Resistenz gegenüber INH und Empfindlichkeit gegenüber EMB, RMP und Clarithromycin. Für Infektionen mit $M$. marinum ist eine mehrmonatige Zweifachkombination mit Clarithromycin und RMP zu empfehlen, je nach Wundtiefe und Heilungsverlauf (vier Monate oder mehr) [216]. Die Therapie kann vermutlich durch die Addition von EMB durch den synergistischen Effekt mit RMP optimiert werden [128,217]. Auch die Kombinationen von Clarithromycin und EMB sowie von RMP und EMB sind als gut wirksam beschrieben [1]. Weiterhin können auch Minocyclin, Doxycyclin und Trimethoprim/Sulfmethoxazol eingesetzt werden [1]. Bei tiefergehenden Haut- und Weichteilinfektionen durch M. marinum kann ein chirurgisches Vorgehen (Debridement) indiziert sein, allerdings nur in Kombination mit einer medikamentösen Behandlung.

\subsubsection{M. simiae}

Mikrobiologie

M. simiae ist eine selten isolierte Mykobakterienspezies, die auch in der Umwelt vorkommen soll [1]. In seltenen Fällen ist M. simiae für pulmonale Infektionen verantwortlich, extra-pulmonale Lokalisationen sind sehr selten und vorwiegend bei immunsupprimierten Patienten beschrieben [218].

\section{Therapie}

M. simiae ist in der Resistenzbestimmung gegen nahezu alle Antibiotika resistent [210]. Empfindlich können Clarithromycin, Moxifloxacin und Protionamid (PTH) sein. Eine optimale Kombination und Dauer einer Therapie ist nicht etabliert. Eine Behandlung, die Clarithromycin, Moxifloxacin und Trimethoprim/Sulfamethoxazol enthält, wird empfohlen [1].

\subsubsection{M. szulgai}

Mikrobiologie

M. szulgai gehört zu den skotochromogenen Mykobakterien mit einer gelb-orangen Pigmentierung. M. szulgai kann bei Patienten mit entsprechenden Lungengrundkrankheiten tuberkuloseähnliche Krankheitsbilder verursachen, sowohl was den Lokalbefund als auch die Allgemeinsymptomatik angeht [219]. Zu beachten ist, dass die IGRA-Teste hier wie bei M. kansasii, M. flavescens und M. marinum positiv ausfallen können, sich also nicht zum Ausschluss einer Tuberkulose eignen [93, 94].

Therapie

In der Empfindlichkeitsprüfung ist M. szulgai generell resistent gegen INH und empfindlich gegen EMB, RMP, Clarithromycin. M. szulgai ist mit den meisten antimykobakteriell wirksamen 
Medikamenten therapierbar. Die optimale Zusammensetzung und Dauer der Therapie ist nicht etabliert. Neben einer Dreifachtherapie, die sich an Infektionen durch $M$. kansasii orientiert (12 Monate INH, RMP und EMB), erscheint auch die Kombination von RMP, EMB und Clarithromycin entsprechend der Empfindlichkeitstestung als ein gangbares Konzept, muss aber stets klinisch überprüft werden [1].

\subsubsection{M. ulcerans}

Mikrobiologie

M. ulcerans ist genetisch sehr nahe mit M. marinum verwandt und kann nur durch spezifische genetische Analysen unterschieden werden. Im Gegensatz zu M. marinum wächst der Keim jedoch auf den üblichen Medien nicht oder nur sehr spärlich. Isoliert wird M. ulcerans aus den Hautläsionen von Patienten mit Buruli-Ulkus [74].

\section{Therapie}

Die medikamentöse Therapie großer Ulzera ist unbefriedigend. Eine Resistenzbestimmung ist aufgrund des eingeschränkten Wachstums nicht möglich. Bei tiefergehenden Haut- und Weichteilinfektionen kann ein chirurgisches Vorgehen (Debridement) indiziert sein, allerdings nur in Kombination mit einer medikamentösen Behandlung (Clarithromycin und RMP oder RMP und Streptomycin jeweils über 8 Wochen werden empfohlen) [1]. Außerdem wird die Thermotherapie zur Lokalbehandlung als weiterer neuer Therapieansatz beschrieben [139].

\subsubsection{M. xenopi}

Mikrobiologie

M. xenopi wird im Leitungswasser nachgewiesen und ist deshalb in den meisten Fällen ohne klinische Relevanz, kann aber bei anderen Grunderkrankungen pulmonale Infektionen verursachen [220].

Therapie

Obwohl in der Resistenzbestimmung von M. xenopi eine Vielzahl von Medikamenten empfindlich getestet wird (RMP, Clarithromycin, Fluorchinolone, PTH; variabel bei INH und EMB) gibt es keine gesicherte wirksame Therapie [220]. Für Erkrankungen durch M. xenopi empfehlen ATS/IDSA dieselbe Dreifachkombination wie für M. avium [1], jedoch ist Isoniazid in vivo als durchaus wirksam zu betrachten, ähnlich den Verhältnissen bei M. kansasii [210].

\subsection{Schnell wachsende Mykobakterien}

Schnell wachsende Mykobakterien sind sehr widerstandsfähig gegenüber verschiedensten Umweltbedingungen und deshalb weit verbreitet anzutreffen [8,103]. Der Nachweis von schnell wachsenden Mykobakterien aus nicht-sterilen klinischen Proben kann häufig durch eine Kontamination verursacht sein. Die namensgebende Eigenschaft von schnell wachsenden Mykobakterien, dass sie in weniger als 7 Tagen bei ihrer optimalen Wachstumstemperatur ein deutliches Wachstum zeigen, bezieht sich nur auf Standardkulturbedingungen. Kulturelles Wachstum von schnell wachsenden Mykobakterien im Untersuchungsgut kann deshalb auch längere Zeit beanspruchen. Sind in der allgemeinen Bakteriologie kleine grampositve Bakterien verschiedener Morphologie erkennbar, sollte man stets auch an schnell wachsende Mykobakterien denken und eine säurefeste Färbung veranlassen. Schnell wachsende Mykobakterien wachsen in der Regel besser bei niedrigeren Temperaturen (z. B. $31^{\circ} \mathrm{C}$ ) als bei der in der Tuber- kulosediagnostik üblichen Temperatur $\left(37^{\circ} \mathrm{C}\right)$. Deshalb sollten Proben mit Verdacht auf schnell wachsende Mykobakterien parallel auch bei einer niedrigeren Temperatur inkubiert werden. Aufgrund ihrer enormen genetischen Variabilität wurden in den letzten Jahren immer mehr neue Spezies innerhalb der schnell wachsenden Mykobakterien als neue, eigenständige Arten beschrieben. Klinische Bedeutung haben in der Regel nur sehr wenige Spezies, in der Mehrzahl sind es M. abscessus und M. chelonae.

\subsubsection{M. abscessus}

Mikrobiologie

Die systematische Zuordnung von M. abscessus wurde in den letzten Jahren, basierend auf genetischen Daten, mehrfach geändert. Die Ausgliederung von M. massiliense und M. bolletii [221, 222] aus M. abscessus wurde inzwischen wieder rückgängig gemacht und zu M. abscessus mit den beiden Subspezies M. $a b$ scessus ssp. abscessus und M. abscessus ssp. bolletii zusammengeführt [223]. Die zweite Subspezies enthält die Stämme, die als M. massiliense und M. bolletii beschrieben wurden.

M. abscessus ist bei Patienten mit zystischer Fibrose (Mukoviszidose) eine der am häufigsten isolierten Mykobakterienspezies [224]. Nach Lungentransplantationen besteht daher ein erhöhtes Risiko einer Infektion mit M. abscessus [225]. M. abscessus kann auch bei Patienten ohne zystische Fibrose pulmonale Infektionen, aber auch Hautläsionen verursachen [1].

Therapie

Die Therapie der Erkrankungen durch M. abscessus ist schwierig. Eine Kombinationstherapie aus oralem Clarithromycin und der parenteralen Gabe von Amikacin plus Cefoxitin oder Imipenem über 2-4 Monate gefolgt von einer 6-12 monatigen oralen Therapie mit als empfindlich getesteten Medikamenten verspricht Besserung, aber oft keine endgültige Heilung [1]. Unter den Makroliden hat womöglich Azithromycin eine bessere Wirksamkeit als Clarithromycin [226]. Moxifloxacin ist ebenfalls wirksam, jedoch in Kombination mit Makroliden wurde eine antagonistische Wirkung beobachtet [227]. In einer Studie in Taiwan fanden sich folgende Empfindlichkeiten in vitro unter 40 Isolaten für: Amikacin (95,0\%), Cefoxitin (32,5\%), Ciprofloxacin (10,0\%), Clarithromycin (92,5\%), Doxycyclin (7,5\%), Imipenem (12,5\%), Moxifloxacin (22,5\%), Sulfamethoxazol (7,5\%) und Tigecyclin (100\%) [228]. Die Autoren sahen unter einer Kombinationstherapie mit Clarithromycin, Amikacin und einem weiteren Antibiotikum immer noch in 27,3\% ein Versagen 12 Monate nach Beginn der Therapie. Weil die medikamentöse Therapie oft allein nicht ausreicht, kann ein zusätzliches chirurgisches Vorgehen sinnvoll sein [229]. Bei pulmonalen Infektionen beträgt die Therapiedauer nach der ersten negativen Kultur weitere 12 Monate [230].

Bei Erkrankungen durch bestimmte Stämme der Subspezies M. abscessus ssp. bolletii (kurzzeitig als M. massiliense bezeichnet) ist das Ansprechen auf die Therapie mit Makroliden besser, da sich seltener Resistenzen entwickeln [226].

\subsubsection{M. chelonae}

M. chelonae kann ebenfalls pulmonale Infektionen und Hautläsionen verursachen [1].

Therapie

Für Erkrankungen durch $M$. chelonae wird eine Therapie über 12 Monate nach kultureller Sputumkonversion mit Clarithromycin in Kombination mit einem Antibiotikum empfohlen, das in 
vitro wirksam ist. In der Regel ist der Erreger sensibel gegenüber Tobramycin, Linezolid und Clarithromycin, in der Mehrzahl (75\%) auch gegenüber Amikacin und Moxifloxacin [1]. Bei pulmonalen Infektionen beträgt die Therapiedauer nach der ersten negativen Kultur weitere 12 Monate [230].

\subsubsection{M. fortuitum}

Mikrobiologie

Die Spezies der M. fortuitum-Gruppe (M. fortuitum, M. peregrinum, M. mucogenicum, M. senegalense, $M$. septicum und eine unbenannte Gruppe [Biovariante 3]) sind weitgehend ohne klinische Bedeutung und treten nur in Einzelfällen bei von außen eingebrachten Infektionen auf.

\section{Medikamentöse Therapie}

M. fortuitum ist in vitro fast immer gegen Amikacin, Ciprofloxacin, Levofloxacin, Moxifloxacin, Sulfonamide und Imipenem empfindlich [1]. Zirka $80 \%$ der Erreger weisen darüber hinaus eine Empfindlichkeit gegenüber Cefoxitin, Clarithromycin und Linezolid auf. Empfohlen wird beispielsweise die parenterale Gabe von Amikacin und Cefoxitin über 2-6 Wochen, gefolgt von der oralen Gabe von TMP/SMX und einem Fluorchinolon über 2-6 Monate. Bei pulmonalen Infektionen beträgt die Therapiedauer nach der ersten negativen Kultur weitere 12 Monate [230].

\section{Anhang 2: Eigenschaften der in der Therapie von NTM-Erkrankungen eingesetzten Medikamente (in alphabetischer Reihenfolge)}

Die folgende Übersicht zitiert im Wesentlichen die Angaben zu den antituberkulösen Medikamenten aus den Therapieempfehlungen zur Tuberkulose des DZK und der DGP (dort weitere Einzelheiten [135]), ergänzt um einige Medikamente, die speziell in der Therapie der nichttuberkulösen Mykobakteriosen eingesetzt werden.

\section{Amikacin (AK)}

Amikacin ist ein synthetisches Derivat von Kanamycin. Der Wirkmechanismus, die Pharmakokinetik und die bakterizide Wirkstärke sind ähnlich wie die des Streptomycin. Die Dosierung beträgt $15 \mathrm{mg} / \mathrm{kg}$ Körpergewicht (Höchstdosis $1000 \mathrm{mg}$ ).

Unerwünschte Arzneimittelwirkungen (UAW) treten wie bei Streptomycin auf, allerdings ist die Nierentoxizität etwas ausgeprägter.

\section{Azithromycin}

Die orale Dosis beträgt 250 - 500 mg. Die Resorption beträgt zirka $40 \%$ nach der oralen Gabe von 500 mg. Azithromycin wird überwiegend hepatisch eliminiert.

Häufige Nebenwirkungen sind Diarrhoen und Übelkeit. Bei der langfristigen Anwendung besteht offenbar auch ein deutlich erhöhtes Risiko für schwerwiegende und z.T. tödliche Herzrhythmusstörungen.

Kontraindikationen sind neben einer Allergie vor allem die gleichzeitige Gabe von Statinen und relevante Herzrhythmusstörungen.

Makrolide sind potente Induktoren von Cytochrom-P-Enzymen und führen daher zu einer Vielzahl von Arzneimittelinteraktionen (siehe Gebrauchsinformation).

\section{Clarithromycin}

Die orale Dosierung beträgt $2 \times 500 \mathrm{mg}$. Die Resorption beträgt nach oraler Gabe zirka $50 \%$. Die maximale Serumkonzentration liegt nach $500 \mathrm{mg}$ oral bei $3-4 \mu \mathrm{g} / \mathrm{ml}$. Nach hepatischer Metabolisierung erfolgt die Ausscheidung renal.

Häufige Nebenwirkungen sind Übelkeit, Geschmacksstörungen und Durchfälle. Seltene, aber gefährliche UAW sind Hörminderungen (Audiogrammkontrollen sind notwendig) und die Induktion von Herzrhythmusstörungen (QT-Zeitverlängerung, torsade de pointes).

Kontraindikationen sind neben einer Allergie vor allem die gleichzeitige Gabe von Statinen und relevante Herzrhythmusstörungen.

Makrolide sind potente Induktoren von Cytochrom-P-Enzymen und führen daher zu einer Vielzahl von Arzneimittelinteraktionen (siehe Gebrauchsinformation).

\section{Ciprofloxacin}

Da nach der Empfehlung der WHO Ciprofloxacin in der Therapie der Tuberkulose nicht mehr eingesetzt werden sollte, empfehlen wir auch bei NTM in der Regel die Anwendung von Levofloxacin oder Moxifloxacin.

\section{Ethambutol (EMB)}

Die orale Dosierung beträgt $15 \mathrm{mg} / \mathrm{kg}$ Körpergewicht (Höchstdosis $2000 \mathrm{mg}$ ). Der maximale Serumspiegel nach $25 \mathrm{mg} / \mathrm{kg}$ liegt bei $5 \mathrm{mg} / \mathrm{l}$. EMB wird gut (zu ca. 80 - 85\%) aus dem Gastrointestinaltrakt resorbiert, es findet eine verhältnismäßig gute Diffusion in Gewebe und Körperflüssigkeiten statt. Eine Penetration der Blut-Hirn-Schranke ist nur bei entzündeten Meningen gegeben. EMB tritt in den fetalen Kreislauf über, das Ausmaß des Übertritts in die Muttermilch ist nicht bekannt.

Geringe hepatische Metabolisierung und überwiegend renale Elimination, was eine Dosisanpassung bei Niereninsuffizienz notwendig macht.

Die Verträglichkeit ist gut.

Die wichtigste Wechselwirkung ist eine verminderte Resorption mit Senkung des Blutspiegels durch Antazida.

Unerwünschte Arzneimittelwirkungen:

Die wichtigste unerwünschte Arzneimittelwirkung ist die retrobulbäre Opticus-Neuropathie zunächst mit Verlust der RotGrün-Diskrimination und nachfolgend irreversiblen Sehschäden (Visusverschlechterung, Zentralskotom, Lichtempfindlichkeit). Daher ist EMB kontraindiziert bei Patienten, die Sehstörungen nicht wahrnehmen können (z.B. sehr junge oder komatöse Patienten), und bei Patienten mit schwerwiegenden Augenkrankheiten, die das Sehvermögen bedrohen.

Okuläre UAW kommen bei ca. 2,6\% der Patienten unter einer Dosis von $25 \mathrm{mg} / \mathrm{kg} / \mathrm{KG}$ und $<1 \%$ der Patienten unter einer Dosis von $15 \mathrm{mg} / \mathrm{kg} / \mathrm{KG}$ vor. Vorherige und wiederholte augenärztliche Untersuchungen (z.B. einmal monatlich) sind daher zwingend erforderlich. Vor jeder Therapieeinleitung muss zumindest das Farbsehvermögen (z.B. Ishihara-Tafel) geprüft werden, wenn eine augenärztliche Untersuchung erst nach Therapiebeginn möglich ist.

EMB-assoziierte Retrobulbär-Neuropathien können über Monate persistieren, sind jedoch in der Regel reversibel.

Selten: Arthralgien.

Sehr selten: Kutane UAW, Polyneuropathien.

Als Kontraindikationen gelten: EMB-Allergie, vorbestehende schwerwiegende Augenerkrankungen (z.B. Vorschädigung des Nervus opticus, ausgeprägte diabetische Retinopathie, u.a.), 
Unvermögen, über Sehstörungen zu berichten (z. B. hohes Alter, Kleinkinder), schwere Nierenfunktionsstörungen.

\section{Isoniazid (INH)}

Die Dosierung beträgt $5 \mathrm{mg} / \mathrm{kg}$ Körpergewicht (Höchstdosis 300 $\mathrm{mg}$ ). Das Medikament wird fast vollständig aus dem Gastrointestinaltrakt resorbiert, diffundiert schnell in Gewebe und Körperflüssigkeiten und passiert die Blut-Hirn-Schranke. Es tritt in den fetalen Kreislauf und in die Muttermilch über (s. Schwangerschaft und Stillzeit). Eine parenterale (i.v. und i.m.) Gabe ist möglich. Die hepatische Metabolisierung (80\%) erfolgt mittels des Enzyms Acetyltransferase. Es wird in genetisch determinierte „Langsam“- und „Schnellacetylierer“ unterschieden, dies ist aber in der Praxis ohne klinische Bedeutung; der maximale Serumspiegel nach $300 \mathrm{mg}$ liegt bei $6,5 \mathrm{mg} / \mathrm{l}$ für Schnellacetylierer und $10 \mathrm{mg} / \mathrm{l}$ für Langsamacetylierer. Nach Hydrolysierung und Konjunktion werden die Metaboliten überwiegend renal eliminiert. Die Verträglichkeit ist gut.

Wichtige Wechselwirkungen sind: Serumspiegel erhöht durch Prednisolon, PAS, Protionamid. Erhöht den Serumspiegel von Cumarinen, Phenytoin, Valproat, Theophyllin, Carbamazepin und Diazepam. Senkt den Serumspiegel von Azolen.

Isoniazid interagiert mit Pyridoxin (Vitamin B6) und kann somit einen entsprechenden Mangel mit der Folge einer Neuropathie induzieren. Bei Patienten mit erhöhtem Risiko für eine periphere Neuropathie und in der Gravidität wird die zusätzliche Gabe von Pyridoxin $(50 \mathrm{mg} / \mathrm{d})$ empfohlen. Auch bei perniziöser Anämie und vorhandenen Polyneuropathien werden $50 \mathrm{mg} / \mathrm{d}$ Pyridoxin gegeben.

Wichtige unerwünschte Arzneimittelwirkungen:

Häufig: Hepatotoxizität, kutane UAW (Akne), Konzentrationsstörungen

Selten: Hepatitis, Polyneuropathie, Senkung der Krampfschwelle, Exantheme

Sehr selten: Blutbildveränderungen (aplastische und hämolytische Anämie, Agranulozytose), medikamentös induzierter Lupus erythematodes, Krampfanfälle, Vertigo, Bewusstseinsstörungen, Opticus-Neuritis, Arthralgien, Gynäkomastie, Alkoholunverträglichkeit (pathologischer Rausch).

Als absolute Kontraindikationen gelten: Isoniazid-Allergie, akute Hepatitis, schwerwiegende Störungen der Hämostase und Hämatopoese. Relative Kontraindikationen sind: Zerebrale Anfallsleiden, Psychosen, klinisch relevante periphere Neuropathien.

\section{Levofloxacin}

Die Dosierung beträgt oral $15 \mathrm{mg} / \mathrm{kg}$ Körpergewicht (Standarddosis: $500 \mathrm{mg} / \mathrm{Tag}$ Höchstdosis $1000 \mathrm{mg} / \mathrm{Tag}$ ).

Es liegt eine sehr gute orale Resorption vor, die zu hohen Gewebskonzentrationen führt. Die hepatische Metabolisierung ist minimal, da zirka 90\% der unveränderten Substanz renal ausgeschieden werden.

Wichtige Wechselwirkungen sind eine enterale Komplexbindung mit Eisen, Magnesium, Zink, Vitaminen und Sucralfat, die die Resorption stark vermindern. Die gleichzeitige Gabe der genannten Medikamente muss daher unterbleiben. Streng ist auch auf die Interaktion mit Didanosin zu achten.

Unerwünschte Wirkungen umfassen ZNS-UAW (Kopfschmerzen, Schlaflosigkeit, schlechte Träume), gastrointestinale UAW (Übelkeit, Erbrechen), Sehnenrupturen (cave gleichzeitige Gabe von Steroiden), Lebertoxizität, Herzrhythmusstörungen und eine Photosensibilisierung.
Als Kontraindikationen gelten Schwangerschaft, Allergie und eine QT-Zeit-Verlängerung. Bei der Therapie von Patienten $<18$ Jahre muss über das Risiko einer Knorpelschädigung aufgeklärt werden.

\section{Linezolid}

Linezolid kann bei komplex resistenten NTM-Stämmen im Rahmen eines Heilversuchs eingesetzt werden. Die Dosierung beträgt $1 \times 600 \mathrm{mg}$. Bei einer höheren Dosierung $(2 \times 600 \mathrm{mg})$ ist mit bedeutend mehr UAW zu rechnen. Die Resorption ist sehr gut. Nach hepatischer Metabolisierung erfolgt die Elimination renal. Die Substanz ist jedoch bei einer Therapiedauer von mehr als 4 Wochen reich an unerwünschten Wirkungen (u. a. Leberfunktionsstörungen, langanhaltende Thrombozytopenie, Optikusneuropathie mit Erblindungen) und extrem teuer. Linezolid sollte daher nicht länger als 4 Wochen eingenommen werden, es sei denn es fehlen Alternativen. In einem solchen Fall ist die Aufklärung des Patienten über die bestehenden Risiken umfänglich zu dokumentiert.

Da Linezolid Monoamin-Oxidasen inhibiert, besteht ein erhebliches Interaktionspotenzial (siehe Gebrauchsinformation).

\section{Moxifloxacin}

Die orale Dosierung beträgt $400 \mathrm{mg}$. Moxifloxacin wirkt schnell bakterizid auf intra- und extrazelluär proliferierende Erreger. Die Substanz wird gleichermaßen hepatisch und renal unverändert eliminiert. Wichtige Wechselwirkungen sind eine enterale Komplexbindung mit Eisen, Calcium, Magnesium, Zink, Vitaminen und Sucralfat, die die Resorption stark vermindern. Die gleichzeitige Gabe der genannten Medikamente muss daher unterbleiben.

Unerwünschte Wirkungen umfassen ZNS-UAW (Kopfschmerzen, Schlaflosigkeit, schlechte Träume), gastrointestinale UAW (Übelkeit, Erbrechen), Sehnenrupturen (cave Komedikation mit Steroiden), Herzrhythmusstörungen, Lebertoxizität und Photosensibilisierung.

Als Kontraindikationen gelten Schwangerschaft, FQ-Allergie und QT-Zeit-Verlängerung. Bei der Therapie von Patienten<18 Jahre muss über das Risiko einer Knorpelschädigung aufgeklärt werden.

\section{Protionamid (PTH)}

Die Dosierung beträgt $15 \mathrm{mg} / \mathrm{kg}$ Körpergewicht (Höchstdosis $1000 \mathrm{mg}$ ), wenn kein INH gegeben wird. Bei gleichzeitiger INH Gabe wird die Dosis auf 7,5 mg/kg Körpergewicht (Höchstdosis $500 \mathrm{mg}$ ) reduziert. Nach oraler Gabe beträgt die Resorption zirka $70 \%$. Es besteht eine gute Gewebe- und Liquorgängigkeit. Der Metabolismus ist ausschließlich hepatisch (95\%), die Metaboliten werden renal eliminiert.

Die wichtigste unerwünschte Wirkung ist eine ausgeprägte gastrointestinale Unverträglichkeit, die in Einzelfällen durch eine zweimal tägliche Gabe $(2 \times 500 \mathrm{mg})$ vermindert werden kann. Weitere UAW umfassen Lebertoxizität, Funktionsstörungen des ZNS (Nervensystem und Psyche - bis zur Suizidalität), Schilddrüsenfunktionsstörungen und Allergien.

Da Protionamid zur Blutzuckersenkung führen kann, muss bei der Behandlung des Diabetes mellitus eine entsprechende Überprüfung der Medikation erfolgen, um Hypoglykämien zu vermeiden. 


\section{Rifampicin (RMP)}

Die Dosierung beträgt $10 \mathrm{mg} / \mathrm{kg}$ Körpergewicht (Höchstdosis $600 \mathrm{mg}$ ). Die maximale Serumkonzentration nach $600 \mathrm{mg}$ liegt bei $7-8 \mathrm{mg} / \mathrm{l}$.

RMP wird fast vollständig aus dem Gastrointestinaltrakt resorbiert und diffundiert schnell in Gewebe und Körperflüssigkeiten (mit mäßiger Penetration der Blut-Hirn-Schranke) und tritt in den fetalen Kreislauf und in die Muttermilch über. Eine parenterale Gabe ist möglich. RMP bewirkt initial rasch eine Autoinduktion abbauender Enzyme. RMP wird hepatisch metabolisiert und bis zu $95 \%$ biliär eliminiert.

Die Verträglichkeit ist gut.

Es sind vielfältige Wechselwirkungen durch Induktion mikrosomaler Enzyme der Leber, insbesondere des Zytochrom-P-450Komplexes, zu beachten. Die wichtigste Interaktion besteht mit systemisch wirkenden hormonellen Kontrazeptiva, die unter RMP Gabe als nicht ausreichend wirksam angesehen werden müssen. Desweiteren senkt RMP u.a. den Serumspiegel von Cumarinen, Glukokortikoiden, Tamoxifen, L-Thyroxin, Sulfonylharnstoffen, Diazepam, Zolpidem, Methadon, Digoxin, Digitoxin, Verapamil, Nifedipin, Betablockern, ACE-Inhibitoren, Sartanen, Statinen, Theophyllin, Ciclosporin, Azolen, Clarithromycin, Doxycyclin, Atovaquon und Chloramphenicol. Intensive Interaktionen bestehen mit Proteaseinhibitoren und Nicht-NukleosidischenReversen-Transskriptase-Inhibitoren (siehe Kapitel 6 „Nichttuberkulöse Mykobakteriosen bei HIV-Infektion“, S. 616). Wichtige unerwünschte Arzneimittelwirkungen:

Immer: Rotfärbung von Körpersekreten (Urin, Tränen [cave: Weiche Kontaktlinsen verfärben sich], Stuhl)

Häufig: Milde Lebertoxizität (Transaminasenerhöhung $<3 \times$ oberer Normwert), Cholestase

Selten: Hepatitis, kutane unerwünschte Reaktionen, gastrointestinale Unverträglichkeit und milde Blutzellschädigungen (Thrombozytopenie), Flu-like-Syndrom (bei intermittierender Gabe immunologische Aktivierung mit Antikörperbildung; die Symptomatik reicht von Grippesymptomen bis zu schweren immunologischen Erkrankungen).

Sehr selten: Akutes Nierenversagen und hämolytische Anämie (RMP rasch absetzten und nicht wieder in die Therapie einführen!), Anaphylaxie, zentralnervöse UAW (Müdigkeit, Kopfschmerzen, Benommenheit, Vertigo, Ataxie, Verwirrtheit, Sehstörungen, Adynamie).

Immunologische Unverträglichkeitsreaktionen unter RMP:

Die Therapie mit RMP muss beim Auftreten eines „flu-like-syndrome", einer Thrombopenie, einer Hämolyse oder eines beginnenden Nierenversagens sofort abgesetzt werden und darf nicht wiederaufgenommen werden.

Als absolute Kontraindikationen gelten:

RMP-Allergie, akute Hepatitis, Gallengangsobstruktion; schwerwiegende Leberfunktionsstörungen (Child Pugh C [179]).

\section{Rifabutin (RFB)}

Der Wirkmechanismus entspricht dem des Rifampicins.

Die Dosierung beträgt $300 \mathrm{mg}$. Bei gleichzeitiger Gabe antiretroviraler Medikamente muss unter Umständen eine Reduktion auf $150 \mathrm{mg}$ erfolgen.

Die Resorption nach oraler Gabe ist sehr gering (10-20\%). Allerdings ist die Gewebegängigkeit sehr gut, sodass die Gewebekonzentrationen deutlich über den Serumkonzentrationen liegen. Die Ausscheidung erfolgt biliär und renal. Das Interaktionspotenzial und die unerwünschten Arzneimittelwirkungen sind dem des Rifampicins vergleichbar. Bei hoher Dosis ( $450 \mathrm{mg} / \mathrm{Tag}$ ) ist die Uveitis (Augenschmerzen, Visusschädigung) sehr häufig.

\section{Streptomycin (SM) ${ }^{1}$}

Die Dosierung beträgt $15 \mathrm{mg} / \mathrm{kg}$ Körpergewicht (Höchstdosis $1000 \mathrm{mg}$ ). Der maximale Serumspiegel nach $1 \mathrm{~g}$ liegt bei $25-45$ $\mathrm{mg} / \mathrm{l}$. SM muss parenteral (i.m. oder i.v.) verabreicht werden, es diffundiert mäßig gut in Gewebe und Körperflüssigkeiten und penetriert die Blut-Hirn-Schranke nur bei entzündeten Meningen in ausreichendem Maße. SM tritt in den fetalen Kreislauf und in die Muttermilch über. Die Elimination findet als unveränderte Substanz überwiegend renal statt. Eine Anpassung der Dosis bei Niereninsuffizienz ist daher erforderlich.

Die Verträglichkeit ist relativ gut.

Die wichtigste Arzneimittelinteraktion betrifft die Oto- und Nephrotoxizität der Aminoglykoside. Die Gabe weiterer potenziell oto- oder nephrotoxischer Substanzen (z. B. Cephalosporine, Amphotericin B, Colistin, Ciclosporin, Cisplatin, Schleifendiuretika, Methoxyfluran, Makrolide) ist nach Möglichkeit zu vermeiden.

Unerwünschte Arzneimittelwirkungen:

Die wichtigsten unerwünschten Arzneimittelwirkungen sind die toxische Schädigung des VIII. Hirnnerven (bevorzugt der vestibulären Funktion) und die Induktion einer Niereninsuffizienz durch eine diffuse tubuläre Schädigung. Präventiv sind daher regelmäßige Audiogramm-Kontrollen und Vestibularisuntersuchungen vor Beginn der Therapie und bei unauffälligem Verlauf alle 4 Wochen sowie regelmäßige Kontrolle der Nierenfunktion (wöchentlich) und bei Bedarf auch die Messung von Serumspiegeln indiziert.

Das Risiko der Ototoxizität ist dabei dosisabhängig und liegt bei einer Dosis von $2 \mathrm{~g} / \mathrm{Tag}$ über $60-120$ Tage bei $75 \%$; bei einer Dosis von $1 \mathrm{~g} /$ Tag über 120 Tage bei $30 \%$. Das Risiko steigt neben der Dosis mit dem Alter, dem Ausmaß einer vorbestehenden Nierenfunktionseinschränkung oder einer vorbestehenden Innenohrschädigung sowie durch die Gabe anderer ototoxischer Medikamente. Die Ototoxizität ist meist reversibel, eine schwerwiegende Vestibularis-Schädigung kann langanhaltend sein.

Selten: Tinnitus, kutane UAW.

Sehr selten: Nierenfunktionsstörungen, Agranulozytose, aplastische Anämie, Anaphylaxie, neuromuskuläre Blockaden, Atemdepression, Parästhesien, Dermatitis exfoliativa, Überempfindlichkeitsreaktionen mit Fieber, Exanthemen und Eosinophilie.

Bei Pflegepersonal sind Kontaktallergien beschrieben.

Als Kontraindikationen gelten eine SM-Allergie, Gravidität, schwere Nierenfunktionsstörungen, Cochlearis- oder Vestibularis-Schädigungen und die Myasthenia gravis.

\section{Weitere Substanzen}

Weitere, selten eingesetzte Antibiotika in der Therapie von NTMErkrankungen sind Trimethoprim/Sulfamethoxazol (TMP/SMZ), Doxycyclin und Imipenem. Hinsichtlich der Eigenschaften dieser Medikamente wird auf die jeweiligen Gebrauchsinformationen verwiesen. Cefoxitin ist in Deutschland nicht erhältlich. Auch hier wird auf die Gebrauchsinformation verwiesen.

Dosierungen bei NTM-Erkrankungen:

TMP/SMZ Oral: $2 \times 160 / 800 \mathrm{mg} / \mathrm{Tag}$

Cefoxitin: $12 \mathrm{~g} /$ Tag entweder $4 \times 3 \mathrm{~g}$ i.v. oder $6 \times 2 \mathrm{~g}$ i.v.

Imipenem: $4 \times 1 \mathrm{~g}$ i.v.

Doxycyclin: Oral: $100 \mathrm{mg} / \mathrm{Tag}$

\footnotetext{
${ }^{1}$ Da SM derzeit nach unserem Kenntnisstand in Deutschland nicht im normalen Handel erhältlich ist, kann stattdessen Amikacin verwendet werden.
} 


\section{Glossar}

\begin{tabular}{|c|c|}
\hline $\begin{array}{l}\text { ATS } \\
\text { BAL }\end{array}$ & $\begin{array}{l}\text { American Thoracic Society } \\
\text { bronchoalveoläre Lavage }\end{array}$ \\
\hline CLAR & Clarithromycin \\
\hline OPD & $\begin{array}{l}\text { „chronic obstructive pulmonary disease“ } \\
\text { (chronisch-obstruktive Lungenkrankheit) }\end{array}$ \\
\hline CF & Zystische Fibrose (Mukoviszidose) \\
\hline EMB & Ethambutol \\
\hline & Fluorchinolon \\
\hline GERD & $\begin{array}{l}\text { „gastroesophageal reflux disease“ } \\
\text { (gastro-ösophageale Refluxkrankheit) }\end{array}$ \\
\hline HIV & humanes Immundefizienz-Virus \\
\hline $\mathrm{RCT}$ & „high-resolution“ (hoch auflösendes) CT \\
\hline SA & Infectious Diseases Society of America \\
\hline RA & Interferon- $\gamma$ Release Assay \\
\hline$N-\gamma$ & Interferon- $\gamma$ \\
\hline IL & Interleukin \\
\hline $\mathrm{H}$ & Isoniazid \\
\hline IS & $\begin{array}{l}\text { „Immune reconstitution inflammatory syndrome“ } \\
\text { (Immunrekonstitutionssyndrom) }\end{array}$ \\
\hline$A C$ & M. avium-Komplex \\
\hline IOTT & $\begin{array}{l}\text { „mycobacteria other than tuberculosis“ (Mykobakte- } \\
\text { rien, die nicht zum M. tuberculosis-Komplex gehören) }\end{array}$ \\
\hline MRT & Magnetresonanztomografie \\
\hline & Nukleinsäureamplifikationstest \\
\hline$\Gamma \mathrm{M}$ & nichttuberkulöse Mykobakterien \\
\hline NA & ribosomale RNA kodierende DNA \\
\hline & Rifabutin \\
\hline MP & Rifampicin \\
\hline & Streptomycin \\
\hline
\end{tabular}

\section{Danksagung}

Das DZK dankt dem Bundesministerium für Gesundheit für die Unterstützung.

\section{Interessenkonflikt}

Die Autoren geben an, dass kein Interessenkonflikt besteht.

\section{Institute}

${ }^{1}$ Klinik für Pneumologie, Lungenklinik Heckeshorn, HELIOS Klinikum Emil von Behring, Berlin

${ }^{2}$ Abteilung für Infektionsepidemiologie, Fachgebiet für respiratorisch übertragbare Erkrankungen, Robert Koch-Institut, Berlin

${ }^{3}$ Forschungszentrum Borstel, Nationales Referenzzentrum für Mykobakterien

${ }^{4}$ Deutsches Zentralkomitee zur Bekämpfung der Tuberkulose, Berlin

${ }^{5}$ Abteilung für Epidemiologie, Helmholtz-Zentrum für Infektionsforschung, Braunschweig

${ }^{6}$ Klinik für Pädiatrie m. S. Pneumologie und Immunologie, Charité Universitätsmedizin Berlin

${ }^{7}$ Fachkrankenhaus Coswig, Zentrum für Pneumologie und Thoraxchirurgie

${ }^{8}$ Institut für Mikrobiologie, Immunologie und Laboratoriumsmedizin,

HELIOS Klinikum Emil von Behring, Berlin

${ }^{9}$ Forschungszentrum Borstel, Medizinische Klinik

${ }^{10}$ Medizinische Klinik III, Universitätsklinikum Schleswig-Holstein, Campus Lübeck

${ }^{11}$ Zentrum für Pneumologie, Agaplesion Diakonieklinikum Rotenburg

\section{Literatur}

1 Griffith DE, Aksamit T, Brown-Elliott BA et al. An official ATS/IDSA statement: diagnosis, treatment, and prevention of nontuberculous mycobacterial diseases. Am J Respir Crit Care Med 2007; 175: 367 416 Erratum in: Am J Respir Crit Care Med 2007; 175: 744-745. Dosage error in article text.

2 van Ingen J, Wagner D. Epidemiologie der nichttuberkulösen mykobakteriellen Erkrankungen in Deutschland und weltweit. Pneumologe 2011; 8: 396-403

3 Kendall BA, Winthrop KL. Update on the epidemiology of pulmonary nontuberculous mycobacterial infections. Sem Respir Crit Care Med 2013; 34: $87-94$

4 American Thoracic Society. Mycobacterioses and the acquired immunodeficiency syndrome. Joint Position Paper of the American Thoracic Society and the Centers for Disease Control. Am Rev Respir Dis 1987; 136: $492-496$

5 Radenbach $K L$, Loddenkemper $R$. Zunehmende Bedeutung der Lungenkrankheiten durch sogenannte atypische Mykobakterien. Öffentl. Ges.-Wes. 1985; 47: 459-462

6 Schütt-Gerowitt $H$. On the development of mycobacterial infections. II. Changing mycobacterial infection spectrum in the Cologne area 1983-1993. Zentralbl Bakteriol 1995; 283: 225 - 238

7 Schönfeld N, Schaberg T, Loddenkemper R. Neue Entwicklungen bei nicht-tuberkulösen Mykobakteriosen. Teil 1: Erkrankungen bei Patienten ohne HIV-Infektion. Pneumologie 1996; 50: 313-322

8 Falkinham JO. Nontuberculous mycobacteria in the environment. Clin Chest Med 2002; 23: 529-551

9 Adjemian J, Olivier KN, Seitz AE et al. Prevalence of nontuberculous mycobacterial lung disease in U.S. Medicare beneficiaries. Am J Respir Crit Care Med 2012; 185: 881 - 886

10 Adjemian J, Olivier KN, Seitz AE et al. Spatial clusters of nontuberculous mycobacterial lung disease in the United States. Am J Respir Crit Care Med 2012; 186: $553-558$

11 Schulze-Röbbecke R, Janning B, Fischeder R. Occurrence of mycobacteria in biofilm samples. Tuber Lung Dis 1992; 73: 141 - 144

12 Leite CQ Anno IS, Leite SR et al. Isolation and identification of mycobacteria from livestock specimens and milk obtained in Brazil. Mem Inst Oswaldo Cruz 2003; 98: 319-323

13 Jordão Junior CM, Lopes FC, David S et al. Detection of nontuberculous mycobacteria from water buffalo raw milk in Brazil. Food Microbiol 2009; 26: $658-661$

14 Eltholth MM, Marsh VR, Van Winden S et al. Contamination of food products with Mycobacterium avium paratuberculosis: a systematic review. J Appl Microbiol 2009; 107: 1061 - 1071

15 Shankar H, Singh SV, Singh PK et al. Presence, characterization, and genotype profiles of Mycobacterium avium subspecies paratuberculosis from unpasteurized individual and pooled milk, commercial pasteurized milk, and milk products in India by culture, PCR, and PCR-REA methods. Int J Infect Dis 2010; 14: e121-126

16 Daley $C L$, Griffith $D E$. Pulmonary non-tuberculous mycobacterial infections. Int J Tuberc Lung Dis 2010; 14: 665-671

17 Marras TK, Wallace RJ Jr, Koth LL et al. Hypersensitivity pneumonitis reaction to Mycobacterium avium in household water. Chest 2005; 127: $664-671$

18 Hanak V, Golbin JM, Ryu JH. Causes and presenting features in 85 consecutive patients with hypersensitivity pneumonitis. Mayo Clin Proc 2007; 82: $812-816$

19 Hartman TE, Jensen E, Tazelaar HD et al. CT findings of granulomatous pneumonitis secondary to Mycobacterium avium-intracellulare inhalation: "hot tub lung". Am J Roentgenol 2007; 188: 1050 - 1053

20 Tillie-Leblond I, Grenouillet F, Reboux G et al. Hypersensitivity pneumonitis and metalworking fluids contaminated by mycobacteria. Eur Respir J 2011; 37: 640 - 64

21 Marras TK, Chedore P, Ying AM et al. Isolation prevalence of pulmonary non-tuberculous mycobacteria in Ontario, 1997- 2003. Thorax 2007; 62: $661-666$

22 Prevots DR, Shaw PA, Strickland D et al. Nontuberculous mycobacterial lung disease prevalence at four integrated health care delivery systems. Am J Respir Crit Care Med 2010; 182: 970-976

23 Winthrop KL, McNelley E, Kendall B et al. Pulmonary nontuberculous mycobacterial disease prevalence and clinical features: an emerging public health disease. Am J Respir Crit Care Med 2010; 182: 977 - 982

24 Thomson RM. Changing epidemiology of pulmonary nontuberculous mycobacteria infections. Emerg Infect Dis 2010; 16: 1576-1583 
25 Lai CC, Tan CK, Chou CH et al. Increasing incidence of nontuberculous mycobacteria, Taiwan, 2000-2008. Emerg Infect Dis 2010; 16: 294 296

26 Moore JE, Kruijshaar ME, Ormerod LP et al. Increasing reports of nontuberculous mycobacteria in England, Wales and Northern Ireland, 1995-2006. BMC Public Health 2010; 10: 612

27 van Ingen J, Bendien SA, de Lange WC et al. Clinical relevance of nontuberculous mycobacteria isolated in the Nijmegen-Arnhem region, The Netherlands. Thorax 2009; 64: 502 - 506

28 van Ingen J, Hoefsloot $W$, Dekhuijzen $P N$ et al. The changing pattern of clinical Mycobacterium avium isolation in the Netherlands. Int J Tuberc Lung Dis 2010; 14: 1176-1180

29 Andrejak C, Thomsen VO, Johansen IS et al. Nontuberculous pulmonary mycobacteriosis in Denmark: incidence and prognostic factors. Am J Respir Crit Care Med 2010; 181: 514-552

30 Jankovic M, Samarzija M, Sabol I et al. Geographical distribution and clinical relevance of non-tuberculous mycobacteria in Croatia. Int Tuberc Lung Dis 2013; 17: 836-841

31 Koh WJ. Epidemiology of pulmonary non-tuberculous mycobacterial infections: need to identify environmental sources. Int J Tuberc Lung Dis 2013; 17: 713

32 Jones $D$, Havlir DV. Nontuberculous mycobacteria in the HIV infected patient. Clin Chest Med 2002; 23: 665 - 667

33 Henry MT, Inamdar L, O'Riordain D et al. Nontuberculous mycobacteria in non-HIV patients: epidemiology, treatment and response. Eur Respir J 2004; 23: 741 - 746

34 Schönfeld N. The mycobacterial mystery. Eur Respir J 2006; 28: 1076 1078

35 Behr MA, Falkinham J03rd. Molecular epidemiology of nontuberculous mycobacteria. Future Microbiol 2009; 4: 1009-1020

36 van Soolingen $D$, van Ingen J. On the road to unravelling the aetiology of non-tuberculous mycobacterial disease. Int J Tuberc Lung Dis 2012; 16: 1279

37 Simons S, van Ingen J, Hsueh PR et al. Nontuberculous mycobacteria in respiratory tract infections, eastern Asia. Emerg Infect Dis 2011; 17: $343-349$

38 Hoefsloot $W$, van Ingen J, Andrejak $C$ et al. The geographic diversity of nontuberculous mycobacteria isolated from pulmonary samples: a NTM-NET collaborative study. Eur Respir J 18. 04. 2013 [Epub ahead of print]

39 Wolinsky E. Nontuberculous mycobacteria and associated diseases. Am Rev Respir Dis 1979; 119: 107 - 159

40 Radenbach $K L$. Diagnostische und therapeutische Fortschritte bei nichttuberkulösen Mykobakteriosen. Prax Klin Pneumol 1985; 39: 43-49

41 Billinger ME, Olivier KN, Viboud C et al. Nontuberculous mycobacteriaassociated lung disease in hospitalized persons, United States, 19982005. Emerg Infect Dis 2009; 15: 1562 - 1569

42 Iseman MD, Marras TK. The importance of nontuberculous mycobacterial lung disease. Am J Respir Crit Care Med 2008; 178: 999 1000

43 Szabó I, Kiss KK, Várnai I. Epidemic pulmonary infection associated with Mycobacterium xenopi indigenous in sewage-sludge. Acta Microbiol Acad Sci Hung 1982; 29: 263 - 266

44 Bryant JM, Grogono DM, Greaves D et al. Whole-genome sequencing to identify transmission of Mycobacterium abscessus between patients with cystic fibrosis: a retrospective cohort study. Lancet 2013; 381: $1551-1560$

45 Matthiessen W, Schmidt C, Rüsch-Gerdes S et al. Bedeutung der lokalen und allgemeinen Risikofaktoren für die Pathogenese der pulmonalen nicht-tuberkulösen Mykobakteriosen bei Nicht-AIDS-Patienten. Eine Untersuchung der Wissenschaftlichen Arbeitsgemeinschaft für die Therapie von Lungenkrankheiten (WATL). Pneumologie 2010; 64: $281-290$

46 Braun E, Sprecher H, Davidson S et al. Epidemiology and clinical significance of non-tuberculous mycobacteria isolated from pulmonary specimens. Int J Tuberc Lung Dis 2013; 17: 96 -99

47 Sexton P, Harrison AC. Susceptibility to nontuberculous mycobycterial lung disease. Eur Respir J 2008; 31: 1322 - 1333

48 Chan ED, Iseman MD. Underlying host risk factors for nontuberculous mycobacterial lung disease. Sem Respir Crit Care Med 2013; 34: $110-123$

49 Prince DS, Peterson DD, Steiner RM et al. Infection with Mycobacterium avium complex in patients without predisposing conditions. N Engl J Med 1989; 321: $863-868$
50 Kartalija M, Ovrutsky AR, Bryan CL et al. Patients with nontuberculous mycobacterial lung disease exhibit unique body and immune phenotypes. Am J Respir Crit Care Med 2013; 187: 197 - 205

51 Fowler CJ, Olivier KN, Leung JM et al. Abnormal nasal nitric oxide production, ciliary beat frequency, and toll-like receptor response in pulmonary nontuberculous mycobacterial disease epithelium. Am J Respir Crit Care Med 2013; 187: 1374-1381

52 Vesenbeckh S, Schönfeld N, Wagner S et al. Pathogenität von Mycobacterium kansasii. Pneumologie 2013; 67 (Suppl. 01): P428

53 Witty LA, Tapson VF, Piantadosi CA. Isolation of mycobacteria in patients with pulmonary alveolar proteinosis. Medicine (Baltimore) 1994; 73: $103-109$

54 Fritscher LG, Marras TK, Bradi AC et al. Nontuberculous mycobacterial infection as a cause of difficult-to-control asthma: a case-control study. Chest 2011; 139: 23-27

55 Schönfeld N, Matthiessen W, Grassot A. Komplikationen der pulmonalen Beteiligung beim M. Bechterew. Aktuelle Radiol 1991; 1: 249 252

56 Kim RD, Greenberg DE, Ehrmantraut ME et al. Pulmonary nontuberculous mycobacterial disease. Prospective study of a distinct preexisting syndrome. Am J Respir Crit Care Med 2008; 178: 1066 - 1074

57 Andréjak $C$, Nielsen $R$, Thomsen VØ et al. Chronic respiratory disease, inhaled corticosteroids and risk of non-tuberculous mycobacteriosis. Thorax 2013; 68: 256-262

58 Reich JM, Johnson RE. Mycobacterium avium complex pulmonary disease presenting as an isolated lingular or middle lobe pattern. The Lady Windermere syndrome. Chest 1992; 101: 1605 - 1609

$59 \mathrm{Yu}$ JA, Pomerantz M, Bishop A et al. Lady Windermere revisited: treatment with thoracoscopic lobectomy/segmentectomy for right middle lobe and lingular bronchiectasis associated with non-tuberculous mycobacterial disease. Eur J Cardiothorac Surg 2011; 40: 671 - 675

60 Koh WJ, Lee JH, Kwon YS et al. Prevalence of gastroesophageal reflux disease in patients with nontuberculous mycobacterial lung disease. Chest 2007; 131: 1825-1833

61 Forschbach G. Nicht-tuberkulöse Infektionen durch Mykobakterien. Internist 1975; 16: $393-400$

62 Olivier KN, Weber DJ, Wallace RJ Jr et al. Nontuberculous mycobacteria in Cystic Fibrosis Study Group. Nontuberculous mycobacteria. I: multicenter prevalence study in cystic fibrosis. Am J Respir Crit Care Med 2003; 167: 828-834

63 Roux AL, Catherinot E, Ripoll $F$ et al. for the OMA Group. Multicenter study of prevalence of nontuberculous mycobacteria in patients with cystic fibrosis in France. J Clin Microbiol 2009; 47: 4124-4128

64 Leung JM, Olivier KN. Nontuberculous mycobacteria in patients with cystic fibrosis. Sem Respir Crit Care Med 2013; 34: 124-134

65 Fowler SJ, French J, Screaton NJ et al. Nontuberculous mycobacteria in bronchiectasis: prevalence and patient characteristics. Eur Respir J 2006; 28: 1204 -1210. Erratum in: Eur Respir J 2007; 29: 614-615

66 Tomashefski JF Jr, Stern RC, Demko CA et al. Nontuberculous mycobacteria in cystic fibrosis. An autopsy study. Am J Respir Crit Care Med 1996; 154: $523-528$

67 Brown-Elliott BA, Mann LB, Hail D et al. Antimicrobial susceptibility of nontuberculous mycobacteria from eye infections. Cornea 2012; 31 : $900-906$

68 Bennett SN, Peterson DE, Johnson DR et al. Bronchoscopy-associated Mycobacterium xenopi pseudoinfections. Am J Respir Crit Care Med 1994; 150: $245-250$

69 Sousa TS, Matherne RJ, Wilkerson MG. Case report: cutaneous nontuberculous mycobacterial abscesses associated with insulin injections. J Drugs Dermatol 2010; 9: 1439-1442

70 Song $Y, W u$ J, Yan $H$ et al. Peritoneal dialysis-associated nontuberculous mycobacterium peritonitis: a systematic review of reported cases. Nephrol Dial Transplant 2012; 27: 1639-1644

71 Winthrop KL, Abrams M, Yakrus $M$ et al. An outbreak of mycobacterial furunculosis associated with footbaths at a nail salon. N Engl J Med 2002; 346: 1366 - 1371

72 LeBlanc PM, Hollinger KA, Klontz KC. Tattoo ink-related infectionsawareness, diagnosis, reporting, and prevention. N Engl J Med 2012; 367: 985 - 987

73 Lewis FM, Marsh BJ, von Reyn CF. Fish tank exposure and cutaneous infections due to Mycobacterium marinum: tuberculin skin testing, treatment, and prevention. Clin Infect Dis 2003; 37: 390 - 397

74 Walsh DS, Portaels F, Meyers WM. Buruli Ulcer: Advances in understanding Mycobacterium ulcerans infection. Dermatol Clin 2011; 29: $1-8$ 
75 Kirk O, Gatell JM, Mocroft A et al. Infections with Mycobacterium tuberculosis and Mycobacterium avium among HIV-infected patients after the introduction of highly active antiretroviral therapy. EuroSIDA Study Group JD. Am J Respir Crit Care Med 2000; 162: 865-872

76 Panel on Opportunistic Infections in HIV-Infected Adults and Adolescents. Guidelines for the prevention and treatment of opportunistic infections in HIV-infected adults and adolescents: recommendations from the Centers for Disease Control and Prevention, the National Institutes of Health, and the HIV Medicine Association of the Infectious Diseases Society of America. Available at http://aidsinfo.nih.gov/contentfiles/lvguidelines/adult_oi.pdf. Accessed 20.07.13

77 Rutsky EA, Rostand SG. Mycobacteriosis in patients with chronic renal failure. Arch Intern Med 1980; 140: 57-61

78 Sartori FG, Leandro LF, Montanari $L B$ et al. Isolation and identification of environmental mycobacteria in the waters of a hemodialysis center. Curr Microbiol 2013; 67: 107-111

79 Daley CL. Nontuberculous mycobacterial disease in transplant recipients: early diagnosis and treatment. Curr Opin Organ Transplant 2009; 14: 619-624

80 Ferreira J, Grochowsky J, Krakower D et al. Mycobacterium marinum: an increasingly common opportunistic infection in patients on infliximab. Am J Gastroenterol 2012; 107: 1268-1269

81 Kump PK, Högenauer C, Wenzl HH et al. A case of opportunistic skin infection with Mycobacterium marinum during adalimumab treatment in a patient with Crohn's disease. J Crohns Colitis 2013; 7: e15-18

82 Winthrop KL, Chang E, Yamashita S et al. Nontuberculous mycobacteria infections and anti-tumor necrosis factor-alpha therapy. Emerg Infect Dis 2009; 15: 1556 - 1561

83 Iseman MD. Mycobacterial infections in the era of modern biologic agents. Am J Med Sci 2011; 341: $278-280$

84 Dirac MA, Horan KL, Doody DR et al. Environment or host? A case-control study of risk factors for Mycobacterium avium complex lung disease. Am J Respir Crit Care Med 2012; 186: 684-691

85 Rupp J, Schaaf B. Infektionen mit nichttuberkulösen Mykobakterien bei Patienten mit Immundefekten. Pneumologe 2011; 8: 402 - 407

86 Colombo RE, Hill SC, Claypool RJ et al. Familial clustering of pulmonary nontuberculous mycobacterial disease. Chest 2010; 137: 629-634

87 Vinh DC, Patel SY, Uzel G et al. Autosomal dominant and sporadic monocytopenia with susceptibility to mycobacteria, fungi, papillomaviruses, and myelodysplasia. Blood 2010; 115: 1519-1529

88 Cassidy PM, Hedberg K, Saulson A et al. Nontuberculous mycobacterial disease prevalence and risk factors: a changing epidemiology. Clin Infect Dis 2009; 49: e124-e129

89 Tortoli $E$. The new mycobacteria: an update. FEMS Immunol Med Microbiol 2006; 48: 159-178

90 Taillard C, Greub G, Weber R et al. Clinical implications of Mycobacterium kansasii species heterogeneity: Swiss National Survey. J Clin Microbiol 2003; 41: 1240 - 1244

91 Lindeboom JA, Bruijnesteijn van Coppenraet LE, van Soolingen D et al. Clinical manifestations, diagnosis, and treatment of Mycobacterium haemophilum infections. Clin Microbiol Rev 2011; 24: 701 - 717

92 O'Connell ML, Birkenkamp KE, Kleiner DE et al. Lung manifestations in an autopsy-based series of pulmonary or disseminated nontuberculous mycobacterial disease. Chest 2012; 141: 1203 - 1209

93 Hauer B, Loddenkemper R, Detjen A et al. Interferon-gamma assays description and assessment of a new tool in the diagnosis of tuberculosis. Pneumologie 2006; 60: 29-44

94 Lalvani A, Millington KA. Screening for tuberculosis infection prior to initiation of anti-TNF therapy. Autoimmun Rev 2008; 8: 147-152

95 van Ingen J. Diagnosis of nontuberculous mycobacterial infections. Sem Respir Crit Care Med 2013; 34: 103 - 109

96 Roth A, Reischl U, Schönfeld $N$ et al. Mycobacterium heckeshornense sp. nov., A new pathogenic slowly growing Mycobacterium sp. causing cavitary lung disease in an immunocompetent patient. J Clin Microbiol 2000; 38: 4102-4107

97 Kendall BA, Varley $C D$, Hedberg $K$ et al. Isolation of non-tuberculous mycobacteria from the sputum of patients with active tuberculosis. Int J Tuberc Lung Dis 2010; 14: 654-656

98 Damaraju $D$, Jamieson $F$, Chedore $P$ et al. Isolation of non-tuberculous mycobacteria among patients with pulmonary tuberculosis in Ontario, Canada. Int J Tuberc Lung Dis 2013; 17: 676-681

99 Koh WJ, Yu CM, Suh GY et al. Pulmonary TB and NTM lung disease: comparison of characteristics in patients with AFB smear-positive sputum. Int J Tuberc Lung Dis 2006; 10: 1001 - 1007
100 Greinert U, Lotz W. Pulmonale Infektionen durch nichttuberkulöse Mykobakterien. Radiologische Aspekte und Differenzialdiagnose. Pneumologe 2011; 8: 404-411

101 Richter E, Brown-Elliott BA, Wallace RJJ. 29. Mycobacterium: Laboratory Characteristics of Slowly Growing Mycobacteria. In: Versalovic J ed. Manual of clinical microbiology. 01. Washington, DC: ASM Press; 2011

102 DIN 58943-4 Medizinische Mikrobiologie - Tuberkulosediagnostik Teil 4: Primärproben zur Tuberkulose- und Mykobakteriosediagnostik - Qualitative und quantitative Anforderungen, Gewinnung, Transport und Aufbewahrung. Text Deutsch und Englisch (DIN 58943-4: 2009)

103 Falkinham JO 3rd. Surrounded by mycobacteria: nontuberculous mycobacteria in the human environment. J Appl Microbiol 2009; 107: $356-367$

104 Del Guidice G, Iadevaia C, Sntoro G et al. Nontuberculous mycobacterial lung disease in patients without HIV infection: a retrospective analysis over 3 years. Clin Respir J 2011; 5: 203-210

105 DIN 58943-32 Medizinische Mikrobiologie - Tuberkulosediagnostik Teil 32: Mikroskopische Methoden zum Nachweis von Mykobakterien (DIN 58943-32:1995)

106 Richter E, Beer J, Diel R et al. MIQ 05: Tuberkulose Mykobakteriose. In: Qualitätsstandards in der mikrobiologisch-infektiologischen Diagnostik. Podbielski A, Mauch H, Herrmann M, Kniehl E, Rüssmann H, Hrsg. 2. Auflage, Urban \& Fischer in Elsevier; 2010: ISBN: 978-3-43741531-9

107 Richter E, Rüsch-Gerdes S, Niemann S et al. Detection, identification, and treatment of a novel, non-cultivable Mycobacterium species in an HIV patient. AIDS 2000; 14: 1667 - 1668

108 DIN 58943-3 Medizinische Mikrobiologie - Tuberkulosediagnostik Teil 3: Kulturelle Methoden zum Nachweis von Mykobakterien. (DIN 58943-3:1996)

109 Hanna BA, Ebrahimzadeh A, Elliott LB et al. Multicenter evaluation of the BACTEC MGIT 960 system for recovery of mycobacteria. J Clin Microbiol 1999; 37: 748-752

110 Tortoli E, Cichero P, Piersimoni $C$ et al. Use of BACTEC MGIT 960 for recovery of mycobacteria from clinical specimens: multicenter study. J Clin Microbiol 1999; 37: 3578-3582

111 Richter E, Rüsch-Gerdes S, Hillemann D. Evaluation of the GenoType Mycobacterium Assay for identification of mycobacterial species from cultures. J Clin Microbiol 2006; 44: 1769-1775

112 Russo C, Tortoli E, Menichella D. Evaluation of the new GenoType Mycobacterium assay for identification of mycobacterial species. J Clin Microbiol 2006; 44: 334-339

113 Lee AS, Jelfs $P$, Sintchenko $V$ et al. Identification of non-tuberculous mycobacteria: utility of the GenoType Mycobacterium CM/AS assay compared with HPLC and 16S rRNA gene sequencing. J Med Microbiol 2009; 58: 900-904

114 Mäkinen J, Sarkola A, Marjamäki M et al. Evaluation of genotype and LiPA MYCOBACTERIA assays for identification of Finnish mycobacterial isolates. J Clin Microbiol 2002; 40: 3478-3481

115 Tortoli E, Mariottini A, Mazzarelli G. Evaluation of INNO-LiPA MYCOBACTERIA v2: improved reverse hybridization multiple DNA probe assay for mycobacterial identification. J Clin Microbiol 2003; 41: $4418-4420$

116 Kirschner P, Springer B, Vogel $U$ et al. Genotypic identification of mycobacteria by nucleic acid sequence determination: report of a 2-year experience in a clinical laboratory. J Clin Microbiol 1993; 31: 2882 2889

117 Roth A, Fischer M, Hamid ME et al. Differentiation of phylogenetically related slowly growing mycobacteria based on 16S-23S rRNA gene internal transcribed spacer sequences. J Clin Microbiol 1998; 36: $139-147$

118 Han XY, Pham AS, Tarrand JJ et al. Rapid and accurate identification of mycobacteria by sequencing hypervariable regions of the $16 \mathrm{~S}$ ribosomal RNA gene. Am J Clin Pathol 2002; 118: 796-801

119 Pauls RJ, Turenne CY, Wolfe JN et al. A high proportion of novel mycobacteria species identified by $16 \mathrm{~S}$ rDNA analysis among slowly growing AccuProbe-negative strains in a clinical setting. Am J Clin Pathol 2003; $120: 560-566$

120 Woods GL, Brown-Elliott B, Conville PS et al. Susceptibility testing of mycobacteria, nocardiae, and other aeroboic actinomycetes: approved standard. Clinical and Laboratory Standards Institute 2011; M 24A2: $1-64$ 
121 Scarparo C, Ricordi P, Ruggiero G et al. Evaluation of the fully automated BACTEC MGIT 960 system for testing susceptibility of Mycobacterium tuberculosis to pyrazinamide, streptomycin, isoniazid, rifampin, and ethambutol and comparison with the radiometric BACTEC 460TB method. J Clin Microbiol 2004; 42: 1109-1114

122 Rüsch-Gerdes S, Pfyffer GE, Casal M et al. Multicenter laboratory validation of the BACTEC MGIT 960 technique for testing susceptibilities of Mycobacterium tuberculosis to classical second-line drugs and newer antimicrobials. J Clin Microbiol 2006; 44: 688-692

123 Lucke K, Hombach M, Friedel U et al. Automated quantitative drug susceptibility testing of non-tuberculous mycobacteria using MGIT 960/ EpiCenter TB eXiST. J Antimicrob Chemother 2012; 67: 154-158

124 Hombach $M$, Somoskövi A, Hömke R et al. Drug susceptibility distributions in slowly growing non-tuberculous mycobacteria using MGIT 960 TB eXiST. Int J Med Microbiol 2013; 303: 270 - 276

125 DIN 58943-8 Medizinische Mikrobiologie - Tuberkulosediagnostik Teil 8: Empfindlichkeitsprüfung von Tuberkulosebakterien gegen Chemotherapeutika (DIN 58943-8:2009)

126 Nash KA, Brown-Elliott BA, Wallace RJ Jr. A novel gene, erm(41), confers inducible macrolide resistance to clinical isolates of Mycobacterium abscessus but is absent from Mycobacterium chelonae. Antimicrob Agents Chemother 2009; 53: 1367-1376

127 Bastian S, Veziris N, Roux AL et al. Assessment of clarithromycin susceptibility in strains belonging to the Mycobacterium abscessus group by erm(41) and rrl sequencing. Antimicrob Agents Chemother 2011; 55: 775-781

128 van Ingen J, Boeree MJ, van Soolingen $D$ et al. Resistance mechanisms and drug susceptibility testing of nontuberculous mycobacteria. Drug Resist Updat 2012; 15: 149-161

129 Nash KA, Inderlied CB. Genetic basis of macrolide resistance in Mycobacterium avium isolated from patients with disseminated disease. Antimicrob Agents Chemother 1995; 39: 2625-2630

130 van Ingen J, Egelund EF, Levin $A$ et al. The pharmacokinetics and pharmacodynamics of pulmonary Mycobacterium avium complex disease treatment. Am J Respir Crit Care Med 2012; 186: 559-565

131 Koh WJ, Jeong $B H$, Jeon $K$ et al. Therapeutic drug monitoring in the treatment of Mycobacterium avium complex lung disease. Am J Respir Crit Care Med 2012; 186: 797-802

132 Schluger NW. Treatment of pulmonary Mycobacterium avium complex infections: do drug levels matter? Am J Respir Crit Care Med 2012; 186: 710-711

133 Philley JV, Griffith DE. Management of nontuberculous mycobacterial (NTM) lung disease. Sem Respir Crit Care Med 2013; 34: 135- 142

134 Ballarino GJ, Olivier KN, Claypool RJ et al. Pulmonary nontuberculous mycobacterial infections: antibiotic treatment and associated costs. Respir Med 2009; 103: 1448 - 1455

135 Schaberg T, Bauer T, Castell S et al. Deutsches Zentralkomitee zur Bekämpfung der Tuberkulose (DZK) und Deutsche Gesellschaft für Pneumologie und Beatmungsmedizin (DGP): Empfehlungen zur Therapie, Chemoprävention und Chemoprophylaxe der Tuberkulose im Erwachsenen- und Kindesalter. Pneumologie 2012; 66: 133-171

136 van Ingen J, Verhagen AF, Dekhuijzen PN et al. Surgical treatment of non-tuberculous mycobacterial lung disease: strike in time. Int J Tuberc Lung Dis 2010; 14: 99-105

137 Pomerantz M, Madsen L, Goble M et al. Surgical management of resistant mycobacterial tuberculosis and other mycobacterial pulmonary infections. Ann Thorac Surg 1991; 52: 1108 -1111

138 Nelson KG, Griffith DE, Brown BA et al. Results of operation in Mycobacterium avium-intracellulare lung disease. Ann Thorac Surg 1998; 66: $325-330$

139 Junghanss $T$, Um Boock A, Vogel $M$ et al. Phase change material for thermotherapy of Buruli ulcer: a prospective observational single centre proof-of-principle trial. PLoS Negl Trop Dis 2009; 3: e380

140 Griffith DE, Aksamit TR. Therapy of refractory nontuberculous mycobacterial lung disease. Curr Opin Infect Dis 2012; 25: 218-227

141 Chaisson RE, Moore RD, Richman DD et al. Incidence and natural history of Mycobacterium avium-complex infections in patients with advanced human immunodeficiency virus disease treated with zidovudine. Am Rev Respir Dis 1992; 146: 285-292

142 Nightingale SD, Byrd LT, Southern PM et al. Incidence of Mycobacterium avium-intracellulare complex bacteremia in human immunodeficiency virus-positive patients. J Infect Dis 1992; 165: 1082 - 1085

143 Lawn SD, Bekker LG, Miller RF. Immune reconstitution disease associated with mycobacterial infections in HIV-infected individuals receiving antiretrovirals. Lancet Infect Dis 2005; 5: 361 - 373
144 Corbett EL, Blumberg L, Churchyard GJ et al. Nontuberculous mycobacteria: defining disease in a prospective cohort of South African miners. Am J Respir Crit Care Med 1999; 160: 15-21

145 Bloch KC, Zwerling L, Pletcher MJ et al. Incidence and clinical implications of isolation of Mycobacterium kansasii: Results of a 5-year, population based study. Ann Intern Med 1998; 129: 698-704

146 Cattamanchi A, Nahid P, Marras TK et al. Detailed analysis of the radiographic presentation of Mycobacterium kansasii lung disease in patients with HIV infection. Chest 2008; 133: 875-880

147 Phillips $P$, Bonner S, Gataric $N$ et al. Nontuberculous mycobacterial immune reconstitution syndrome in HIV-infected patients: spectrum of disease and long-term follow-up. Clin Infect Dis 2005; 41: 14831497

148 Shelburne SA3rd, Hamill RJ, Rodriguez-Barradas MC et al. Immune reconstitution inflammatory syndrome: emergence of a unique syndrome during highly active antiretroviral therapy. Medicine (Baltimore) 2002; 81: 213-227

149 Meintjes G, Wilkinson RJ, Morroni C et al. Randomized placebo-controlled trial of prednisone for paradoxical tuberculosis-associated immune reconstitution inflammatory syndrome. AIDS 2010; 24: $2381-2390$

150 Gordin FM, Cohn DL, Sullam PM et al. Early manifestations of disseminated Mycobacterium avium complex disease: A prospective evaluation. J Infect Dis 1997; 176: 126 - 132

151 Chaisson RE, Benson CA, Dube MP et al. Clarithromycin therapy for bacteremic Mycobacterium avium complex disease: a randomized, double-blind, dose-ranging study in patients with AIDS. Ann Intern Med 1994; 121: $905-911$

152 Benson CA, Williams PL, Currier JS et al. A prospective, randomized trial examining the efficacy and safety of clarithromycin in combination with ethambutol, rifabutin, or both for the treatment of disseminated Mycobacterium avium complex disease in persons with acquired immunodeficiency syndrome. Clin Infect Dis 2003; 37: 1234-1243

153 Dunne M, Fessel J, Kumar $P$ et al. A randomized, double-blind trial comparing azithromycin and clarithromycin in the treatment of disseminated Mycobacterium avium infection in patients with human immunodeficiency virus. Clin Infect Dis 2000; 31: 1245-1252

154 Havlir DV, Dube MP, Sattler FR et al. Prophylaxis against disseminated Mycobacterium avium complex with weekly azithromycin, daily rifabutin, or both. N Engl J Med 1996; 335: 392-398

155 Pierce M, Crampton S, Henry D et al. A randomized trial of clarithromycin as prophylaxis against disseminated Mycobacterium avium complex infection in patients with advanced acquired immunodeficiency syndrome. N Engl J Med 1996; 335: 384-391

156 El-Sadr WM, Burman WJ, Grant LB et al. Discontinuation of prophylaxis for Mycobacterium avium complex disease in HIV-infected patients who have a response to antiretroviral therapy. $\mathrm{N}$ Engl J Med 2000; 342: 1085-1092

157 Aberg JA, Williams PL, Liu T et al. A study of discontinuing maintenance therapy in human immunodeficiency virus-infected subjects with disseminated Mycobacterium avium complex. J Infect Dis 2003; 187: $1046-1052$

158 Haas WH. Diagnostik und Therapie von Erkrankungen durch nichttuberkulöse Mykobakterien im Kindesalter. Kinder- und Jugendarzt 2005; 36: 403-408

159 Katila ML, Brander E, Backman A. Neonatal BCG vaccination and mycobacterial cervical adenitis in childhood. Tubercle 1987; 68: 291 296

160 Haverkamp MH, Lindeboom JA, de Visser AW et al. Nontuberculous mycobacterial cervico-facial lymphadenitis in children from the multi-center, randomized, controlled trial in The Netherlands: relevance of polymorphisms in candidate host immunity genes. Int J Pediatr Otorhinolaryn-gol 2010; 74: $752-754$

161 Thegerstrom J, Romanus V, Friman $V$ et al. Mycobacterium avium lymphadenopathy among children, Sweden. Emerg Infect Dis 2008; 14: $661-663$

162 Blyth CC, Best EJ, Jones CA et al. Nontuberculous mycobacterial infection in children: a prospective national study. Pediatr Infect Dis J 2009; 28: $801-805$

163 Reuss AM, Wiese-Posselt M, Weissmann B et al. Incidence rate of nontuberculous mycobacterial disease in immunocompetent children: a prospective nationwide surveillance study in Germany. Pediatr Infect Dis J 2009; 28: $642-644$

164 Casanova JL. Mendelian susceptibility to mycobacterial infection in man. Swiss Med Wkly 2001; 131: 445-454 
165 Reichenbach J, von Bernuth H. Genetisch bedingte Defekte der angeborenen Immunität - Erhöhte Anfälligkeit für mykobakterielle Infektionen, für invasive bakterielle Infektionen und für Herpes-simplexEnzephalitis. Kinder- und Jugendmedizin 2008; 8: 171-178

166 Fauroux B, Delaisi B, Clement A et al. Mycobacterial lung disease in cystic fibrosis: a prospective study. Pediatr Infect Dis J 1997; 16: 354-358

167 Esther CRJr, Henry MM, Molina PL et al. Nontuberculous mycobacterial infection in young children with cystic fibrosis. Pediatr Pulmonol 2005; 40: 39-44

168 Weigl JA, Haas WH. Postoperative Mycobacterium avium osteomyelitis confirmed by polymerase chain reaction. Eur J Pediatr 2000; 159: 64-69

169 Hoefsloot W, van Ingen J, de Lange WC et al. Clinical relevance of Mycobacterium malmoense isolation in The Netherlands. Eur Respir J 2009; 34: 926-931

170 Magdorf K, Bialek R, Detjen AK et al. Tuberkulose und nicht tuberkulöse mykobakterielle Krankheiten. In: Deutsche Gesellschaft für Pädiatrische Infektiologie e.V. (DGPI), Scholz H, Belohradsky BH, Bialek $\mathrm{R}$ et al. (Hrsg). DGPI Handbuch Infektionen bei Kindern und Jugendlichen. 5. ed. Stuttgart: Georg Thieme Verlag; 2009: 528 - 544

171 Haas W. Erkrankungen durch Umweltmykobakterien. In: Reinhardt D Hrsg. Therapie der Krankheiten im Kindes- und Jugendalter. Berlin: Springer; 2004: 449-453

172 von Reyn C, Pozniak A, Haas W, Nichols G. Disseminated infection, cervical adenitis and other MAC infections. In: Pedley S, Bartram J, Rees $\mathrm{G}$ et al. editors. Pathogenic mycobacteria in water: a guide to public health consequences, monitoring and management. London: IWA Publishing on behalf of the World Health Organization; 2004: 95103

173 Detjen AK, Keil T, Roll $S$ et al. Interferon-gamma release assays improve the diagnosis of tuberculosis and nontuberculous mycobacterial disease in children in a country with a low incidence of tuberculosis. Clin Infect Dis 2007; 45: 322-328

174 Mazurek M, Jereb J, Vernon A et al. Updated guidelines for using Interferon Gamma Release Assays to detect Mycobacterium tuberculosis infection - United States, 2010. MMWR Recomm Rep 2010; 59: 1 - 25

175 Carvalho AC, Codecasa L, Pinsi G et al. Differential diagnosis of cervical mycobacterial lymphadenitis in children. Pediatr Infect Dis J 2010; 29: $629-633$

176 Lindeboom JA, Smets AM, Kuijper EJ et al. The sonographic characteristics of nontuberculous mycobacterial cervicofacial lymphadenitis in children. Pediatr Radiol 2006; 36: 1063 - 1067

177 Piersimoni C, Scarparo C. Extrapulmonary infections associated with nontuberculous mycobacteria in immunocompetent persons. Emerg Infect Dis 2009; 15: 1351 - 1358 ; quiz 1544

178 Wolinsky E. Mycobacterial lymphadenitis in children: a prospective study of 105 nontuberculous cases with long-term follow-up. Clin Infect Dis 1995; 20: $954-963$

179 Schaad UB, Votteler TP, McCracken GHJr et al. Management of atypical mycobacterial lymphadenitis in childhood: a review based on 380 cases. J Pediatr 1979; 95: 356-360

180 Lindeboom JA, Kuijper EJ, Bruijnesteijn van Coppenraet ES et al. Surgical excision versus antibiotic treatment for nontuberculous mycobacterial cervicofacial lymphadenitis in children: a multicenter, randomized, controlled trial. Clin Infect Dis 2007; 44: 1057-1064

181 Lindeboom JA, Lindeboom R, Bruijnesteijn van Coppenraet ES et al. Esthetic outcome of surgical excision versus antibiotic therapy for nontuberculous mycobacterial cervicofacial lymphadenitis in children. Pediatr Infect Dis J 2009; 28: 1028- 1030

182 Iversen RH, Illum P. Cervicofacial nontuberculous mycobacterial lymphadenitis in children. Dan Med J 2012; 59: A4349

183 Reuss A, Drzymala S, Hauer B et al. Langzeitverlauf und Therapieerfolg bei Lymphadenitiden durch nichttuberkulöse Mykobakterien bei Kindern in Deutschland. http://www.dgpi2012.de/media/PDFs/Abstractband_DGPI2012.pdf

184 Koh WJ, Jeong BH, Jeon $K$ et al. Clinical significance of the differentiation between Mycobacterium avium and Mycobacterium intracellulare in M avium complex lung disease. Chest 2012; 142: 1482 - 1488

185 Tortoli E, Rindi L, Garcia MJ et al. Proposal to elevate the genetic variant MAC-A, included in the Mycobacterium avium complex, to species rank as Mycobacterium chimaera sp. nov. Int J Syst Evol Microbiol 2004; 54: $1277-1285$

186 Murcia MI, Tortoli E, Menendez MC et al. Mycobacterium colombiense sp. nov., a novel member of the Mycobacterium avium complex and description of MAC-X as a new ITS genetic variant. Int J Syst Evol Microbiol 2006; 56: 2049-2054

187 Bang $D$, Herlin T, Stegger $M$ et al. Mycobacterium arosiense sp.nov., a slowly growing, scotochromogenic species causing osteomyelitis in an immunocompromised child. Int J Syst Evol Microbiol 2008; 58: $2398-2402$

188 van Ingen J, Boeree MJ, Kösters K et al. Proposal to elevate Mycobacterium avium complex ITS sequevar MAC-Q to Mycobacterium vulneris sp.nov. Int J Syst Evol Microbiol 2009; 59: 2277-2282

189 Thorel MF, Krichevsky M, Lévy-Frébault VV. Numerical taxonomy of mycobactin-dependent mycobacteria, emended description of Mycobacterium avium, and description of Mycobacterium avium subsp. avium subsp. nov., Mycobacterium avium subsp. paratuberculosis subsp. nov., and Mycobacterium avium subsp. silvaticum subsp. nov. Int. J. Syst. Bacteriol 1990; 40: 254-260

190 Mijs W, de Haas P, Rossau R et al. Molecular evidence to support a proposal to reserve the designation Mycobacterium avium subsp. avium for bird-type isolates and M. avium subsp. hominissuis for the human/porcine type of M. avium. Int J Syst Evol Microbiol 2002; 52: $1505-1518$

191 Dhama K, Mahendran M, Tiwari R et al. Tuberculosis in birds: insights into the Mycobacterium avium infections. Vet Med Int 2011 [Published online] DOI: $10.4061 / 2011 / 712369$

192 Sweeney RW, Collins MT, Koets AP et al. Paratuberculosis (Johne's disease) in cattle and other susceptible species. J Vet Intern Med 2012; $26: 1239-1250$

193 Over K, Crandall PG, O'Bryan CA et al. Current perspectives on Mycobacterium avium subsp. paratuberculosis, Johne's disease, and Crohn's disease: a review. Crit Rev Microbiol 2011; 37: 141 - 156

$194 \mathrm{Kim}$ SY, Lee ST, Jeong BH et al. Clinical significance of mycobacterial genotyping in Mycobacterium avium lung disease in Korea. Int J Tuberc Lung Dis 2012; 16: 1393-1399

195 Falkinham J03rd. Mycobacterium avium complex. J Med Microbiol 2010; 59: 1198 - 1202

196 Lam PK, Griffith DE, Aksamit TR et al. Factors related to response to intermittent treatment of Mycobacterium avium complex lung disease. Am J Respir Crit Care Med 2006; 173: 1283 - 1289

197 Shafran SD, Talbot JA, Chomyc S et al. Does in vitro susceptibility to rifabutin and ethambutol predict the response to treatment of Mycobacterium avium complex bacteremia with rifabutin, ethambutol, and clarithromycin? Canadian HIV Trials Network Protocol 010 Study Group Clin Infect Dis 1998; 27: 1401-1405

198 Maartens G, Decloedt E, Cohen K. Effectiveness and safety of antiretrovirals with rifampicin: crucial issues for high-burden countries. Antivir Ther 2009; 14: 1039-1043

199 Kobashi Y, Matsushima T, Oka M. A double-blind randomized study of aminoglycoside infusion with combined therapy for pulmonary Mycobacterium avium complex disease. Respir Med 2007; 101: 130138

200 Kohno Y, Ohno H, Miyazaki Y et al. In vitro and in vivo activities of novel fluoroquinolones alone and in combination with clarithromycin against clinically isolated Mycobacterium avium complex strains in Japan. Antimicrob Agents Chemother 2007; 51: 4071 - 4076

201 Butler WR, O'Connor SP, Yakrus MA et al. Mycobacterium celatum sp. nov. Int J Syst Bacteriol 1993; 43: 539-548

202 Piersimoni C, Tortoli E, De Sio G. Disseminated infection due to Mycobacterium celatum in patient with AIDS. Lancet 1994; $344: 332$

203 Bull TJ, Shanson DC, Archard LC et al. A new group (type 3) of Mycobacterium celatum isolated from AIDS patients in the London area. Int J Syst Bacteriol 1995; 45: 861 - 862

204 Piersimoni C, Zitti PG, Nista D et al. Mycobacterium celatum pulmonary infection in the immunocompetent: case report and review. Emerg Infect Dis 2003; 9: 399-402

205 Jun HJ, Lee NY, Kim J et al. Successful treatment of Mycobacterium celatum pulmonary disease in an immunocompetent patient using antimicobacterial chemotherapy and combined pulmonary resection. Yonsei Med J 2010; 51: 980 - 983

206 Böttger EC, Teske A, Kirschner P et al. Disseminated "Mycobacterium genavense" infection in patients with AIDS. Lancet 1992; $340: 76-80$

207 Hoefsloot W, van Ingen J, Peters EJ et al. Mycobacterium genavense in the Netherlands: an opportunistic pathogen in HIV and non-HIV immunocompromised patients. An observational study in 14 cases. Clin Microbiol Infect 2013; 19: $432-437$ 
208 Krebs T, Zimmerli S, Bodmer T et al. Mycobacterium genavense infection in a patient with long-standing chronic lymphocytic leukaemia. J Intern Med 2000; 248: 343 - 348

209 Lorenzen J, Meyer-Olson D, Haubitz M et al. Infection with Mycobacterium genavense in a patient with systemic lupus erythematosus. Clin Rheumatol 2009; 28 (Suppl. 01): 39-41

210 Gößwald A. Klinik, Diagnostik, Therapie und Verlauf pulmonaler Infektionen durch nichttuberkulöse Mykobakterien bei HIV-negativen Patienten in Berlin 1986-1998. Diss. med. Berlin: Freie Universität; 2004

211 Griffith DE, Brown-Elliott BA, Wallace RJ Jr. Thrice-weekly clarithromycin-containing regimen for treatment of Mycobacterium kansasii lung disease: results of a preliminary study. Clin Infect Dis 2003; 37: $1178-1182$

212 Abgueguen P, Rabier V, Mahaza C et al. Mycobacterium malmoense: an underestimated nontuberculous mycobacterium. Diagn Microbiol Infect Dis 2010; 66: 98 - 100

213 Murray MP, Laurenson IF, Hill AT. Outcomes of a standardized tripledrug regimen for the treatment of nontuberculous mycobacterial pulmonary infection. Clin Infect Dis 2008; 47: 222-224

214 Esteban J, García-Pedrazuela M, Muñoz-Egea MC et al. Current treatment of nontuberculous mycobacteriosis: an update. Expert Opin Pharmacother 2012; 13: 967-986

215 Petrini B. Mycobacterium marinum: ubiquitous agent of water-borne granulomatous skin infections. Eur J Clin Microbiol Infect Dis 2006; 25: 609-613

216 Aubry A, Chosidow 0, Caumes E et al. Sixty-three cases of Mycobacterium marinum infection. Arch Intern Med 2002; 162: 1746-1752

217 Cheung JP, Fung B, Wong SS et al. Mycobacterium marinum infection of the hand and wrist. J Orthop Surg (Hong Kong) 2010; 18: 98 - 103

218 Narang R, Narang P, Jain AP et al. Disseminated disease caused by Mycobacterium simiae in AIDS patients: a report of three cases. Clin Microbiol Infect 2010; 16: 912 -914

219 van Ingen J, Boeree MJ, de Lange WC et al. Clinical relevance of Mycobacterium szulgai in The Netherlands. Clin Infect Dis 2008; 46: $1200-1205$
220 Varadi RG, Marras TK. Pulmonary Mycobacterium xenopi infection in non-HIV-infected patients: a systematic review. Int J Tuberc Lung Dis 2009; $13: 1210-1218$

221 Adékambi T, Reynaud-Gaubert M, Greub G et al. Amoebal coculture of "Mycobacterium massiliense" sp. nov. from the sputum of a patient with hemoptoic pneumonia. J Clin Microbiol 2004; 42: 5493-5501

222 Adékambi T, Berger P, Raoult D et al. rpoB gene sequence-based characterization of emerging non-tuberculous mycobacteria with descriptions of Mycobacterium bolletii sp. nov., Mycobacterium phocaicum sp. nov. and Mycobacterium aubagnense sp. nov. Int J Syst Evol Microbiol 2006; 56: 133-143

223 Leao SC, Tortoli E, Euzéby JP et al. Proposal that Mycobacterium massiliense and Mycobacterium bolletii be united and reclassified as Mycobacterium abscessus subsp. bolletii comb. nov., designation of Mycobacterium abscessus subsp. abscessus subsp. nov. and emended description of Mycobacterium abscessus. Int J Syst Evol Microbiol 2011; 61: $2311-2313$

224 Aitken ML, Limaye A, Pottinger P et al. Respiratory outbreak of Mycobacterium abscessus subspecies massiliense in a lung transplant and cystic fibrosis center. Am J Respir Crit Care Med 2012; 185: 231 - 232

225 Gilljam M, Scherstén H, Silverborn $M$ et al. Lung transplantation in patients with cystic fibrosis and M. abscessus infection. J Cyst Fibros 2010; 9: 272 - 276

226 Choi GE, Shin SJ, Won CJ et al. Macrolide treatment for Mycobacterium abscessus and Mycobacterium massiliense infection and inducible resistance. Am J Respir Crit Care Med 2012; 186: 917-925

227 Choi GE, Min KN, Won CJ et al. Activities of moxifloxacin in combination with macrolides against clinical isolates of Mycobacterium abscessus and Mycobacterium massiliense. Antimicrob Agents Chemother 2012; 56: 3549-3555

228 Huang YC, Liu MF, Shen GH et al. Clinical outcome of Mycobacterium abscessus infection and antimicrobial susceptibility testing. J Microbiol Immunol Infect 2010; 43: 401 - 406

229 Jarand J, Levin A, Zhang $L$ et al. Clinical and microbiologic outcomes in patients receiving treatment for Mycobacterium abscessus pulmonary disease. Clin Infect Dis 2011; 52: 565-571

230 Griffith DE. UpToDate Topic 5347 Version 13.0: Rapidly growing mycobacterial infections in HIV-negative patients. Release 21. 06. 2013 